\title{
A NEW APPROACH IN ULTRAPURIFICATION OF COAL BY SELECTIVE FLOCCULATION
}

DOE \# DE-FG22-88PC88917

\author{
Submitted to: \\ The Department of Energy \\ Pittsburgh Energy Technology Center \\ P.O. Box 10940, MS 900-33 \\ Pittsburgh, PA 15236 \\ by: \\ Brij M. Moudgil \\ Mineral Resources Research Center \\ Department of Materials Science and Engineering \\ University of Florida \\ Gainesville, Florida 32611
}




\section{PROJECT PERSONNEL}

Principal Investigator:

Dr. Brij M. Moudgil

Staff:

Dr. Mohan N. Badgujar

Sanjay Behl

Sid Martin

John Niaouris

Edward J. Skompski

E. Watkins

William E. Wiisanen 


\section{ACKNOWLEDGEMENTS}

The authors wish to acknowledge the cooperation of DOE-PETC, Pittsburgh PA, particularly of Dr. W.W. "George" Wen for providing the samples and other relevant information and Dr. G. Luttrell of VPI \& SU, Blacksburg, VA for supplying the relatively pure coal pyrite and coal samples used in this study. American Cyanamid Co. and Calgon Corp. are acknowledged for providing some of the flocculants examined in this study. 


\section{SUMMARY}

Removal of pyritic sulfur and ash forming mineral matter from mechanically cleaned coal would require comminution to -400 mesh size to liberate such impurities from coal particles. At very fine sizes, surface properties dominate the bulk properties, therefore, efficient separation by (conventional) coal-cleaning techniques is not achieved. Selective flocculation is one of the processes which has shown promise in cleaning of fine coal. In this process, selection of the polymer which would adsorb only on the desired component is based on single component flocculation tests. However, the selectivity predicted on the basis of such tests is invariably lost when mixed component flocculation tests are attempted. Heterocoagulation, dissolved ion activation, and physical entrapment are some of the reasons cited in the literature for the loss of selectivity. Recently, heteroflocculation which involves adsorption of some polymer molecules on the inert specie and anchoring of these molecules on the bare active sites of the active component, has been proposed as another major reason for the loss of selectivity in multicomponent systems. The concept of active sites and fractional surface coverage has been employed as the basis of a mathematical model to predict a priori the conditions under which optimum selectivity may be achieved.

SF 362 and SF 16 exhibited selectivity in single mineral flocculation tests; however, no appreciable selectivity was observed when mixed mineral tests were conducted. WCL 762 , a hydrophobic polymer, had exhibited single mineral selectivity at high $\mathrm{pH}$ values. However, due to the presence of mineral matter in the coal and coal pyrite samples it is not clear as to whether the mineral constituents or coal/coal pyrite was flocculating, since no selectivity was obtained for ash or coal pyrite constituents.

FTIR study was undertaken to ascertain the adsorption mechanisms of SF 362. However, due to a large amount of impurities (mineral matter, kaolinite particularly) present in the sample, it is not clear as to where the possible adsorption sites exist.

The major contribution of the study is identification of conditions for efficient separation 
of coal frorn coal pyrite. Selective adsorption of the flocculant (high active site ratio) is a primary requirement. However, even when the flocculant is not selective enough (low active sites ratio), a slight increase in selectivity may be obtained by control'ing the polymer (flocculant) dosage. 


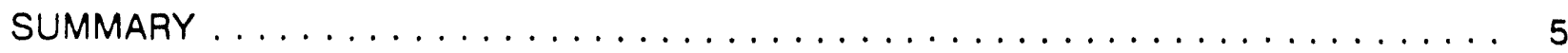

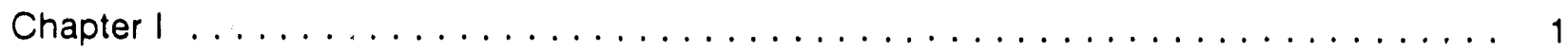

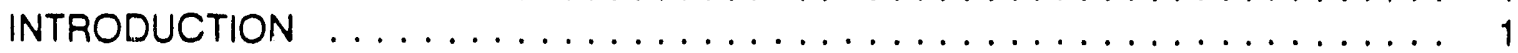

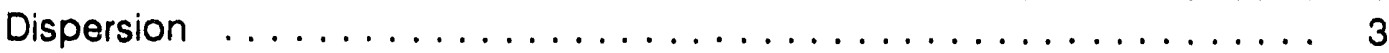

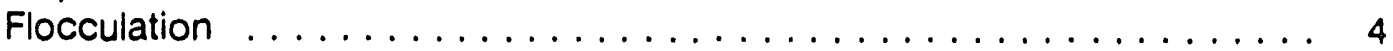

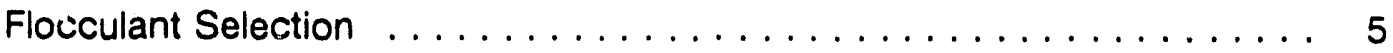

Prediction of Selectivity $\ldots \ldots \ldots \ldots \ldots \ldots \ldots \ldots \ldots$

Effect of Feed Composition . . . . . . . . . . . . . . . . 8

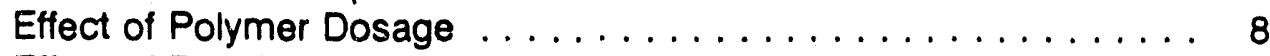

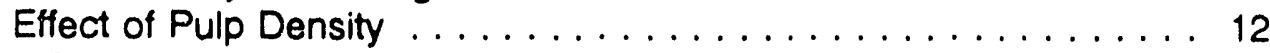

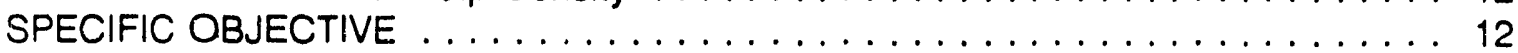

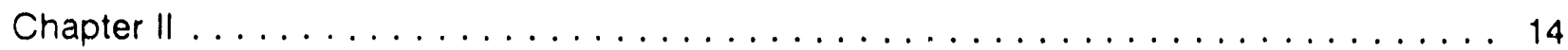

MATHEMATICAL MODELING OF SELECTIVE FLOCCULATION $\ldots \ldots \ldots \ldots \ldots 14$

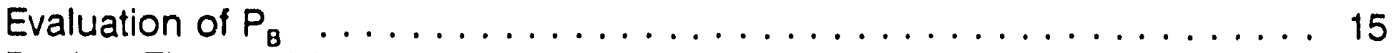

Particle-Floc and Floc-Floc Interactions . . . . . . . . . . . . 20

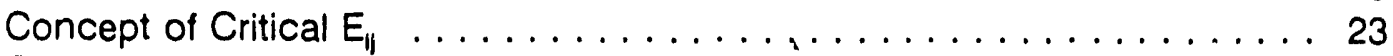

Computational Scheme ......................... 24

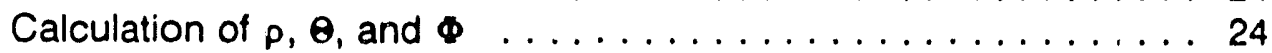

Relative Importance of $\$$ and $\theta \ldots \ldots \ldots \ldots$

Computational Simulations . . . . . . . . . . . . . . 29

Chapter III ................................ 37

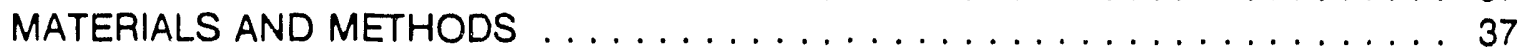

Materials ............................ 37

Procedures ............................ 37

Comminution ....................... 37

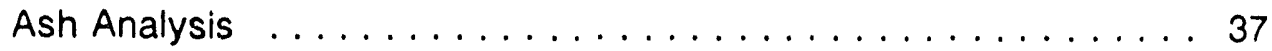

SEM/EDAX Analysis . . . . . . . . . . . . . . . 39

ICP Analysis . . . . . . . . . . . . . . . . . . . . 39

Specific Gravity of Coal . . . . . . . . . . . . . . . . . . 51

Particle Size Analysis . . . . . . . . . . . . . . . . 51

Surface Area Measurements . . . . . . . . . . . . . . . . 51

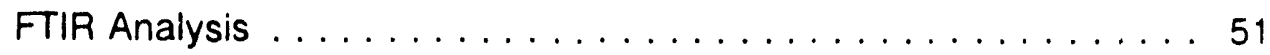

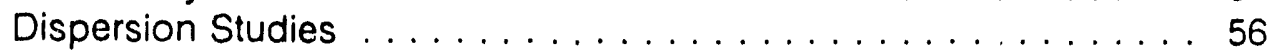

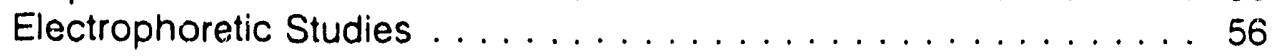

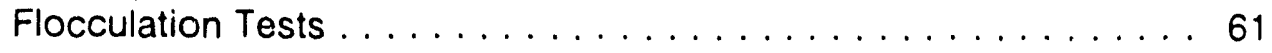

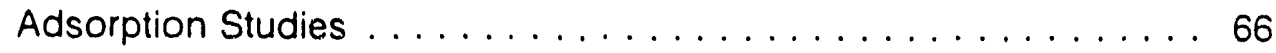

Chapter IV ............................... 68

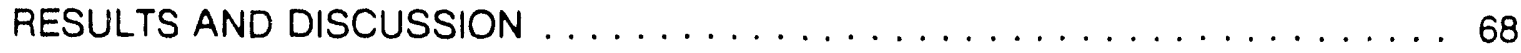

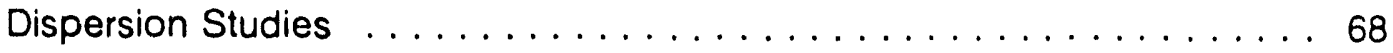

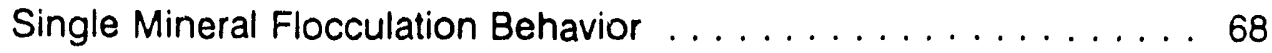

Adsorption Studies . . . . . . . . . . . . . . . . . . . . 82

Saturation Adsorption Tests . . . . . . . . . . . . 82

Nonequilibrium Adsorption (for $\theta$ ) $\ldots \ldots \ldots \ldots \ldots \ldots$. . . . . 82

Model Predictions 
FTIR Analysis $\ldots \ldots \ldots \ldots \ldots \ldots \ldots \ldots \ldots \ldots \ldots \ldots$

Mixed Mineral Flocculation . . . . . . . . . . . . . . . . . . . . . . 90

Coal-Quartz (Mineral Matter) System . . . . . . . . . . . . . . . 90

Coal-Coal Pyrite System . . . . . . . . . . . . . . . . . . . . 90

Virginia Tech. Sample ......................... 96

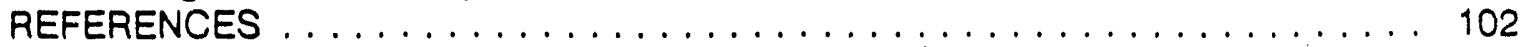




\section{Chapter I}

\section{INTRODUCTION}

Production of clean coal with low ash and sulfur contents is extremely important to satisfy the future energy needs of the United States. Jigs and heavy media separation techniques are used for cleaning of coarse and intermediate size coal, while froth flotation is employed for finer size fractions $(500-75 \mu \mathrm{m})$. However, it has been reported that for further cleaning of coal, comminution to -400 mesh size $(37 \mu \mathrm{m})$ is required to liberate the ash and pyritic sulfur impurities (Killmeyer, 1985). Also, the run-of-mine coal has been found to contain up to $5 \%$ of particles less than $10 \mu \mathrm{m}$ (Cammack, 1982). This would amount to about 75 million tons per annum of fine raw coal at the anticipated level of production of 1500 million tons by 1990.

At very fine sizes, surface properties dominate the bulk properties. Thus, an efficient method of separation would involve techniques which take advantage of surface rather than bulk properties. This has led to the development of techniques such as electrostatic separation, micro-bubble flotation and selective agglomeration, which exploit the differences in surface chemical and/or charge characteristics between the coal macerals and mineral matter. Selective agglomeration process such as selective flocculation, in which relatively small amounts of polymers are used to flocculate the particles, have shown considerable promise in reducing ash and sulfur content of ultrafine coal.

Selective flocculation involves dispersion followed by preferential adsorption of a polymer either onto the valuable or inert/impure mineral (Somasundaran, 1980). Hence the success of the selective flocculation process depends on the identification of proper dispersing agents and polymer flocculants that are selective with respect to one of the components to be separated. Selective adsorption of polymer molecules can be achieved by adjusting the chemical composition of the suspending medium and thereby the surface potential of the mineral or by 
introducing active functional groups into the polymer, which will form complexes with the surface species (Somasundaran, 1980). Selective flocculation can also be achieved if there are differences in the rate of polymer adsorption on various components or desorption of polymer from the surface of one of the components.

The literature on the removal of mineral impurities from coal by selective flocculation is limited. Balachke (1977) studied upgrading of coal slurries using a selective flocculation technique. Sodium carboxymethyl cellulose (a dispersant) and Gigtar (a flocculant) were used in the flocculation of fines. The ash content of the coal was reported to be reduced from 54.5 to $4.6 \%$. The selective flocculation of coal from coal-bentonite mixtures of varying compositions was conducted by Klunder and Koopmans (1982). These investigators have reported that, using waterglass as a dispersant and starch-based flocculants, the ash content of the coal can be reduced from $30 \%$ to approximately $10 \%$. In a more recent study by Attia et al. (1984), an $80 \%$ reduction in ash content was achieved by selective flocculation of high ash ( $<45$ wt\%) coals, with concentrate yields of greater than $90 \%$. In the selective flocculation of bituminous high ash coals with xanthated poly(sodium acrylate) as the dispersant and sulfonated polystyrene as the flocculant, super-clean coals with ash content of less than $3 \%$ were achieved by Attia (1985). It has been reported that the success of the process was based on the ability of the dispersant to separate ultrafine pyrite from coal in the dispersion stage and the ability of the polymer to flocculate hydrophobic coal particles, while rejecting the predominantly hydrophilic minerals "f is to be noted that, although selective flocculation has been used successfully for removal of bulk ash impurities ( $-5 w t \%$ ash in product), commercial application of the process for coal cleaning has not yet been attempted. Ultrapurification of coal to achieve less than $1 \mathrm{wt} \%$ ash and sulfur impurities in the product, on the other hand, has not been studied to any major extent. Application of selective flocculation to ultracleaning of fine coal would require a more fundamental approach in understanding the adsorption/flocculation behavior of various 
constituents in coal.

Production of super-clean coal by selective flocculation would involve (i) successful liberation of ash and pyritic impurities from coal; (ii) an effective dispersion of the suspansion in order to avoid aggregation of coal and mineral impurities; and (iii) selective adsorption /desorption of a polymer on coal or ash and pyritic matter.

\section{Dispersion:}

A good dispersion of the pulp can be achieved by appropriate modification of the surface chernical and/or charge characteristics of the solids. This requires a clear understanding of the surface chemistry of solids in suspension. By proper modification of parameters such as $\mathrm{pH}$, ionic nature and strength and an appropriate selection of a dispersant, the necessary dispersion of the pulp may be achieved.

The electrophoretic properties of anthracite and bituminous coals have been discussed by Campbell and Sun (1970). These investigators nbserved that there is a substantial difference in the variation of zeta potential with $\mathrm{pH}$ of various macerals and that above $\mathrm{pH} 5.0$ all the coal components are negatively charged. Wen and Sun (1981) reported that surface charge characteristics of bituminous coals depend on the extent of oxidation and that the isoelectric point (IEP) of coal maceral decreases with increase in oxidation time. The electrokinetic behavior of quartz (Kulkarni and Somasundaran, 1977) and clays (Moudgil and Vasudevan, 1985), winich constitute the major portion of the mineral matter, indicates that these components also exhibit negative surface charge characteristics above pH 5.0. However, the zeta potential values of quartz and clays vary significantly with types and concentrations of dissolved ions. Rowell et al. (1985) investigating the electrophoretic mobility distribution of dilute aqueous coal dispersions, found that $\mathrm{pH}$ of the su:pension was a fundarnental factor in controlling ine stability of the suspension. 
The effect of chemical additives such as surfactants and polymers on the stability of coal suspension has been a subject of several patents, but the published literature in this area is scarce. The zeta potential of coal-water slurries was correlated with various surfactants and their amount at various $\mathrm{pH}$ values, by Tanaka et al. (1984). These workers found that addition of anionic surfactants increases the negative charge on the coal surface, while cationic or non-lonic surfactants cause a charge reversal to a slightly positive value, thus resulting in flocculation of coal. In the case of clays, polyelectrolytes are the most effective in cispersing clay suspensions (Chanchani, 1976; Moudgil and Vasudevan, 1985).

It is clear that proper selection of $\mathrm{pH}$ and dispersant is critical to achieving a good dispersion of the suspension. It is to be noted that the past work relates to dilute suspensions. Processing of concentrated slurries would require dispersion and aggregation under high solids loading conditions.

Flocculation:

Several flocculants based on acrylamides and ethylene oxide polymers have been used for the flocculation of coal suspension. As discussed earlier, the flocculant should exhibit either completely selective or differential adsorption/desorption characteristics, on the valuable mirieral or gangue. In a study on the adsorption of polymers on black water solids, Mirville and Hogg $(1978,1979)$ found that a non-ionic polyacrylamide flocculant showed ten times more adsorption on coal than on clay and quartz components. Klunder and Koopman (1981) have reported that starch-based flocculant was effective in selectively flocculating roal in a mixture with bentonite. A sulfonated polystyrene was found to be selective in its ability to flocculate hydrophobic coal particles while rejecting the predominantly hydrophilic minerals (Attia, 1985). The mechanism of flocculation of coal particles by PEO was studied by Goehin et al. (1985). It has been reported that adsorption occurs through hydrophobic interaction between methylene groups in PEO and 
the coal, the hydrogen bonding playing a minor role. Application of hydrophobic polymers in selective flocculation of coal from pyrites and other mineral matter was examined by Attia and coworkers (1987). These investigators determined that performance of the hydrophobic polymer was optimum under neutral $\mathrm{pH}$ conditions and it deteriorated above $\mathrm{pH} 9$ especially if the coal surface had undergone aging.

\section{Flocculant Selection:}

It is to be noted that only in a few studies has any attempt been made to understand the mechanisms involved. Most often, the selection of the dispersants and flocculants is made by a trial and error approach and generally there is no scientific basis of selecting a given reagent. This means that if there is a slight change in the characteristics of the feed material, the search for appropriate reagents has to start all over again. The trial and error approach is a primary reason why the potential of the selective flocculation process has not been fully realized in processing of fine particles including ultrafine coal cleaning.

In general, selection of flocculants is based on single component flocculation tests. Invariably, the selectivity predicted on the basis of single mineral tests is not realized when mixed component flocculation tests are attempted. Heterocoagulation, dissolved ion activation, physical entrapment, and entrainment are the reasons given in the literature for the loss of selectivity. Recently Moudgil and Co-Workers[1987,1988,1989,1990,1991] and Shah[1986] have determined heteroflocculaition to be also a major factor in the loss of selectivity during mixed mineral flocculation. Heteroflocculation, shown schematically in Figure 1-1, involves bridging flocculation between inert and active mineral components, although the inert component does not exhibit any flocculation when single component flocculation tests are attempted. $A$ mechanism based on collision efficiency of polymer coated particles was proposed to explain the differences in flocculation response of sing!e and mixed mineral systems and the resultant 


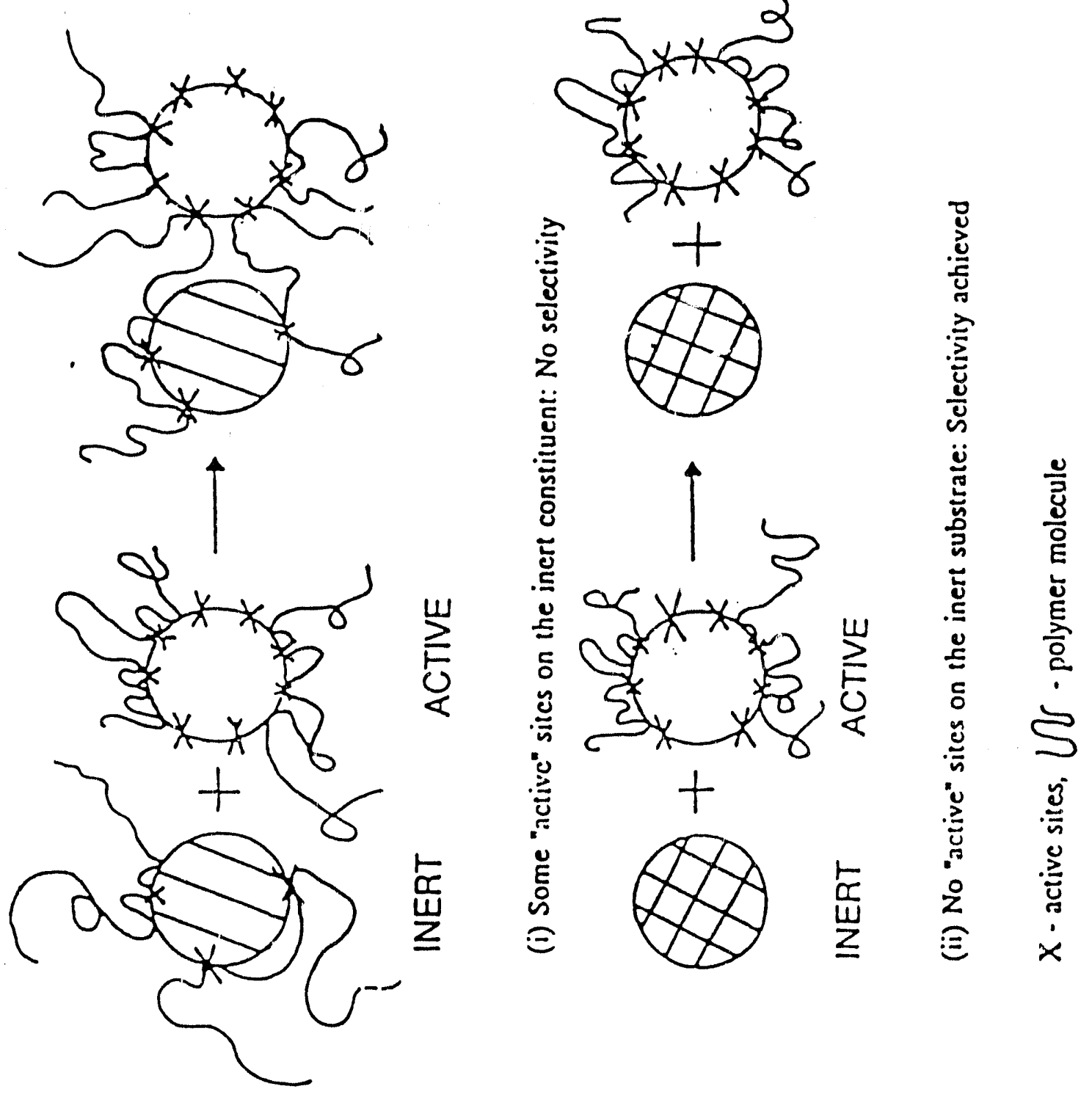

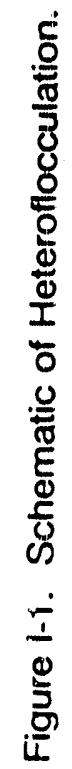


loss in selectivity. The presence of surface sites to which a given polymer attaches forms the basis of a mathematical model developed by Moudgil and Behl [1990], which is presented in Chapter II. A component is termedinert if the polymer does not adsorb on it and it is called active if polymer adsorbs on the surface. The sites to which the polymer molecule attaches are known as "active" sites. The model has predictive capabilities and can be used to identify conditions for optimum separation efficiency. Also the model helps in quantifying the adsorption that can be tolerated by the inert component without actively hetroflocculating. The relative number of active sites on various substrates are assessed by magnitude of adsorption under saturation conditions. An equation of the following type was proposed to describe the collision efficiency $E_{\mathcal{N}}$ between two particles $A$ (active) and I (inert).

$$
E_{A}=\phi_{A} \theta_{A}\left(\phi_{1}-\phi_{1} \theta_{1}\right)+\phi_{1} \theta_{1}\left(\phi_{A}-\phi_{A} \theta_{A}\right)
$$

Where,

$\Phi_{A} \Phi_{1}$ - Number concentration of active sites on particles $A$ and I, respectively.

$\theta_{A}, \theta_{1}$. Fraction of the surface covered by the given polymer on particle $A$ and $\mathrm{I}$, respectively.

In the above equation the first term represents the probability of collision of a polymer adsorbed on $A$ with a bare active site on 1 , while the second term describes the reverse probability.

In a mixed mineral system, the selectivity achieved will be high if the value of $E_{N}$ is low. Selectivity can be achieved by decreasing the value of $\Phi_{1}$ and/or to a lesser extent $\theta_{1}$. For example, in the flocculation of apatite and dolomite with PEO, although the collision efficiency value for apatite was low $\left(0.8 \times 10^{-3}\right)$ compared to that of dolomite $\left(2.2 \times 10^{-1}\right)$ individually, the efficiency of collision in the flocculation of apatite with dolomite was comparatively high $\left(2.2 \times 10^{\circ}\right.$

$\left.{ }^{2}\right)$. Further work carried out with dolomite-quartz and dolomite-alumina systems, to confirm the 
r. lechanism of flocculation, showed that a decrease in $E_{N}$ resulted in higher selectivity (Moudgil, and Vasudevan, 1989).

\section{Prediction of Selectivity:}

An illustration of the application of the matherratical model to predict selectivity in separating the "active" from the "inen" component under various conditions are discussed below. The results are expressed in terms of a selectivity index, S.I.*

1. Effect of Feed Cemposition: The Selectivity Index at lower $\Phi_{\mathrm{A}}$ values shown in Figure 1-2, decreases as the amount of active component in the feed increases. However, at higher values of $\Phi_{R}$, the S.I. remains unchanged as a function of feed composition. The recovery at higher $\Phi_{\mathrm{A}}$ values also remains unchanged but at lower $\Phi_{\mathrm{A}}$ exhibits a minimum at around $60 \%$ of the active component in feed (Figure 1-3). At lower $\Phi_{R}$ the loss of selectivity is due to heteroflocculation.

2. Effect of Polymer Dosage: At lower $\boldsymbol{\theta}$ (fractional surface coverage) of the inactive or inert cormponent, a number of collisions between active inactive particles would be unsuccessful because these collisions would take place between the bare sites on the floc surface (unoccupied polymer sites). However, the success rate of active and inert particle collisions is not affected by the value of $\theta$ of inactive particles which leads to less heteroflocculation and therefore, higher selectivity as illustrated in Figure 1-4. The

* $S I=\frac{\% \text { Coal in Flocs }-\% \text { Coal in Sample }}{100-\% \text { Coal in Sample }}$ 


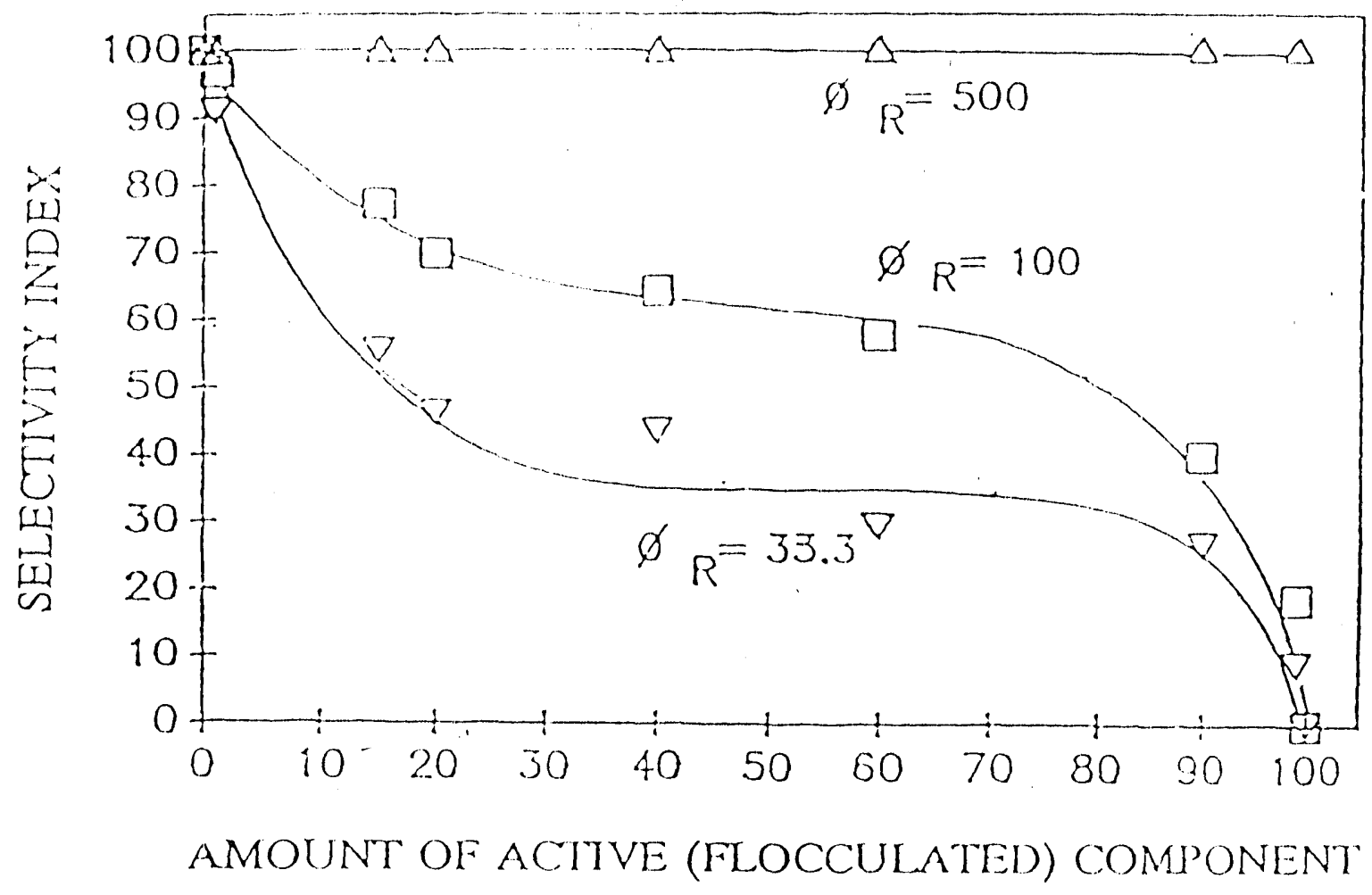

Figure 1-2. Effect of Feed Composition On Selectivity Index. 


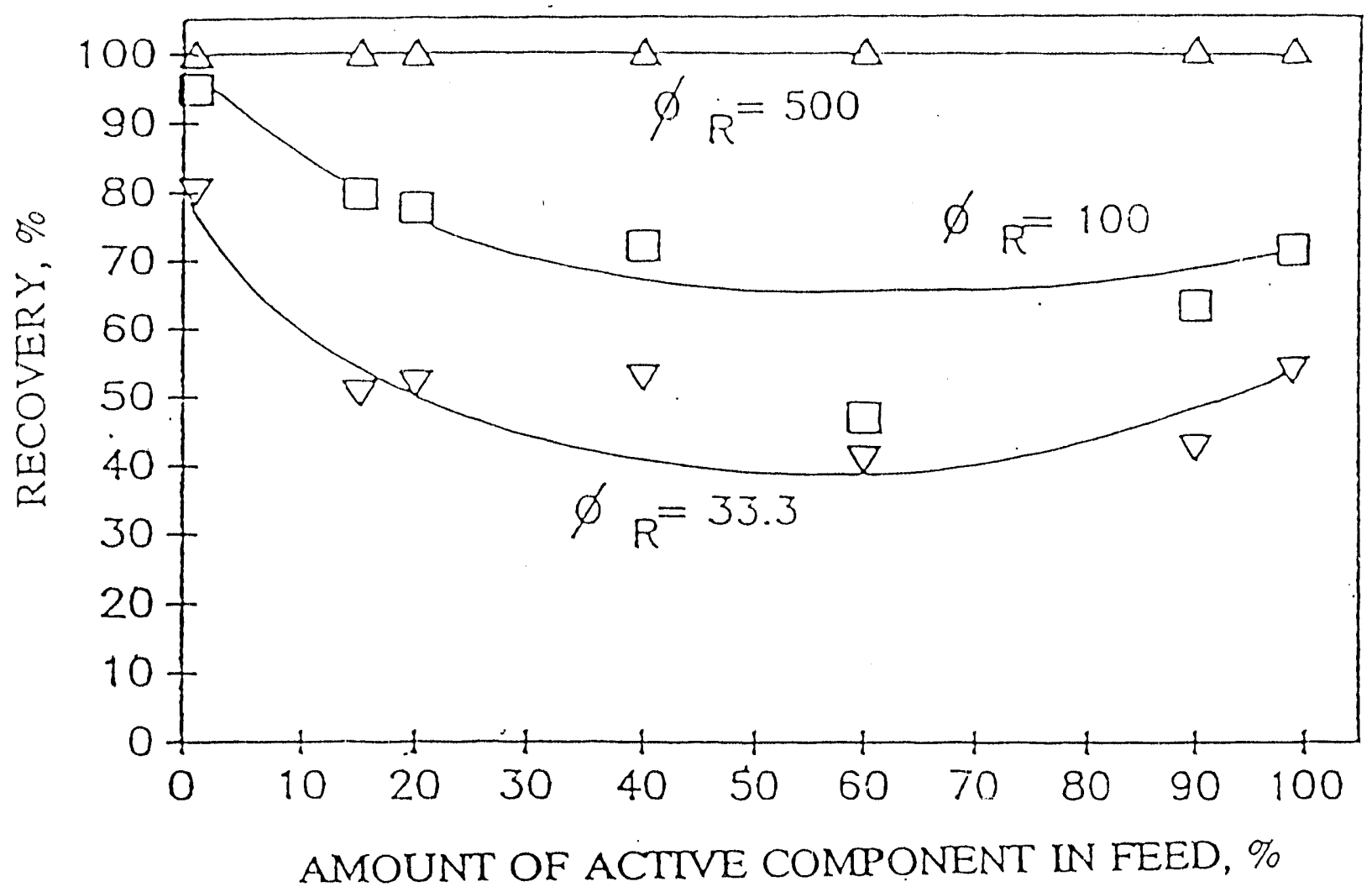

Figure 1-3. Effect of Feed Composition On Recovery. 


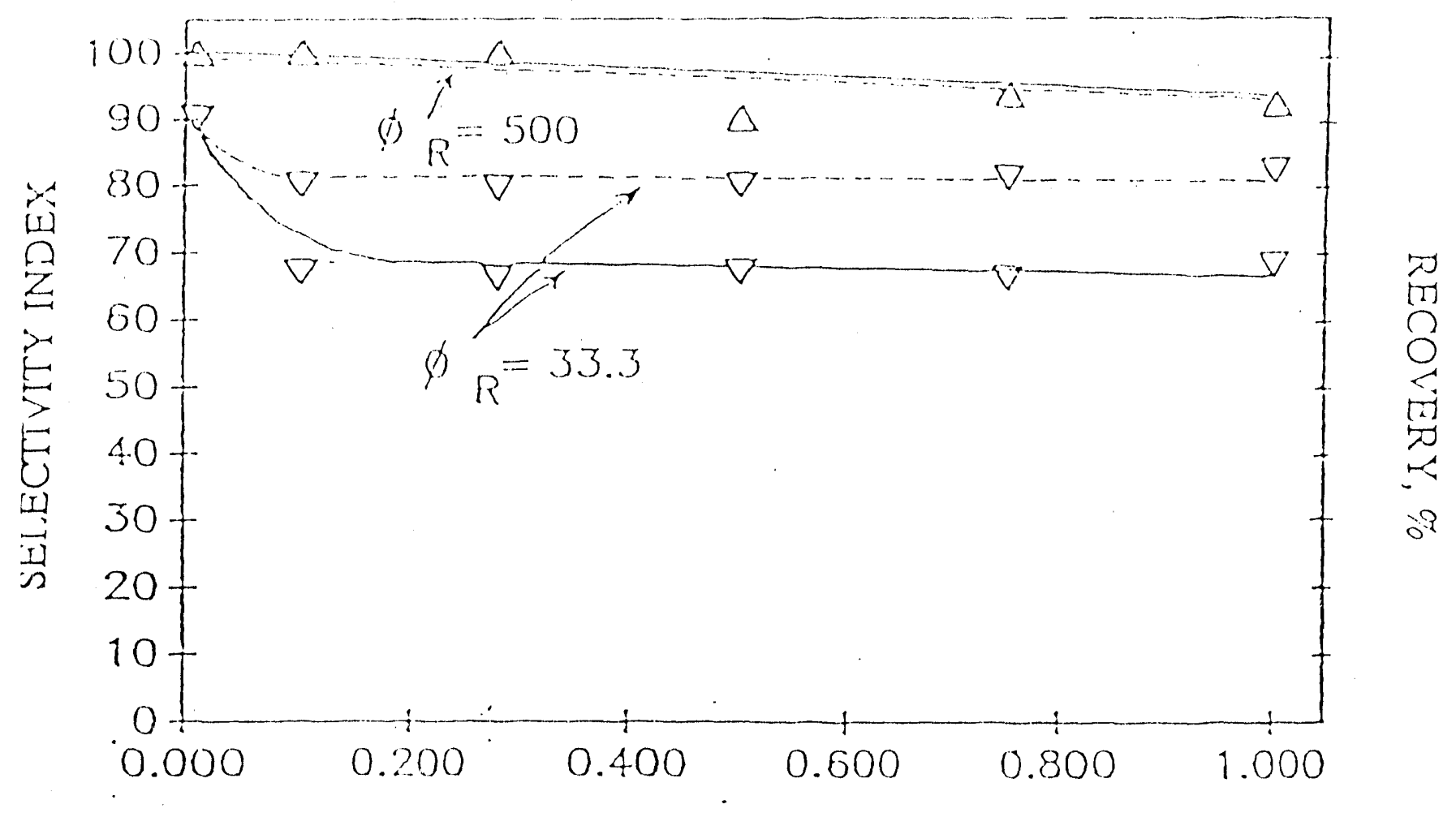

THET $A$ inert

Figure 1-4. Effect of $\Theta_{\text {Iner }}$ On Selectivity Index (-) and Recovery (--.). 
increased recovery at lower $\Phi_{R}$ can be attributed to the formation of a less number of flocs of active particles. These trends are in agreement with the experimental results of Kogan et al.(1988).

3. Effect of Pulp Density: The S.I. and recovery remains constant for a wide range of pulp density (Figure 1-5). Kogan et al (1988) showed that for the coal ash forming materials system there is no appreciable difference in recovery and S.I. for slurries of more than 5 wt. \%.

To obtain a higher Selectivity Index, it is emphasized that high values of $\Phi_{R}$ are required. However, by properly controlling polymer dosage even at low values of $\Phi_{R}$, high S.I. may be obtained (Figure 1-4).

\section{SPECIFIC OBJECTIVE}

The specific objective of the present investigation is to develop a mathematical and computational model to elicit values of active sites $(\phi)$ and fractional surface coverage $(\theta)$ which would yield optimum separation of coal from coal pyrite and coal refuse. Attempts are to be made to select appropriate flocculants and experimental conditions to obtain $\phi$ and $\theta$ values as dictated by the theoretical model so as to achieve the desired separation in naturally occurring samples of fine coal. 


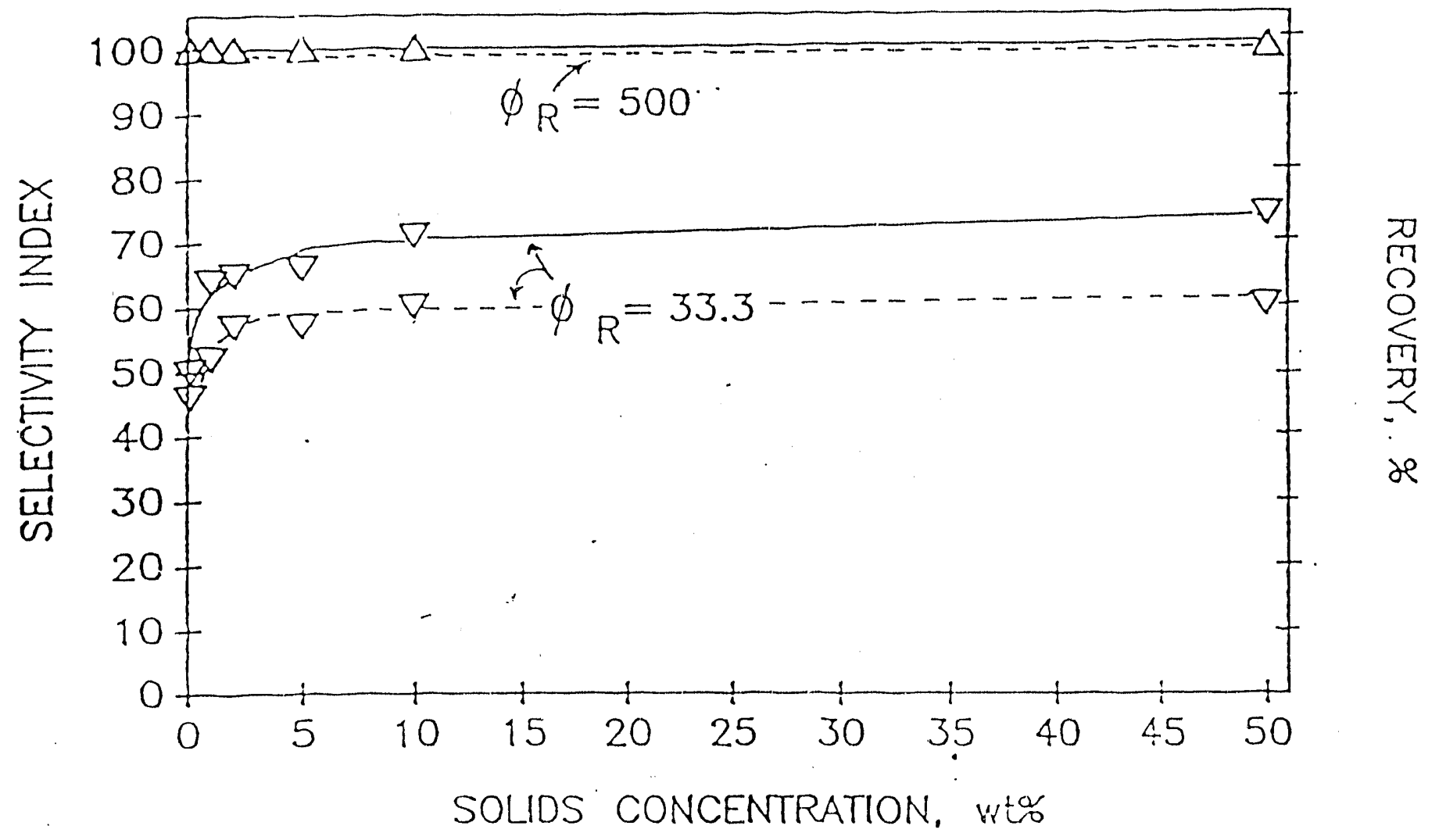

Figure 1-5. Effect of Pulp Density On Selectivity Index (-) and Recovery (---). 


\section{Chapter II}

\section{MATHEMATICAL MODELING OF SELECTIVE FLOCCULATION}

The aggregation of particles by polymer flocculation can occur by a number of mechanisms including bridging, charge neutralization, complex formation and depletion flocculation (Gregory, 1985). Bridging flocculation which occurs when polymer molecules adsorb on a particle attach to other particles, thus forming bridges between particles, is considered to be the predominant flocculation mechanism.

The polymer adsorption on the solid polymer is assumed to be irreversible, as is the case for adsorption of polymers and macromolecules on solid surfaces (Singer et al, 1973). This assumption is valid for the time scale involved in the selective flocculation processes. If the adsorption of the polymer is assumed to be a result of polymer (molecule) - particle collisions, the rate of adsorption would be at least a magnitude larger than the rate of particle-particle collisions. For example, for a typical dosage of $0.1 \mathrm{mg}$ of the polymer per gram of the solid, the number of polymer molecules are about $10^{3}$ to $10^{7}$ times greater than the number of particles. It can therefore be assumed that the polymer adsorption is extremely fast and the particle-particle collision is the rate controlling step.

The model considers only the binary collisions between the particles/clusters in a manner consistent with well known orthokinetic flocculation as suggested by Smoluchowski (1917). The rate expression for selective flocculation is slightly modified form of the expression suggested by Smoluchowski and is given by :

$$
F=K_{F} n^{2} E
$$

$K_{F}$ - flocculation rate constant

$n$ - number of particles 
E - collision efficiency.

In the above expression, $\mathrm{n}^{2}$ represents the probability of a two-particle collision, and $E$ the probability of adhesion of the colliding particles. The collision efficiency $E$ may be represented by a probability equation of the form:

$$
E=P_{B} P_{K}
$$

in which $P_{B}$ represents the probability that an adsorbed polymer will find a bare site on the colliding particle and $P_{K}$ represents the probability of a polymer sticking onto a bare site during the collision. The evaluation of the probability term $P_{B}$ is discussed below.

\section{Evaluation of $P_{8}$ :}

Numerous models have been proposed to describe the polymer flocculation process. Most of them involve the use of a Langmuir type adsorption isotherm described below, which assumes uniform distribution of the polymer among the individual particles,

$$
\theta=\frac{b C}{1-\theta} \quad \text { (Smellie and LaMer, 1958) }
$$

where $\theta$ is the fractional area of surface covered by polymer; $C_{p}$ represents the equilibrium concentration of the flocculant (polymer) and $b$ is the equilibrium constant.

Smellie and LaMer (1958) assumed that the attached polymers would have free active centers (loops and tails) which could then interact with the remaining free surfaces on other particles to form a large, three-dimensional floc by bridging. Thus, there would be a certain polymer concentration that would yield a maximum floc size. At higher dosages the initial coverage of the particle surface would be so large that little or no free surface would remain to 
allow bridge formation. It was further assumed that the entire surface area of the particle could be covered by polymer, and hence the number of sites available for adsorption was determined by the ratio of the surface area of the particle to the cross sectional area of an adsorbed polymer molecule.

Since $\theta$ represents the number of sites covered by polymer, $(1-\theta)$ represents the number of uncovered sites, and the probability of bridge formation between two colliding particles is proportional to $\Theta(1-\theta)$. The rate of floc formation therefore can be expressed as follows:

$$
(d t / d t)=K_{1} n_{0}^{2} \theta(1-\theta)
$$

where the number of floc nuclei and the number of particles per unit volume available to add to floc nuclei are both proportional to $n_{0}$. The optimum polymer concentration would be that which leads to a surface coverage of $\theta=0.5$. Comparing Equation 4 with Equation 1 gives:

$$
E=\theta(1-\theta)
$$

However, Hogg (1984) pointed out that Equation (4) only considers the possibility that the first particle has an adsorbed polymer which contacts a bare surface on the second particle. The reverse situation should also be considered, i.e. the possibility that the second particle has an adsorbed polymer molecule that contacts a bare surface on the first particle. Thus, a more correct formulation of the LaMer model is:

$$
P_{B}=20(1-\theta)
$$

In addition, experimental data showed that optimum flocculation could be observed at coverages much less than $\Theta=0.5$ the value predicted from LaMer's model. In fact, the optimum 
occurred over a broad range of polymer dosages. Therefore, Hogg (1984) considered the possibility of particles reorienting themselves during collision into configurations favorable to adhesion. Particle-particle, particle-polymer and polymer-polymer interactions would lead to bridging if there is at least one adsorbed polymer segment on one particle, and at least one bare site on the other. The modified relationship for collision efficiency factor for particles $\mid$ and $\}$, therefore, can be expressed as follows:

$$
P_{B_{i j}}=1-\phi^{N+N}-(1-\phi)^{n+N} \quad \text { (Hogg, 1984) }
$$

where $\theta$ is the fractional surface coverage, and $\mathrm{ni}$ and $\mathrm{nj}$ represent the number of sites on particles $i$ and $j$, respectively.

Moudgil et al. (1987) proposed another correction to the flocculation model, based on experimental data. They suggested that the sites on the surface of a particle can be divided into two categories: active and nonactive sites, the polymer molecules attaching only to active sites. The fraction of active sites (to total number of sites) is represented by $\phi$. It varies between 0 and 1 for different polymer-mineral combinations. For example, in the dolomite/apatite system dolomite becomes saturated with adsorbed polymer at $8 \mathrm{mg} / \mathrm{g}$ of polyethylene oxide (PEO), whereas apatite became saturated at $0.9 \mathrm{mg} / \mathrm{g}$ PEO (Shah, 1986). Thus dolomite would have a larger $\phi$ value than apatite. Therefore, the probability of a surface site on particle $i$ being covered is:

$$
P_{1}=\phi_{1} \theta_{1}
$$

$$
\text { Since, } \begin{aligned}
\phi_{1} \theta_{1} & =\frac{\text { No. of Active Sites }}{\text { Total No. of Sites }} \times \frac{\text { No. of Sites Covered }}{\text { No. of Active Sites }} \\
& =\frac{\text { No. of Sites Covered }}{\text { Total No. of Sites }}
\end{aligned}
$$


The probability of a site on particle $j$ being active and free is

$$
P_{1}=\phi_{1}-\phi_{1} \theta_{1}
$$

Thus, the probability of adhesion is represented by a new equation:

$$
P_{\theta_{i}}=\phi_{1} \theta_{1}\left(\theta_{1}-\phi_{1} \theta_{j}\right)+\phi_{1} \theta_{1}\left(\theta_{1}-\phi_{1} \theta_{1}\right)
$$

The first term is the probability of a polymer on particle $i$ attaching to a free active site on particle j, and the second term represents the reverse function, i.e. has the site on particle i active and free, and the site on particle / covered by polymer.

Note that Hogg's corrections have not been included in the above model. While it was believed that some reorientation of polymer molecules could take place, calculations showed that there was insufficient time for this to occur during the rapid collisions that are characteristic of orthokinetic flocculation.

For a single mineral, assuming all surface sites are active, i.e. $\phi=1$, Equation (10) reduces to:

$$
P_{B}=2 \theta(1-\theta)
$$

which is Hogg's corrected version of LaMer's equation (Hogg, 1984).

The above flocculation model could better explain the experimental data and also the incongruency often found between single and mixed mineral flocculation tests.

Rewriting Equation (1) for flocculation of two type of particles $i$ and $j$; 


$$
F_{y}=K_{p_{1}} n_{1} n_{1} P_{B_{\eta}} P_{k}
$$

where, $P_{B_{y}} P_{k}=E_{y}=P_{B_{y}} P_{A_{y}}+P_{B_{y}} P_{A_{y}}$

and $P_{A_{j}}=e^{-N / A t}, \quad P_{A_{H}}=e^{A / / t}$

$A_{1}$ and $A_{1}$ are the activation energies for adsorption of polymer on $i$ and $j$ species, respectively. $K$ is the Botzman constant and $T$ is the adsorption/flocculation temperature.

The probability of attachment of polymer to the bare particle site after collision, $P_{k}$, which involves the adsorption energy factor, can be considered to be unity since most polymer adsorption processes involve hydrogen bonding, rendering the activation energy term to be relatively small in magnitude.

Thus, $P_{k}=1$

The term $\mathrm{P}_{\mathrm{B}_{11}}$, which represents the probability of an adsorbed polymer chain on one kind of particle ( $i$ or $j$ ) finding a bare site on another particle ( $i$ or $j)$, is given by Equation (10).

According to Smoluchowski's (1917) interpretation of orthokinetic flocculation, the collision frequency between particles of diameters $d_{1}$ and $d_{1}$, represented by $K_{F_{11}} n_{1} n_{1}$ in Equation (12), is given by:

$$
\begin{gathered}
F_{y}=K_{F_{l}} n_{1} n_{1}=1 / 6 S\left(D_{1}+d_{1}\right)^{3} n_{1} n_{1} \\
=K_{F_{i l}}\left(d_{1}+d_{1}\right)^{3} n_{1} n_{1}
\end{gathered}
$$

where $K_{F_{H}}=1 / 6 \mathrm{~S}$

Here $\bar{S}$ represents the mean-point velocity gradient, in units of $\sec ^{-1}$. Thus the rate of 
flocculation of two types of particles of diameters $d_{1}$ and $d_{1}$ respectively, is given by substitution of Equation (16) in Equation (12). Thus,

$$
F_{4}=K_{F_{i}} n_{1} n_{1}\left(d_{1}+d_{i}\right)^{3} P_{B_{i l}} P_{k}
$$

\section{Particle-Floc and Floc.Floc Interactions:}

The above equation represents only primary particle flocculation and does not account for floc-particle and/or floc-floc interactions. When considering interaction between flocs, both decreases in surface area and mobility with increasing number of particles in the floc would decrease flocculation. These modifications are ircorporated in the flocculation equations as described below (Moudgil et al., 1989).

An object in a moving fluid experiences a force in the direction of the motion of the fluid relative to the object (drag force, D), and a force normal to the flow direction (lift force, $L$ ).

$$
\begin{aligned}
& D=C_{D}\left(\rho V^{2} / 2\right) A \\
& L=C_{/}\left(\rho V^{2} / 2\right) A
\end{aligned}
$$

Where, $A$ is the projected area normal to the flow direction, $\rho$ is the density of the fluid and $V$ is the fluid velocity. $C_{0}$ and $C_{L}$ are the drag and lift coefficients, respectively.

Under the influence of agitation, a particle also experiences a horizontal centripetal force, and a vertical gravitational force.

$$
F_{c}=\frac{m V_{H}^{2}}{r}
$$




$$
F_{0}=m V_{T}^{2}
$$

Where, $m$ represents the mass of the particle, and $V_{T}$ and $V_{H}$ its velocity in each direction. The radius of the particle's circular motion is r. Assuming spherical particles, and substituting (density $x$ volume) for mass,

$$
\begin{aligned}
& F_{c}=\frac{\rho_{p} \pi / 6 d_{p}^{3} V_{H}^{2}}{r} \\
& F_{0}=\phi_{p} \pi / 6 d_{p}^{3} v_{T}^{2}
\end{aligned}
$$

The value of $r$ is assumed constant and set equal to unity. This simplification will not affect relative flocculation values obtained for a given system. Thus,

$$
F_{c}=p \pi / 6 d_{p}^{3} v_{H}^{2}
$$

Since $D$ and $L$ are also representations of horizontal and vertical forces, respectively, Equations (19) and (25), and (20) and (24) can be set equal. Solving for the floc velocity in the two directions,

$$
\begin{aligned}
& V_{H}=\left[3 C_{d} \frac{\rho}{\rho_{p}} V^{2} d_{p}^{-1}\right]^{1 / 2} \\
& V_{t}=\left[3 C_{L} \frac{\rho}{\rho_{p}} V^{2} d_{p}^{-1}\right]^{1 / 2}
\end{aligned}
$$


The values for $C_{D}, C_{L}, P$, and $V$ will be constant for a given agitation system. Therefore,

$$
V_{H} \propto \frac{1}{\sqrt{p_{p} d_{p}}}
$$

and

$$
V_{T} \propto \frac{1}{\sqrt{p_{p} d_{p}}}
$$

The resultant force, $F_{A}$, is

$$
F_{R} \propto \frac{1}{\sqrt{2 p_{p} d_{p}}}
$$

The mobility, $M$, is proportional to $F_{\mathrm{A}}$, therefore

$$
M \propto \frac{1}{\sqrt{\rho_{p} d_{p}}}
$$

This relationship is also valid for flocs:

$$
M \propto \frac{1}{\sqrt{p_{1} d_{l}}}
$$

As density is proportional to mass/diameter ${ }^{3}$, it can be seen that as the floc grows, the increase in mass decreases the mobility. 
Another effect of increasing floc size is a decrease in specific surface area. Specific surface area is inversely proportional to the diameter of the flocs, i.e.

$$
A_{1} \propto \frac{1}{d_{1}}
$$

Incorporation of the modifications in Equations (31) and (32) into Equation (18) results in a general expression of the form:

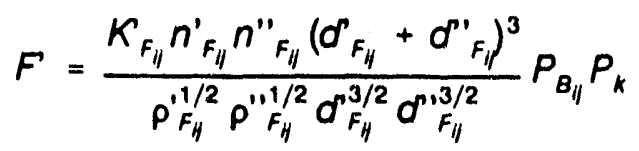

where: $F^{\prime}$ - rate of agglomeration of two flocs consisting of two types of particles/flocs, $i$ and $j$, in units of number/sec

$K_{F_{I I}^{\prime}}$ - flocculation rate constant

$n^{\prime} F_{i \mid}$ and $n^{\prime \prime} F_{i \mid}$ - number of flocsdiameters $d^{\prime} F_{i \mid}$ and $d^{\prime \prime} F_{i \mid}$ respectively

$\rho^{\prime} F_{\| \mid}$and $\rho^{\prime \prime} F_{\|}$- densities of the two interacting flocs.

\section{Concept of Critical $E_{1}:$}

Equation 18 can be rewritten as:

$$
F=k n, n, E_{\|}
$$

where $k$ is a constant in which all the other parameters of equation (18) are lumped. Applying the model to a single mineral, which is active for polymer adsorption (i.e. high $E_{\|} \sim 0.1-1.0$ ), the above equation, as expected, would yield high flocculation rates and show appreciable floc formation. In case of flocculation of inactive/inert particles, $E_{i \mid}$ would be low, typically $10^{-6}$ to $10^{-3}$; 
however, a reasonable amount of flocculation wisuld be predicted for an extremely large number of particles since the rate has a square dependence on $n$ (number) as compared to a linear dependence on $E_{\|}$. This is clearly not observed experimentally. To understand this, $E_{\|}$has to be considered in some detail. In the proposed model only those collisions where particles collide with the right orientation i.e. collision of polymer coated active site with a bare active site or vice versa, will lead to floc formation. In case the value of $E_{\| 1}$ is small it is implied from equation 3 that the number of active sites is extremely small therefore a large number of collisions would not be fruitful. To take this into account in the model for computational purposes, a parameter called critical collision efficiency is introduced. In case the collision efficiency parameter is below the critical value, an extremely large number of collisions are required for an appreciable floc formation and in model, floc formation is assumed to be absent. However, a value below critical $E_{1}$ does not mean that there is no floc formation but it implies that it is not significant and, therefore, the rate is negligible. The value of critical $E_{\|}$would be system specific and is determined experimentally.

The above equations are used to determine floc formation for a given system using a computational scheme, which is described next.

\section{Computational Scheme:}

The computational scheme is described in Figure II-1. It involves a stepwise evaluation of maximum number of flocs of a particular type that are possible. Then the rate of the particular type of floc formation is estimated by assuming that all the types of collisions are independent of each other, and therefore the probability for this to occur, would be the fraction of total rate. Calculation of $\rho, \theta$, and $\Phi$ : In the simulation model, the floc size and density keep changing as smaller flocs combine to form bigger flocs. In general, as size increases, the density of the flocs decreases. The diameter of a growing floc has been determined to follow an empirical equation of the form 


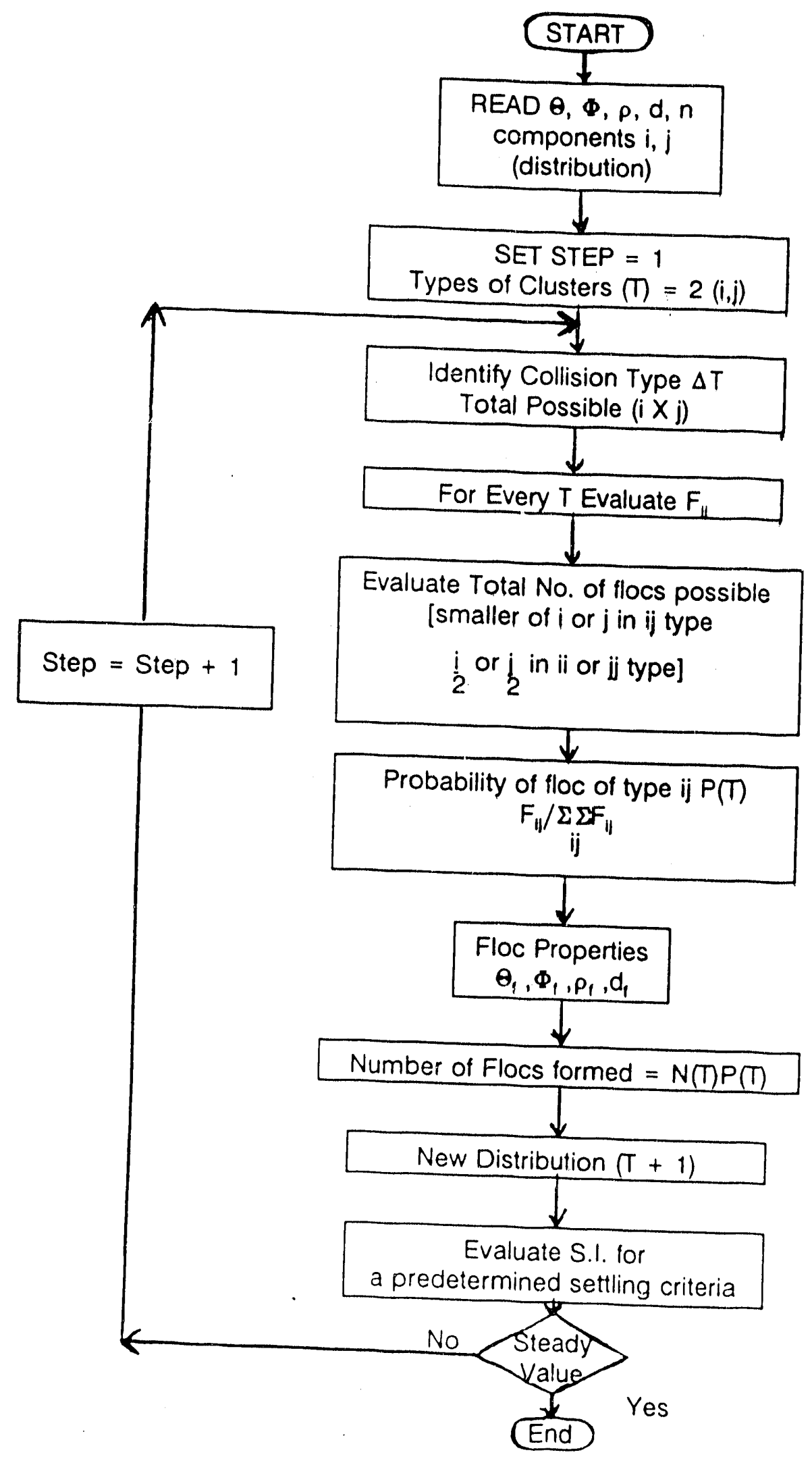

Figure II-1. Computational Scheme for Heteroflocculation. 


$$
d_{F}=1.13 d_{p} Z^{0} .429
$$

in which $d_{p}$ is the primary particle diameter and $Z$ is the number of particles in the floc. The density of the floc can be calculated as follows:

Using Equation (35), the density of a growing floc can be determined by the procedure given below.

To avoid geometric complications, flocs are assumed to be spherical, thus

$$
V_{F}=\pi / 6 d_{F}^{3}
$$

$V_{F}$ is the volume of the floc. By definition,

$$
\begin{aligned}
& \rho_{F}=\frac{M_{F}}{V_{F}} \\
& =\frac{M_{F}}{\pi / 6 d_{p}^{3}}
\end{aligned}
$$

The mass of the floc is equal to the number of particles in the floc times the mass of a single particle:

$$
M_{F}=Z M_{p}
$$

Also, the diameter of a floc has already been stated in Equation 35 as

$$
d_{F}=1.13 d_{p} z^{0} .429
$$

Coiveining Equations (39) and (35), the following relationship is obtained: 


$$
\rho_{F}=\frac{Z M_{p}}{1.44 Z^{1} .287\left(\pi / 6 d_{p}^{3}\right)}
$$

\section{Since}

$$
\frac{M_{p}}{\pi / 6 d_{p}^{3}}=\rho_{p}
$$

equation 42 is reduced to:

$$
\rho_{F}=0.694 \rho_{p} Z^{0} .287
$$

To consider particles of different size and density in a floc, the original expression has been modified. The values of $\Theta$ and $\Phi$ for the flocs formed are estimated by weighing the $\Theta$ and $\Phi$ for single particles with the total surface areas. The modified equations are:

$$
\begin{aligned}
& \rho_{a v}=\frac{n_{1} \rho_{1} d_{1}^{3}+n_{2} \rho_{2} d_{2}^{3}}{n_{1} d_{1}^{3}+n_{2} d_{2}^{3}} \\
& \rho_{f}=0.694 \rho_{a v}\left(n_{1}+n_{2}\right)^{-0.287}
\end{aligned}
$$




$$
\phi_{1}=\frac{n_{1} \phi_{1}\left(\frac{d_{1}}{d_{2}}\right)^{2}+n_{2} \phi_{2}}{n_{1}\left(\frac{d_{1}}{d_{2}}\right)^{2}+n_{2}}
$$

Where $n_{1}$ is the number of particles with diameter $d_{1}$ and density $\rho_{1}$ and $n_{2}$ is the number of particles with diameter $d_{2}$ and density $p_{2}, p_{f}, \theta_{1}$, and $\Phi_{1}$ represent the density, fractional surface coverage and active sites ratio of the flocs respectively.

The value of $\theta$ and $\Phi$ for a pure floc (i.e. floc of same material) is the same as that of a single particle i.e. the exposed surface still has the same characteristics. Flocs satistying a predetermined separation criteria are assumed to be separated from the bulk. For these simulations the settling criteria was the experimental Stokes settling velocity of the floc $(>0.31$ $\mathrm{cm} / \mathrm{sec})$. At each step, the selectivity index (S.I. $)^{\star \star}$ is calculated and a steady value is taken as the criteria to stop the simulation. In certain cases, where the number of particles were extremely large, due to limited computational storage, the process was carried out to as far as possible and the results extrapolated.

Relative Importance of $\phi$ and $\Theta$ : A number of single and mixed mineral flocculations were simulated using the model. The calculated value of S.I. agreed with the experimental values indicating validity of the computations. These simulations were carried out for 10 million particles which is of order of magnitude of number of particles encountered in the experimental systems.

$$
\begin{gathered}
\text { Selective Index (S.I. })=\frac{\% \text { Grade of Concentrate }-\% \text { Values in Feed }}{100-\text { Values in Feed }} \times 100 \\
\text { Grade }=\frac{\text { Amt. of Values in Concentrate }}{\text { Total Amount of Concentrate }} \times 100
\end{gathered}
$$


During the simulation studies for different systems, it was generally observed that S.I. and recovery (yield) were a strong function of the value of $\Phi$ (active sites) and not of $\theta$ (fractional surface coverage). In other words, to achieve separation, it is more important to select a polymer which does not adsorb on the inert component $\left(\Phi_{\text {iner }}\right.$ is very small), than to achieve the desired selectivity by controlling the polymer dosage.

Computational Simulations: The following simulations were carried out for a coal-coal pyrite mixture or 10 million particles in the system.

1. $95 / 5 w t \%$ coal - coal pyrite system (corresponding to $3 w t \%$ sulfur) with coal as the active component $\left(\Phi_{\text {coal }}=1.0\right)$. S.I. and recovery are plotted as a function of $\Phi_{A}\left[=\left(\frac{\phi_{c}}{\phi_{\mathrm{Fes}_{2}}}\right)\right]$. It can be seen from Figure $11-2$ and Table $11-1$, that at $\Phi_{\mathrm{F}}=500$ i.e. $\Phi_{\mathrm{FeS}}=0.002$ the selectivity index is 98.8 and recovery of coal is $75.58 \%$.

S.I., in this case, is defined as: $\frac{\% \text { coal in floc bed - and coal in feed }}{100-\% \text { coal in feed }} \times 100$ and Recovery/Yield as: $\frac{\text { amount of coal in supernatant }}{\text { amount of coal in feed }} \times 100$

2. $95 / 5 w t \%$ coal-coal pyrite, with coal pyrite as the active component. The variation of S.I. and recovery as a function of $\Phi_{\mathrm{A}}$ is plotted in Figure $\|$-3 (also see Table II-2). In this case, at $\Phi_{\mathrm{R}}=500$, the recovery is $99 \%$ and the selectivity index is 94.46 .

S.I. in this case is defined as: $\frac{\% \text { coal in supernatant }-\% \text { coal in feed }}{100-\% \text { coal in feed }} \times 100$ 
석익

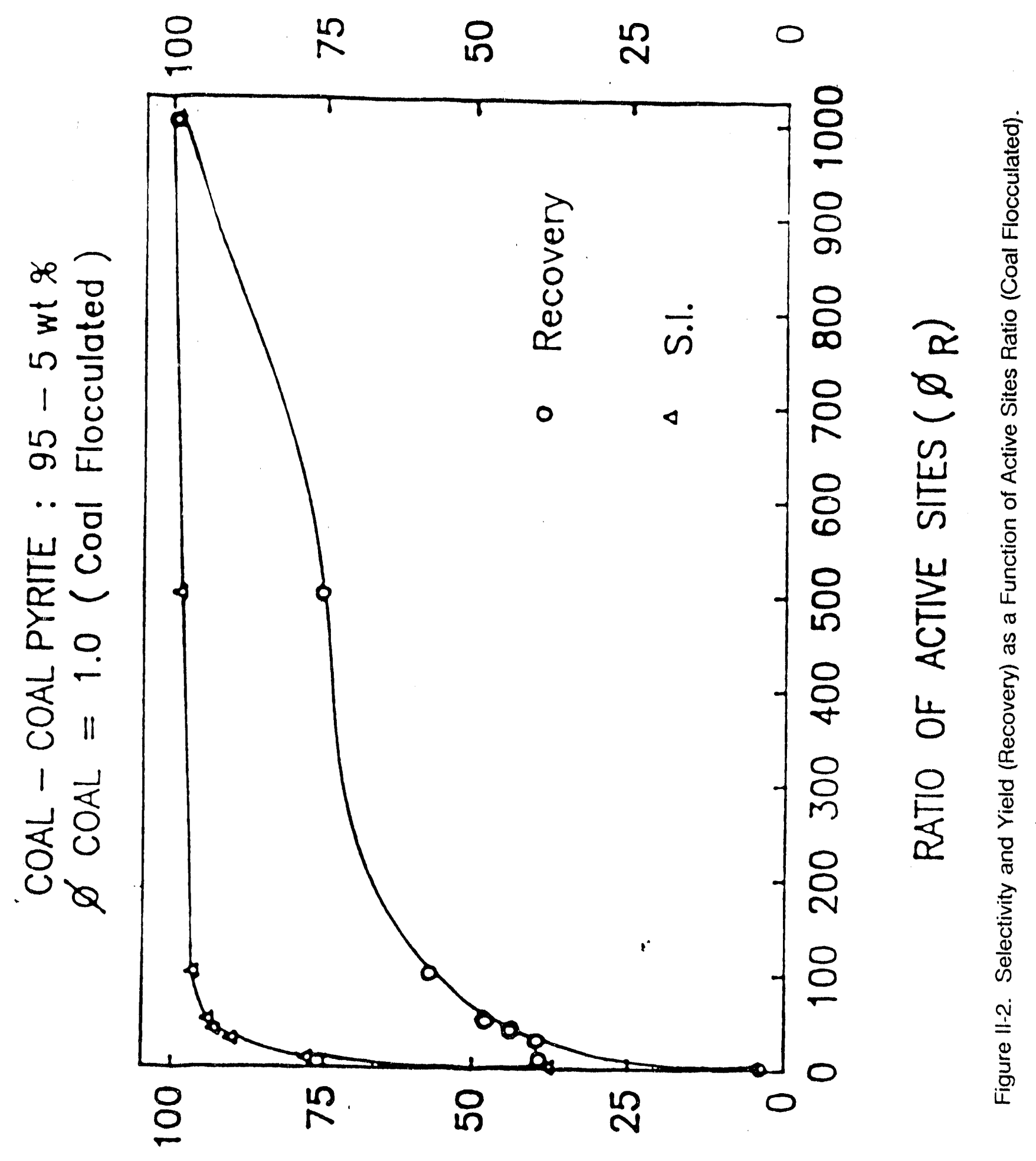

X3ONI UUNILOJ73S 


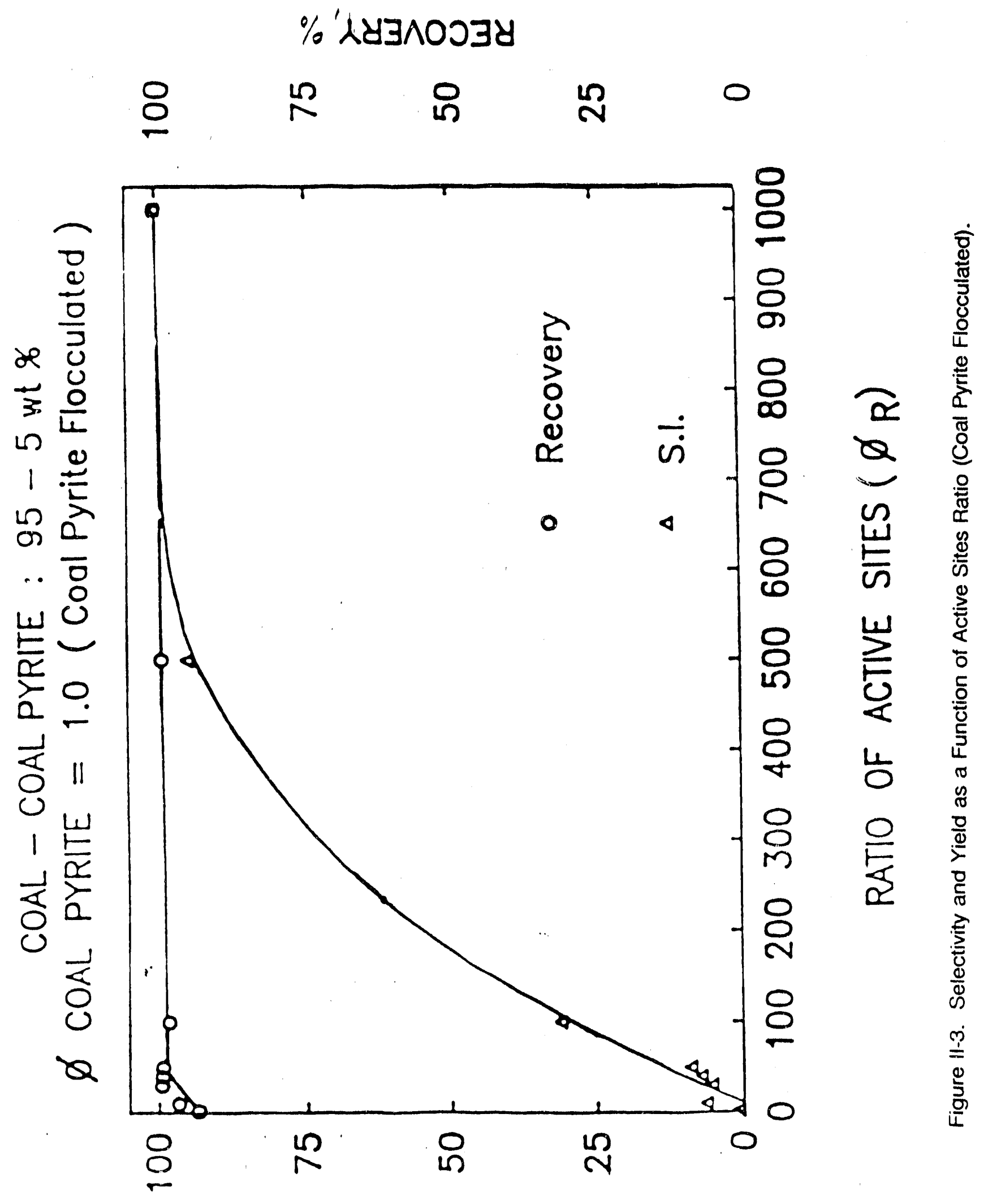

$X \exists O N I N L N \perp 037 \exists S$ 
TABLE II-1

SELECTIVITY AS A FUNCTION OF $\Phi_{R}$ WHEN COAL IS FLOCCULATED

Coal:Coal Pyrite $=95: 5$

$\Phi_{\text {Coal }}=1.0$ (Coal Flocculated)

\begin{tabular}{|lcccccccc|}
\hline$\Phi_{\mathrm{R}}$ & 2 & 10 & 30 & 40 & 50 & 100 & 500 & 1000 \\
$\Phi_{\mathrm{FeS}}$ & 0.5 & 0.1 & 0.033 & 0.025 & 0.02 & 0.01 & 0.002 & 0.001 \\
Recovery \% & 3.8 & 39.2 & 39.6 & 43.76 & 47.87 & 57.37 & 75.58 & 99.8 \\
Grade \% Coal & 96.89 & 98.9 & 99.51 & 99.65 & 99.71 & 99.83 & 99.94 & 100 \\
S.I. & 87.30 & 78.0 & 90.2 & 93.0 & 94.2 & 96.6 & 98.8 & 100 \\
\hline
\end{tabular}


TABLE II-2

SELECTIVITY AS A FUNCTION OF $\Phi_{R}$ WHEN COAL PYRITE IS FLOCCULATED

Coal:Coal Pyrite $=95: 5$

$$
\Phi_{\mathrm{FeS}_{2}}=1.0
$$

\begin{tabular}{|lcccccccc|}
\hline$\Phi_{\mathrm{R}}$ & 2 & 10 & 30 & 40 & 50 & 100 & 500 & 1000 \\
$\Phi_{\text {Coal }}$ & 0.5 & 0.1 & 0.033 & 0.025 & 0.02 & 0.01 & 0.002 & 0.001 \\
Recovery, \% & 93.12 & 96.51 & 99.48 & 99.26 & 99.25 & 98.06 & 99.02 & 100 \\
Grade, \% Coal & 95.03 & 95.31 & 95.26 & 95.35 & 95.44 & 96.55 & 99.72 & 99.99 \\
S.I. & 0.76 & 6.26 & 5.28 & 7.1 & 8.85 & 31.11 & 94.46 & 99.98 \\
\hline
\end{tabular}


Recovery is defined as: $\frac{\text { amount of coal in supernatant }}{\text { amount of coal in feed }} \times 100$

3. Variations of S.I. and recovery with the amount of coal pyrite in the feed are plotted in Figure $\mid 1.4$ (also see Table II-3). It is observed that S.I. is independent of feed composition.

A typical run for computational simulation took about 10 minutes of CPU time on VAX 11.780.

It is observed that the rate of flocculation is high in the case when coal is considered to be active. However, it must be noted that on flocculating coal, appreciable settling of coal pyrite also could occur because of entrainment. Therefore, it is more appropriate to flocculate coal pyrite than coal. 


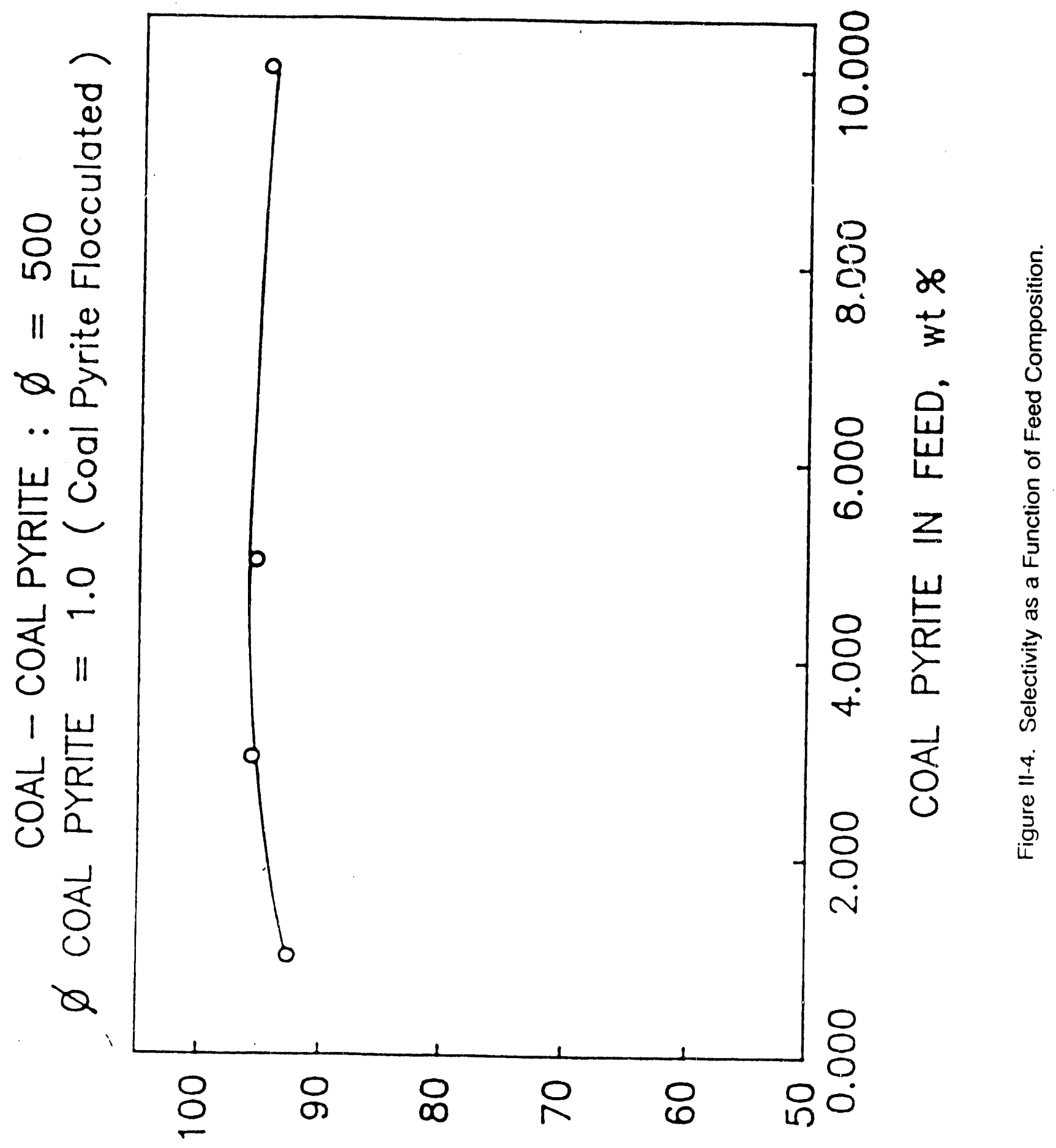

$X \exists$ ONI ULINILOJרIS 
TABLE II-3

SELECTIVITY AS A FUNCTION OF FEED COMPOSITION

$$
\Phi_{\mathrm{R}}=500 \quad \Phi_{\mathrm{Cal}}=0.002 \quad \Phi_{\mathrm{FeS}_{2}}=1.0
$$

\begin{tabular}{|lcccc|}
\hline Amt. of $\mathrm{FeS}_{2}$ (wt\%) & 1 & 3 & 5 & 10 \\
Recovery, \% & 99.75 & 99.87 & 99.72 & 99.47 \\
Grade, \% Coal & 99.926 & 99.87 & 99.72 & 99.47 \\
S.I. & 92.60 & 95.66 & 94.46 & 94.65 \\
$\%$ Pyrite in Coal & 0.074 & 0.129 & 0.277 & 0.54 \\
\hline
\end{tabular}




\section{Chapter III}

\section{MATERIALS AND METHODS}

\section{Materials:}

The coal and coal pyrite samples were obtained from two sources: (1) Coal sample from Pittsburgh-Bruceton Mine and the pyrite sample from the Southwestern Pennsylvania Coal Preparation Plant were provided by the Pittsburgh Energy Technology Center.(samples from DOE-PETC) (2) Coal Research Resource Center at Virginia Tech. Samples obtained from DOE-PETC are labelled as (I) and latter as (II). These samples were received as big lumps of 3-5 inches diameter. Quartz, montmorillonite and kaolinite samples were obtained from the Wards Natural Sciences, Inc. All samples were comminuted to -400 mesh size using a ball mill. The polymeric flocculants obtained from Polysciences Inc., American Cyanamid Co. and Calgon Corp. were used as received (see Table III-1). The deionized water used in the study had conductivity of less than $1 \mu$ mho.

\section{Procedures:}

Comminution: Coal lumps (7 to $12 \mathrm{~cm}$ in size) were passed through a chipmunk jaw crusher followed by a pulverizer to reduce the size. The crushed material obtained was sieved and the large particles were recycled. The fines obtained (-270 mesh) were passed through a laboratory lift type magnetic separator (CARPCO MODEL MSL - $12-103$ ) to remove any possible iron contamination from the jaw crusher and the pulverizer.

The -270 mesh material was comminuted to -400 mesh using a ceramic wet ball mill and the coal samples were stored in water and stored under argon atmosphere to minimize oxidation.

Ash Analysis: The coal samples were analyzed for mineral matter content by an ASTM standard test method (1982) (D 3174-82). Approximately $1 \mathrm{gm}$ of thoroughly mixed sample was transferred to a weighed crucible. The crucible was covered and immediately transferred to a furnace. The heating 


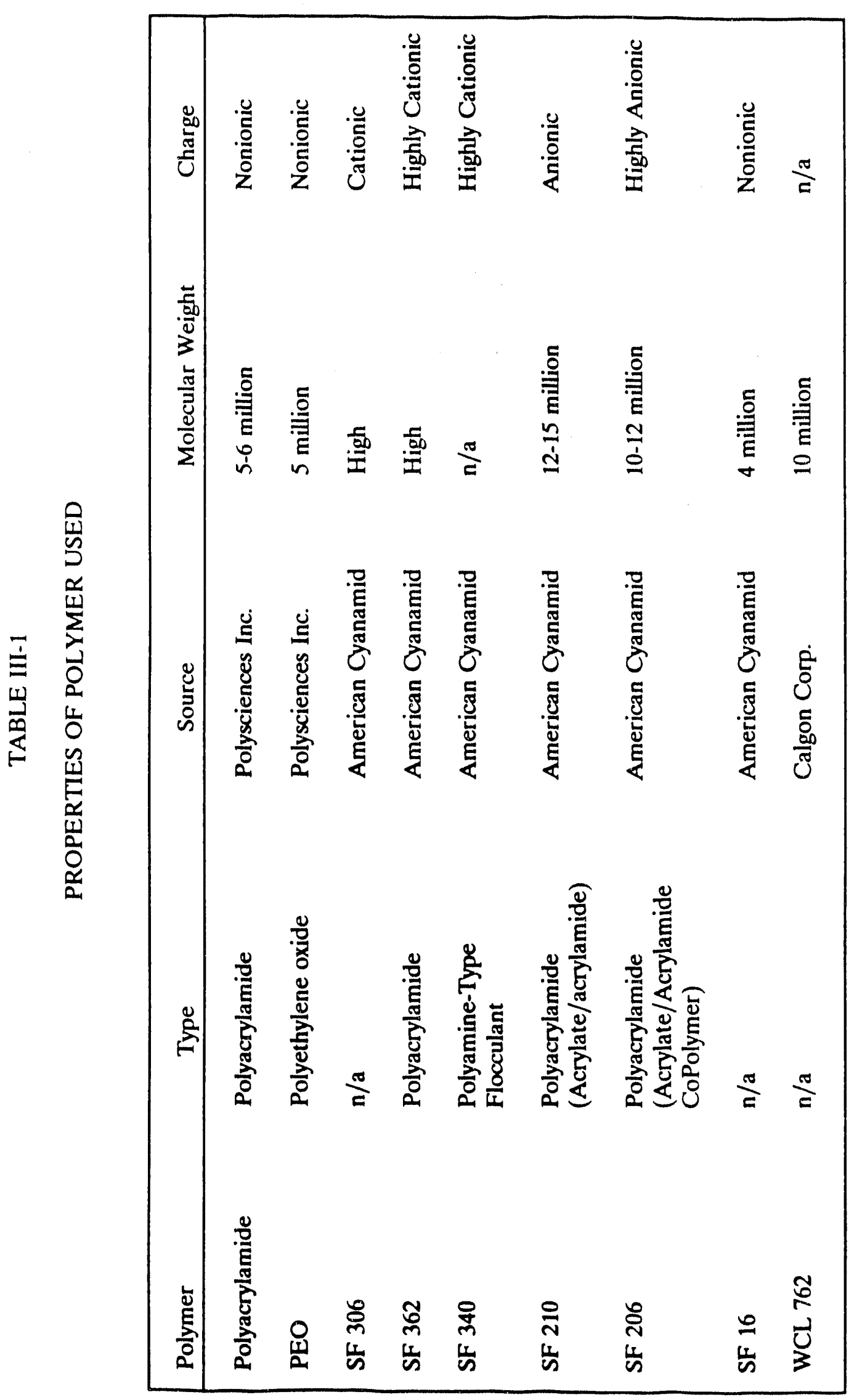


was gradual so that the temperature reached 450 to $500^{\circ}$ in one hour and $700-800^{\circ} \mathrm{C}$ at the end of two hours. The air flow rate of $2.6 \mathrm{l} / \mathrm{min}$ was maintained in the furnace with 2 to 4 changes per minute. The ashing was continued for 2 more hours and the sample was cooled in the desiccator to minimize moisture pickup. The ash analysis indicated $4.2 \%$ mineral matter in the coal sample used in this study. This result was reproduced within $\pm 0.4 \%$.

The proximate and ultimate analysis of coal and coal refuse (DOE-PETC Sample) was performed by Commercial testing and Engineering Company, Birmingham, Alabama and the results are given in Tables III-2 and III-3. The analysis of coal pyrite was performed by the same company and the results are presented in Table III-4. Table III-5 and III-6 give the same for Virginia Tech. Sample.

SEM/EDAX Analysis: The -270 mesh sample of coal was dried and analyzed by SEM and EDAX. A micrograph of the coal sample is presented in Figure III-1. The EDAX analysis of the sample indicated the presence of aluminum, calcium, iron, phosphorus, sulfur, and silicon besides carbon. Also, the analysis of various sizes showed that the major difference between them is the relative presence of the various elements. These results are presented in Figures III-2 to III-5.

ICP Analysis: For quantitative chemical analysis of the sample, the Inductively Coupled Plasma (ICP) spectrometer (PERKIN ELMER PLASMA II) was used. The procedure followed was as follows; $1 \mathrm{gm}$ of 270 mesh coal was digested in $150 \mathrm{ml}$ aqua regia at $70-80^{\circ} \mathrm{C}$ for 10 hours. The slurry was filtered and washed in a volumetric flask and made into 1 liter of solution using deionized water.

To estimate the pyritic sulfur, ASTM Procedure (1982) (D 2492) was used. This method is based on the fact that sulfates are soluble in hydrochloric acid. Pyrite $\left(\mathrm{FeS}_{2}\right)$ is extracted quantitatively by dilute nitric acid and extracted iron is determined by ICP spectrometer. The sulfur is calculated according to stoichiometry.

The values for different elements are listed in Table III-7. The sulfur content in the pyrite sample 


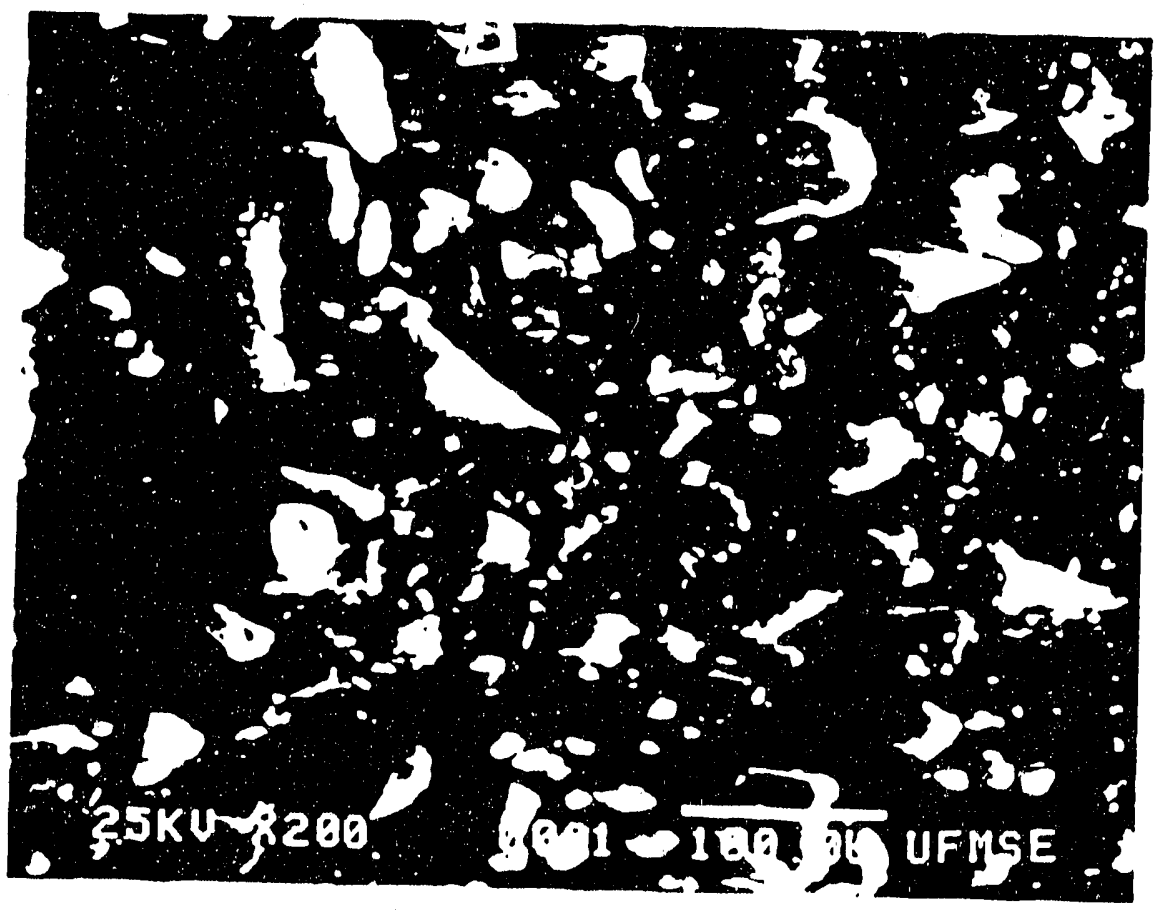

Figure III-1. Microçraph of Coal Sample. 


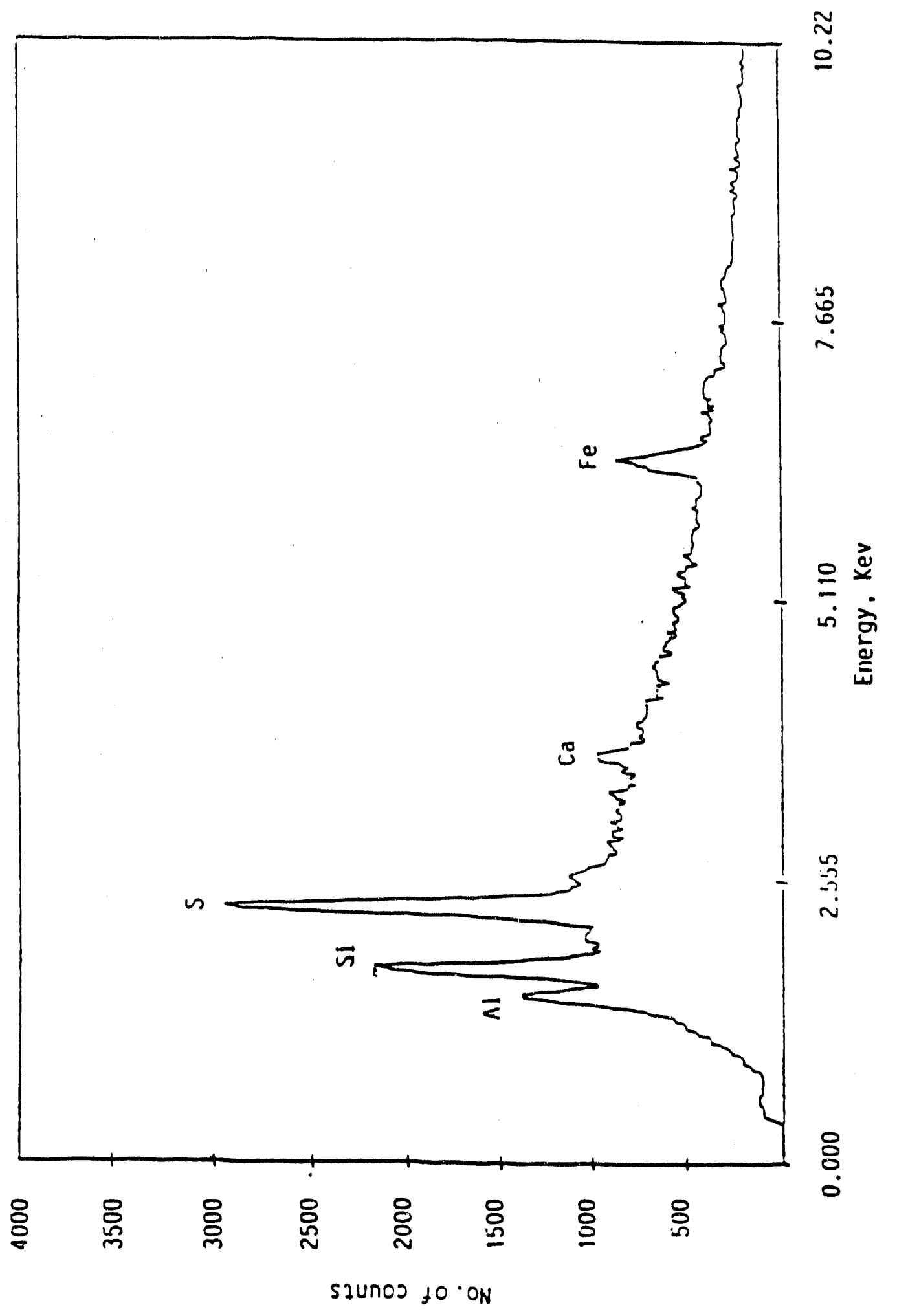

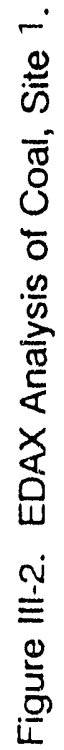




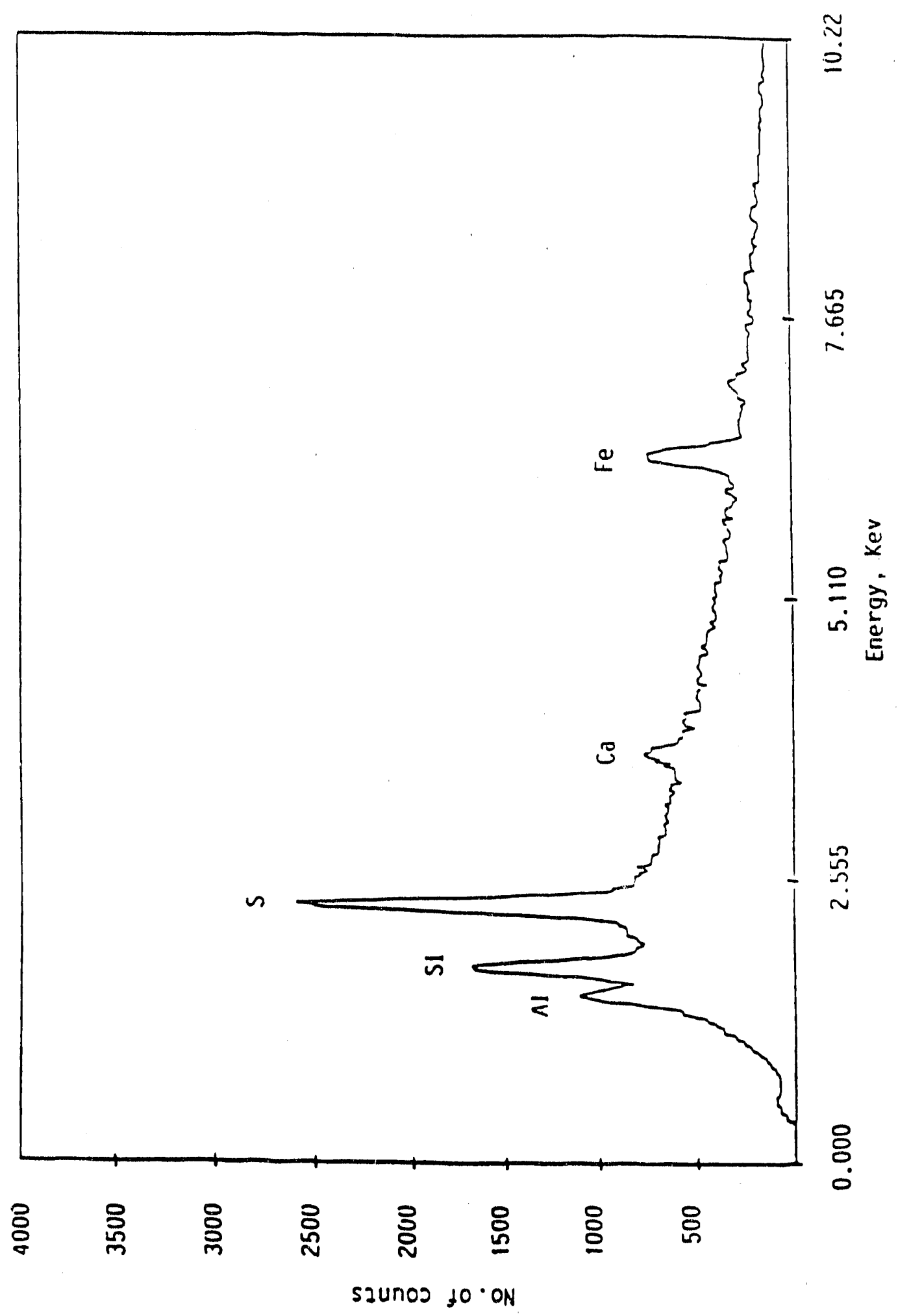

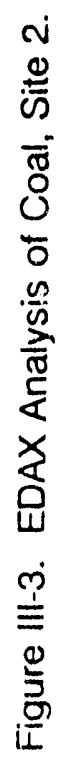




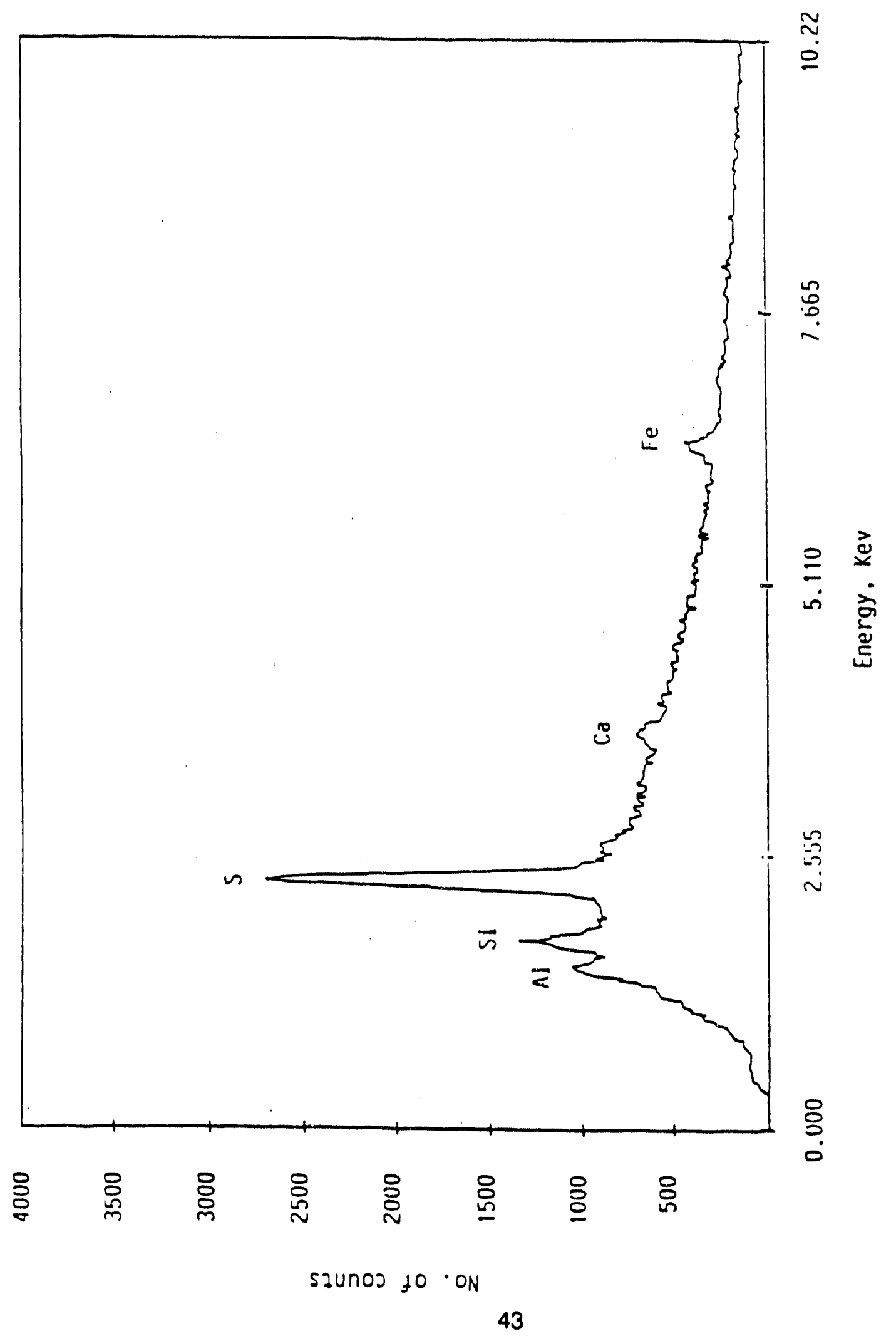

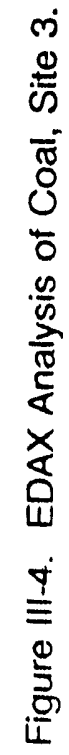




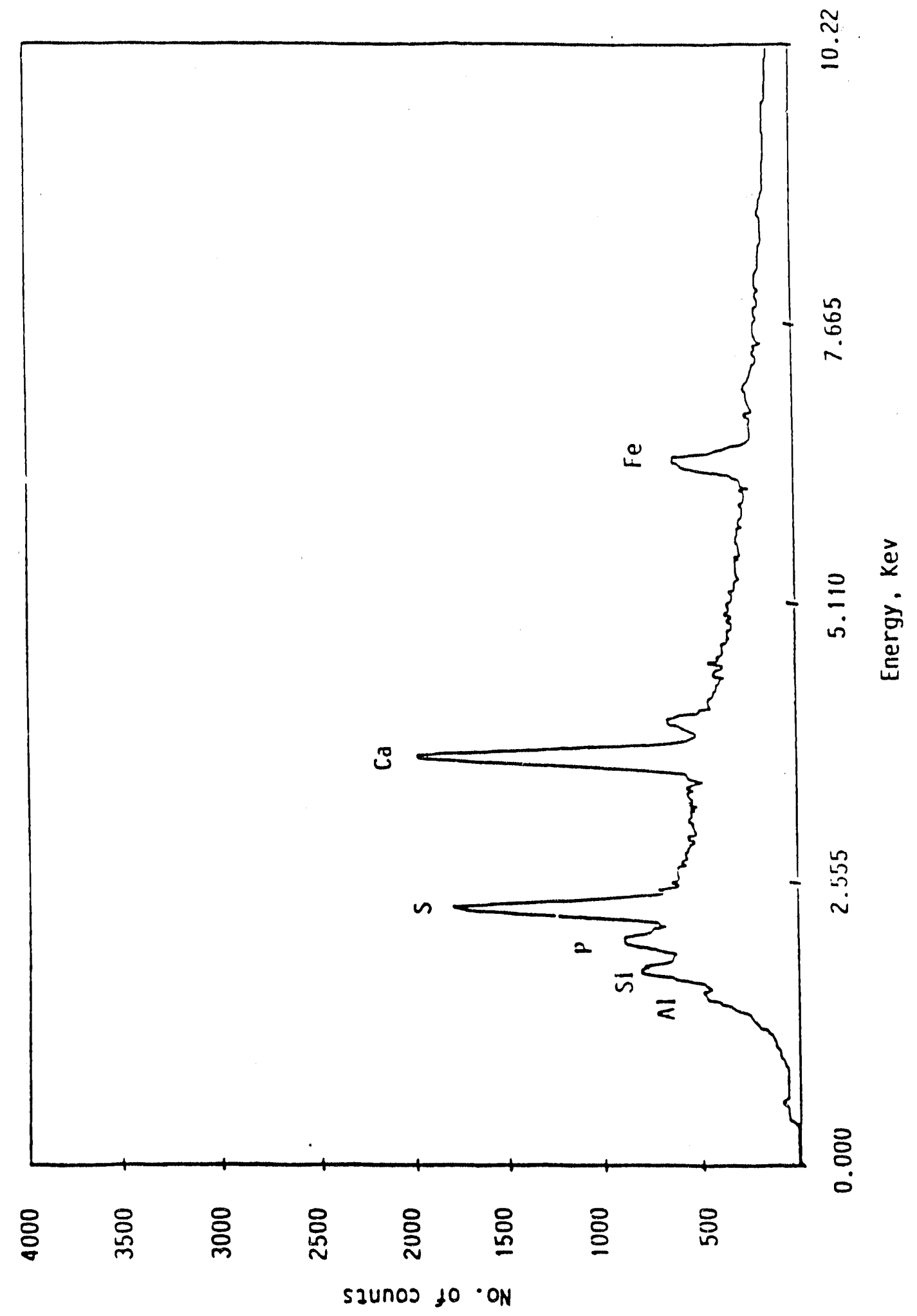

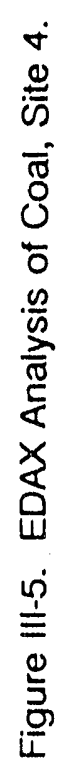


TABLE III-2

ANALYSIS OF COAL (DOE-PETC) SAMPLES

\begin{tabular}{|c|c|c|}
\hline \multicolumn{3}{|c|}{ Proximate Analysis } \\
\hline & As Received & Dry Basis \\
\hline$\%$ Moisture & 2.36 & $\mathbf{x x} . \mathbf{x x}$ \\
\hline$\%$ Ash & 7.62 & 7.80 \\
\hline$\%$ Volatile & 35.41 & 36.27 \\
\hline \multirow{2}{*}{$\%$ Fixed Carbon } & 54.61 & $\underline{55.93}$ \\
\hline & 100.00 & 100.00 \\
\hline $\begin{array}{l}\text { Btu/lb } \\
\% \text { Sulfur }\end{array}$ & $\begin{array}{r}13454 \\
2.43\end{array}$ & $\begin{array}{r}13780 \\
2.49\end{array}$ \\
\hline \multicolumn{3}{|c|}{ Ultimate Analysis } \\
\hline & As Received & Dry Basis \\
\hline$\%$ Moisture & 2.36 & $\mathbf{x x} . \mathbf{x x}$ \\
\hline$\%$ Carbon & 75.08 & 76.90 \\
\hline$\%$ Hydrogen & 4.90 & 5.02 \\
\hline$\%$ Nitrogen & 1.47 & 1.51 \\
\hline$\%$ Chlorine & 0.06 & 0.06 \\
\hline$\%$ Sulfur & 2.43 & 2.49 \\
\hline$\%$ Ash & 7.62 & 7.80 \\
\hline \multirow[t]{2}{*}{$\%$ Oxygen (diff.) } & 6.08 & 6.22 \\
\hline & 100.00 & 100.00 \\
\hline
\end{tabular}


TABLE III-3

ANALYSIS OF COAL (DOE-PETC) REFUSE

\begin{tabular}{|c|c|c|}
\hline \multicolumn{3}{|c|}{ Proximate Analysis } \\
\hline & As Received & Dry Basis \\
\hline$\%$ Moisture & 2.69 & $\mathbf{x X} . \mathbf{x X}$ \\
\hline$\%$ Ash & 85.70 & 88.07 \\
\hline$\%$ Volatile & 8.64 & 8.88 \\
\hline \multirow[t]{2}{*}{$\%$ Fixed Carbon } & 2.97 & $\underline{3.05}$ \\
\hline & 100.00 & 100.00 \\
\hline $\mathrm{Btu} / \mathrm{lb}$ & 682 & 701 \\
\hline \multirow[t]{3}{*}{$\%$ Sulfur } & 0.32 & 0.40 \\
\hline & \multicolumn{2}{|l|}{ Ultimate Analysis } \\
\hline & As Received & Dry Basis \\
\hline$\%$ Moisture & 2.69 & $x x . x x$ \\
\hline$\%$ Carbon & 5.06 & 5.20 \\
\hline$\%$ Hydrogen & 1.05 & 1.08 \\
\hline$\%$ Nitrogen & 1.13 & 1.16 \\
\hline$\%$ Chlorine & 0.01 & 0.01 \\
\hline$\%$ Sulfur & 0.39 & 0.40 \\
\hline$\%$ Ash & 85.70 & 88.07 \\
\hline \multirow[t]{2}{*}{$\%$ Oxygen (diff.) } & 3.97 & 4.08 \\
\hline & 100.00 & 100.00 \\
\hline
\end{tabular}




\section{TABLE III-4}

ANALYSIS OF THE COAL PYRITE (DOE-PETC) SAMPLE

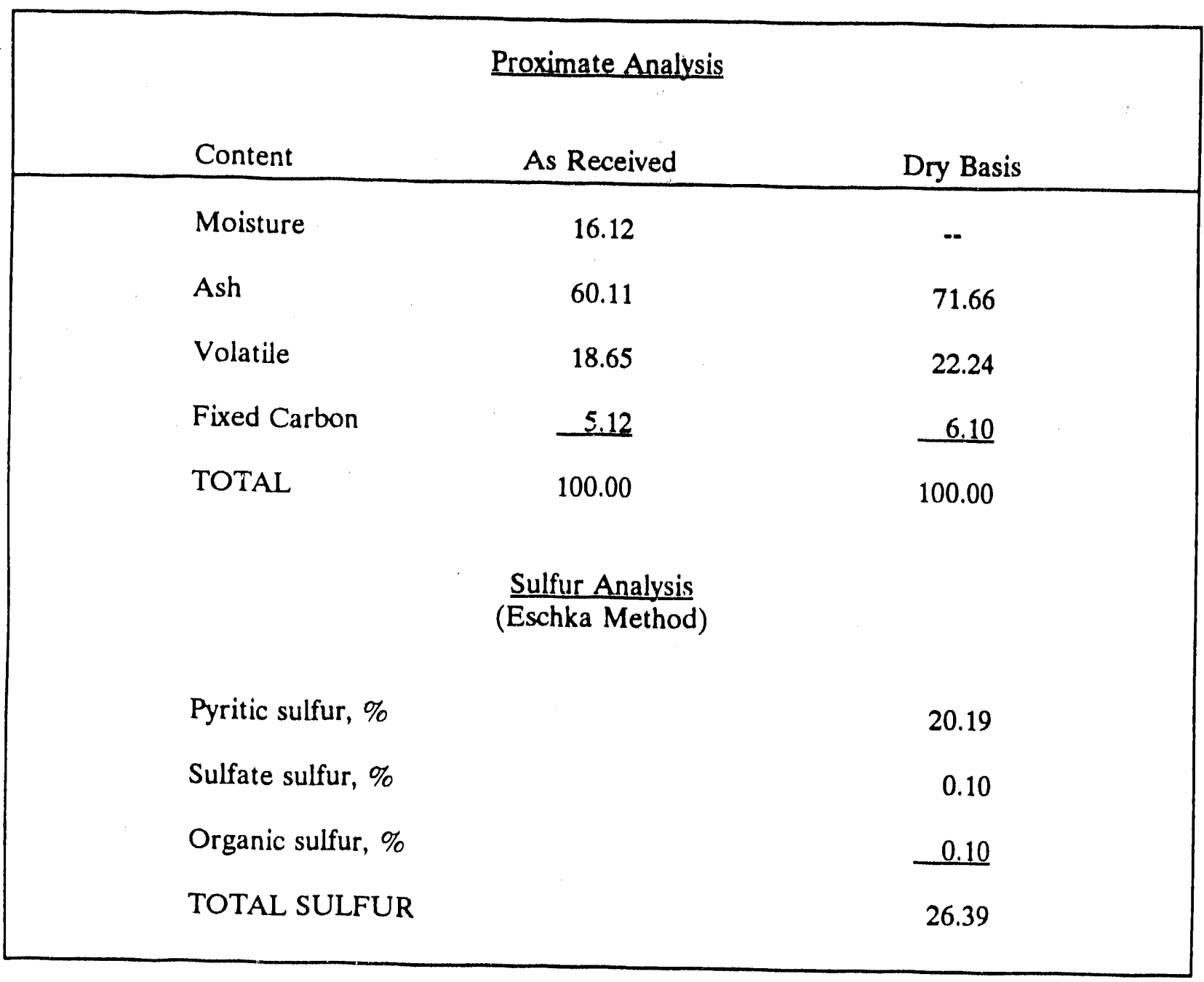


TABLE III-5

ANALYSIS OF COAL - VIRGINIA TECH. SAMPLE

Proximate Analysis

As Received

$\underline{\text { Dry Basis }}$

\% Moisture

1.57

\% Ash

11.28

$\%$ Volatile

37.21

\% Fixed Carbon

49.94

100.00

$-\cdot,--$

11.46

37.80

50.74

100.00

Btu/lb

129.88

$\%$ Sulfur

3.86

131.95

--..-

3.92

149.03

Ultimate Analysis

As Received

\% Moisture

$\%$ Carbon

$\%$ Hydrogen

$\%$ Nitrogen

$\%$ Sulfur

$\%$ Ash

$\%$ Oxygen
1.57

71.62

4.87

1.35

3.86

11.28

5.45

100.00

Forms of Sulfur

As Received

2.07

0.15

$-1.64$
Dry Basis

-.,-

72.76

4.9

1.37

3.92

11.46

$\frac{5.54}{100.00}$
\% Pyritic

$\%$ Sulfate

$\%$ Organic

$\%$ Sulfur
Dry Basis

2.10

0.15

$-\frac{1.67}{3.92}$ 
TABLE III-6

ANALYSIS OF COAL PYRITE - VIRGINIA TECH. SAMPLE

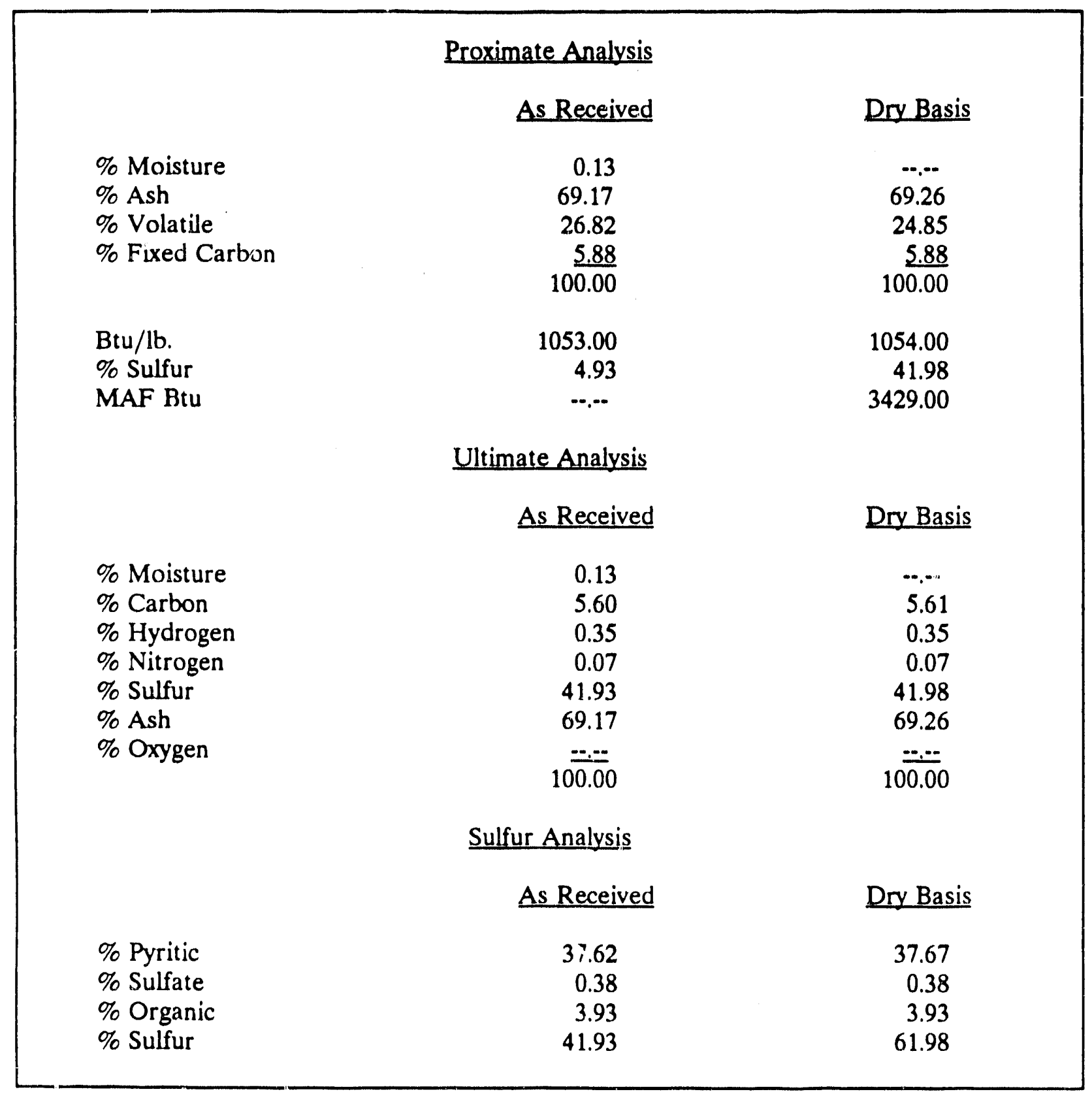


TABLE III-7

ELEMENTAL ANALYSIS OF COAL SAMPLE

\begin{tabular}{|cc|}
\hline Element & Concentration, $\mathrm{mg} / \mathrm{gm}$ of Coal \\
\hline $\mathrm{Al}$ & 1.34 \\
$\mathrm{Ca}$ & 0.74 \\
$\mathrm{Fe}$ & 11.74 \\
$\mathrm{P}$ & Trace \\
$\mathrm{S}$ & 2.5 \\
\hline
\end{tabular}


by iron analysis was determined to be $18.0 \%$. as compared to $20.2 \%$ analyzed by a commercial testing company.

Specific Gravity of Coal: The specific gravity of coal was determined by a specific gravity bottle using $5 \mathrm{gms}$ of coal sample in isopropanol. Isopropanol was used for efficient wetting and penetration of the fluid into the pores of the coal particles. The specific gravity of the coal sample was determined to be $1.306 \mathrm{~g} / \mathrm{cm}^{3}$.

Particle Size Analysis: The particle size analysis was carried out using a HORIBA Particle Size Analyzer. The $d_{50}$ for coal and coal pyrite samples (DOE-PETC)) were determined to be $30 \mu \mathrm{m}$ and $5 \mu \mathrm{m}$, and for samples from VPI 5 and $0.81 \mu \mathrm{m}$ respectively. The particle size distribution for coal and coal pyrite samples from VPI are presented in Figures $\|1-6\| 11-$,7 , and $\| I-8$.

Surface Area Measurements: Surface area measurements were carried out using accelerated surface area and porosimetry system (Micromeritics, ASAP 2000). Results for coal and coal pyrite samples (I) are presented in Table $111-8$. The average specific surface area of coal was determined to be $1.55 \mathrm{~m}^{2} / \mathrm{g}$ and of pyrite $7 \mathrm{~m}^{2} / \mathrm{g}$. This implies the coal pyrite sample has a very large surface area as compared to the coal samples.

FTIR Analysis: FTIR analysis was carried out to ascertain different mineral constituents in the samples (Painter 1980) and also to identify any specific adsorption sites on the solid surface for the polymer. This would help in selecting the appropriate polymer to obtain optimum sclectivity in adsorption.

In the case of evaluating the mineral constituents, diffuse reflectance spectras were obtained. In this method, a small amount of dry solid sample is dispersed in dry $\mathrm{KBr}$ powder $(1.10 \mathrm{wt} \%)$ and ground gently to obtain a uniform mixture. The spectra is taken in the micro capsule using a 740 Nicolet 

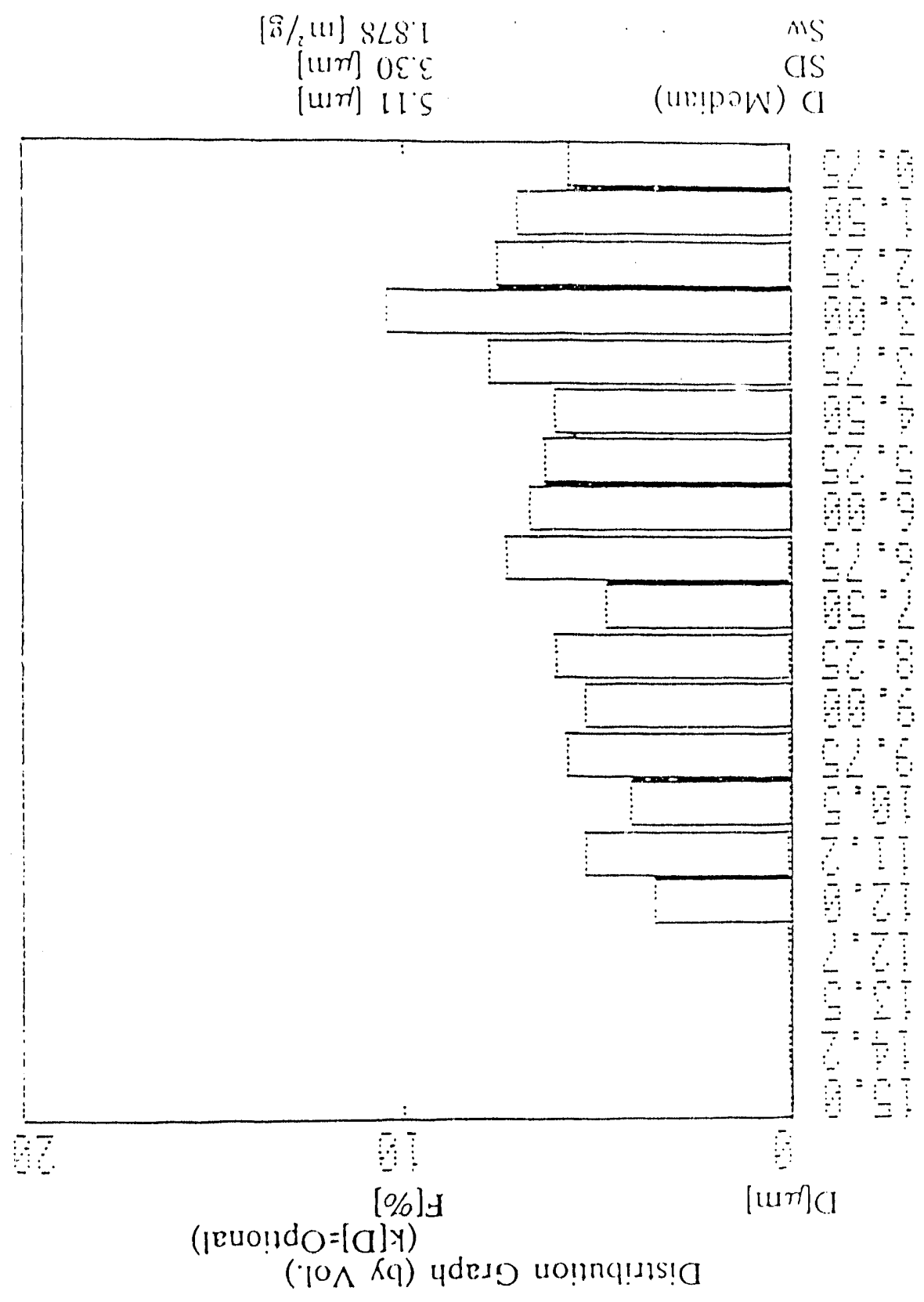

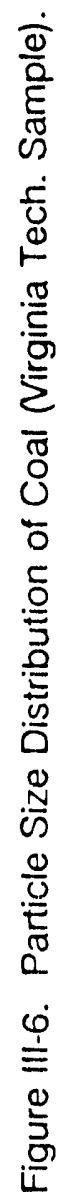
$(10 \wedge \mathrm{Kq})$ y deso uomnq!ns! 


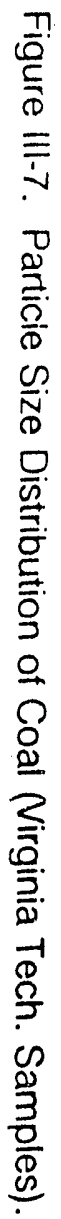

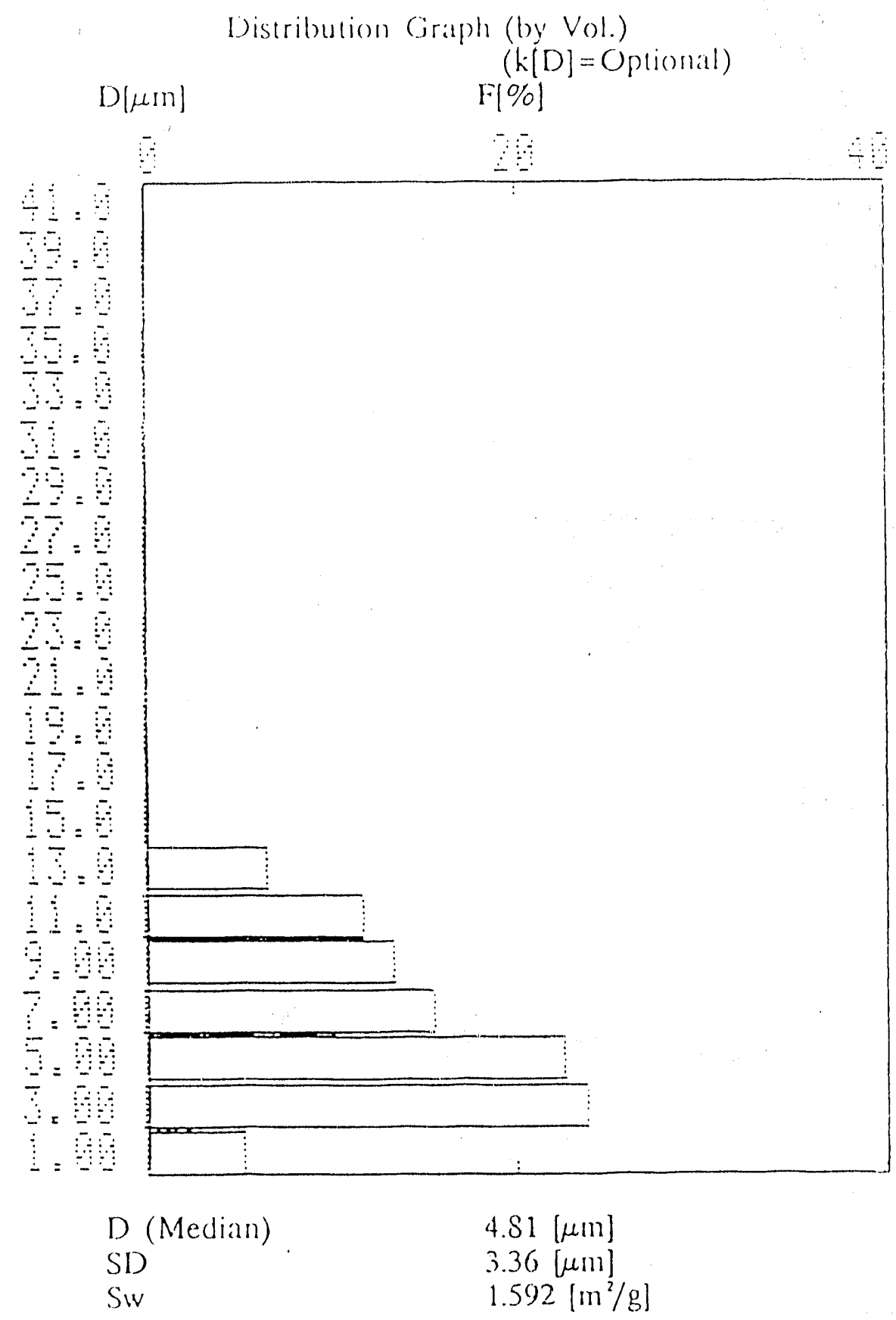




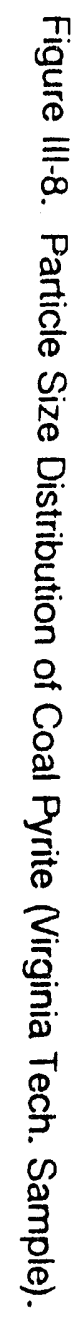

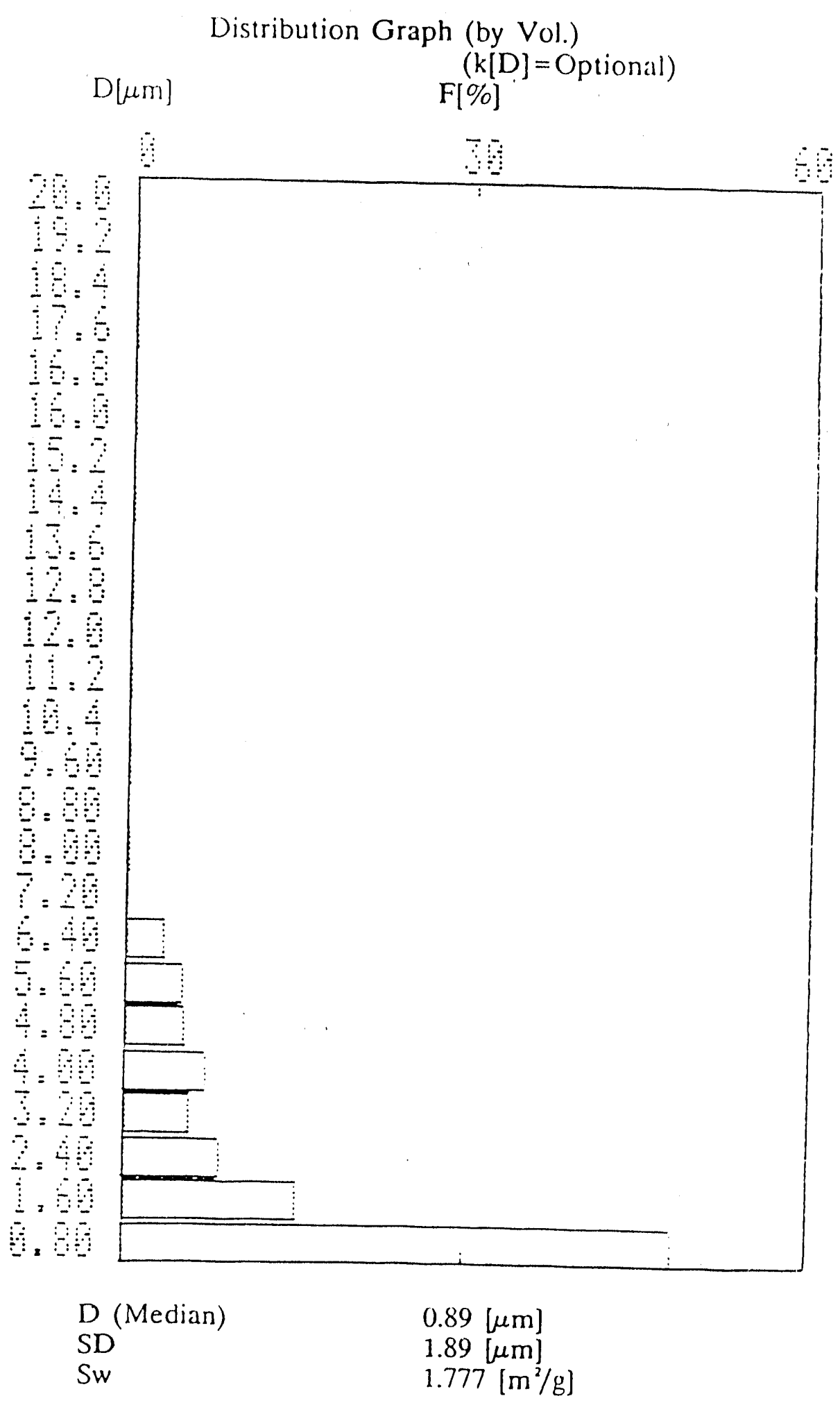


TABLE III-8

PHYSICAL CHARACTERISTICS OF COAL AND COAL PYRITE

\begin{tabular}{|c|c|c|c|c|c|}
\hline \multirow{2}{*}{ Sample } & \multicolumn{2}{|c|}{ Specific Surface Area $\mathrm{m}^{2} / \mathrm{gm}$} & \multicolumn{2}{|c|}{ Pore Size, $A^{0}$} & \multirow{2}{*}{$\begin{array}{l}\text { Pore Volume } \\
\begin{array}{c}\mathrm{cm}^{3} / \mathrm{g} \\
\end{array}\end{array}$} \\
\hline & Single Point & Multiple Point & Average & Maximum & \\
\hline Coal & 1.5 & 1.6 & 65 & 1150 & $5.27 \times 10^{-3}$ \\
\hline Coal Pyrite & 6.7 & 7.2 & 64.5 & 1276 & $2.34 \times 10^{-2}$ \\
\hline
\end{tabular}


Spectrometer. It is clear from the spectra presented in Figures $111-9$ and $111-10$ that both samples have mineral matter, especially kaolinite, associated with them.

Dispersion Studies: The experimental set up used for these studies consisted of a microscope having a micrometer dis in the eye-plece with a least count of $0.1 \mathrm{~mm}$. The pre-aged sample was transferred to a $100 \mathrm{ml}$ graduated cylinder after sonication. The cylinder was shaken well, placed on a horizontal base and the settling rate (level of sediment) monitored.

Visual observations and settling rate data revealed that sonication promotes dispersion. However, there is a critical sonication time, sonication for less time leads to incomplete dispersion and more sonication leads to aggregation of particles.

Settling rate experiments were conducted under natural $\mathrm{pH}$ conditions at $2 \mathrm{wt} \%$ solids to study the extent of dispersions in various suspensions. The amount of material settled as a function of DARVAN $\mathrm{C}$ dosage was determined to monitor the extent of dispersion under given conditions (Table III-9).

Electrophoretic Studios: The zeta potential of coal was determined at various $\mathrm{pH}$ values using Laser Zee Meter (Model 300) and by electro-acoustic analysis (Matec Instrument). The zeta potential versus $\mathrm{pH}$ results are shown in Figure $\mathrm{II}-11$. The former instrument uses a supernatant having less than 0.1 vol\% solids for measurement. The electro-acoustic analyzer, on the other hand, can use as much as $50 w t \%$ solids in the slurry, however to obtain zeta potential values; not more than 10 vol\% slurry is recommended (Mann, 1989). Values of the average particle size and solids volume percent are needed to calculate zeta potential from electrosonic amplitude (ESA) measurements.

As seen in Figure III-11, both instruments indicated that the batch of coal examined has an isoelectric point at around $\mathrm{pH}$ 3. The difference in zeta potential values observed in Figure $111-11$ can be attributed to the difference in solids content of the suspension employed in the two measurements 


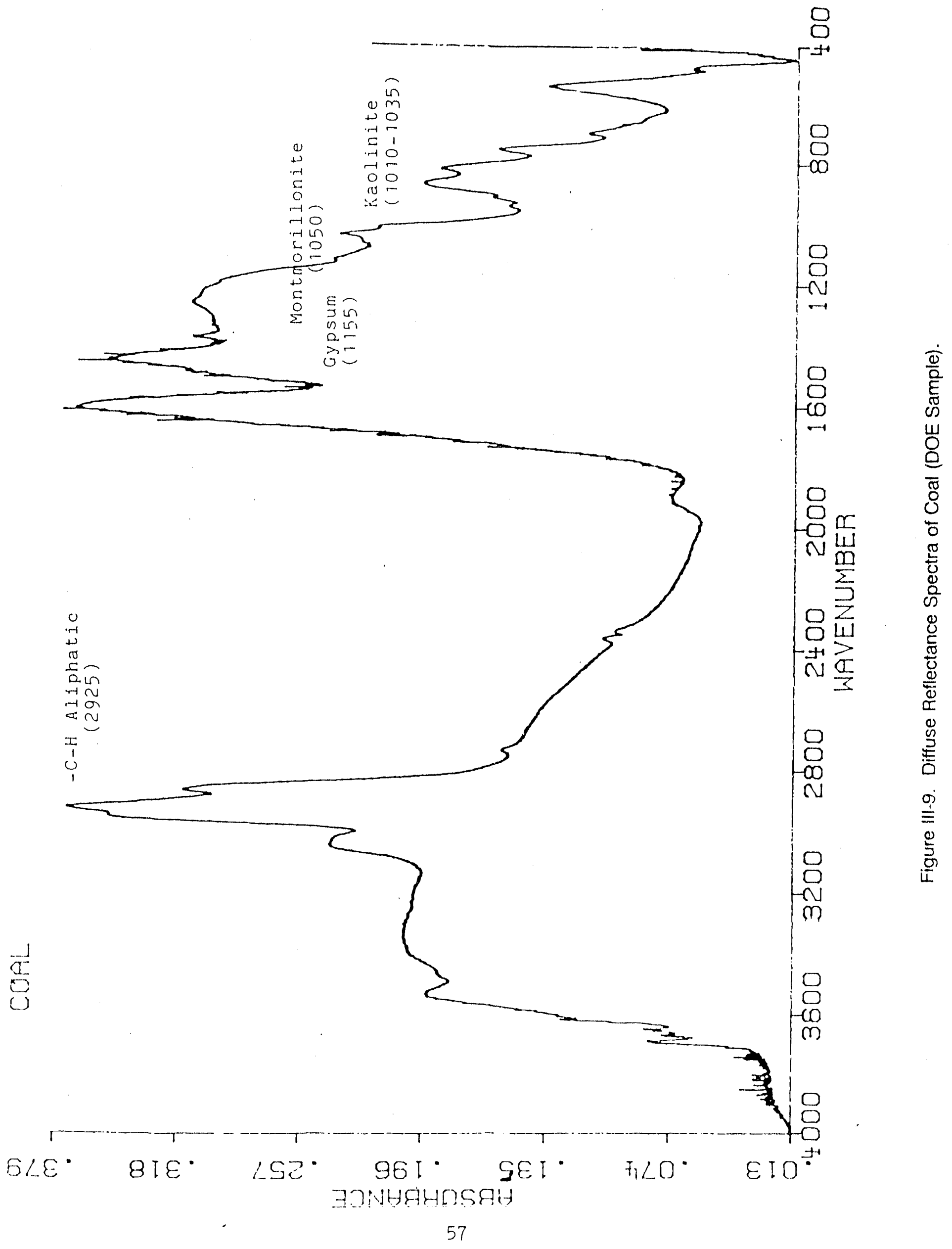




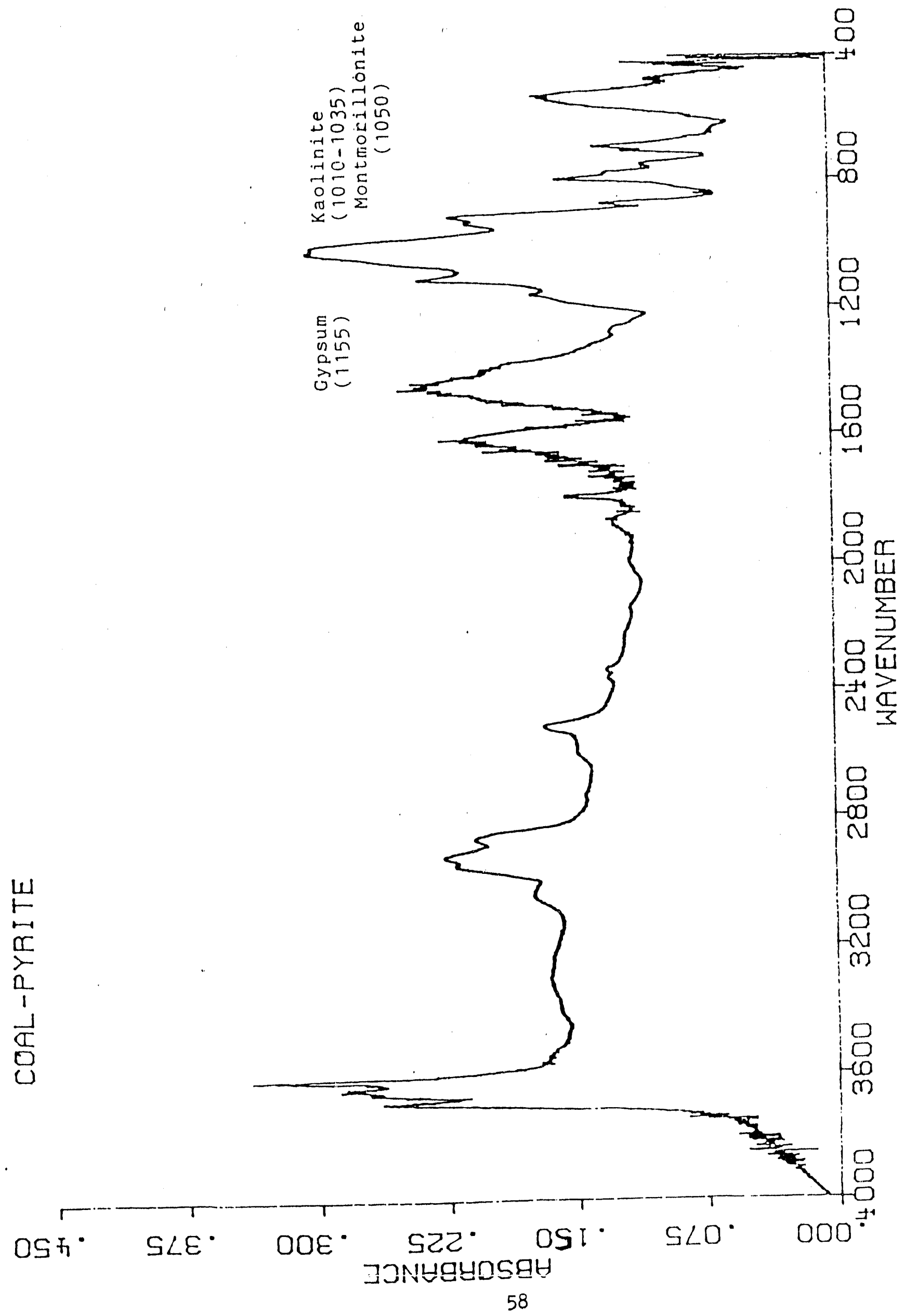

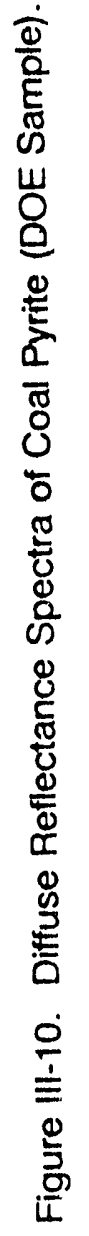




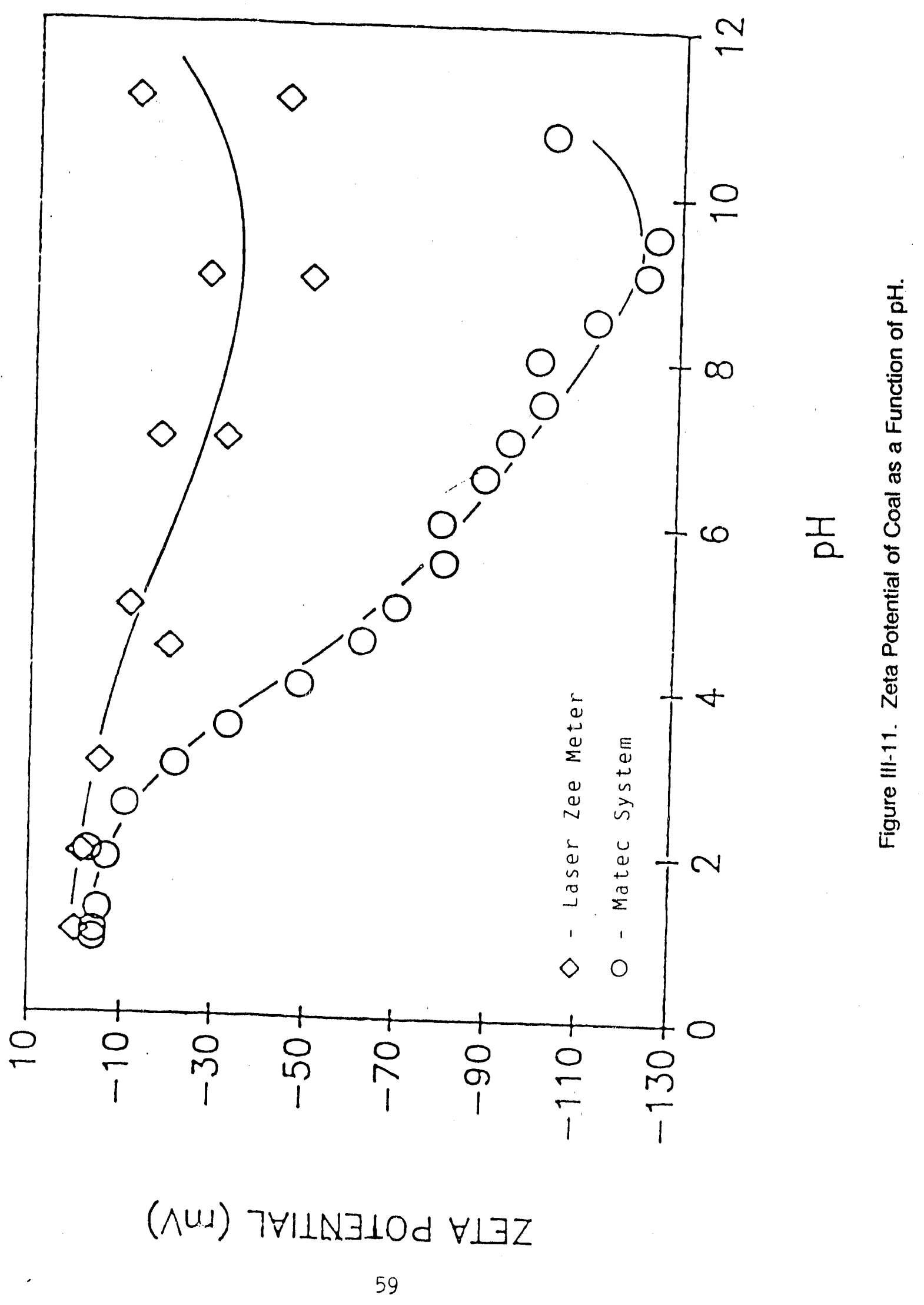


TABLE III-9

\section{EFFECT OF DARVAN C ON COAL DISPERSION}

Settling Time $=2$ minutes

\begin{tabular}{|cc|}
\hline $\begin{array}{c}\text { Darvan C Dosage } \\
\mathrm{kg} / \mathrm{t}\end{array}$ & $\begin{array}{c}\text { Amount Settled } \\
\text { wt \% }\end{array}$ \\
\hline 0 & $3.63,4.32$ \\
0.01 & $3.73,5.06$ \\
0.02 & $3.54,3.29$ \\
0.03 & $4.1,4.15$ \\
0.04 & $4.1,4.74$ \\
\hline
\end{tabular}


(Mann, 1989).

In another experiment, Darvan $\mathrm{C}$ was titrated with the coal slurry under natural $\mathrm{pH}$ conditions. As shown in Figure III-12, the coal suspension attains maximum negative electrosonic amplitude (ESA) at a Darvan $C$ dosage of $0.02 \mathrm{Kg} / \mathrm{t}$. Stability of the coal suspension in the presence of Darvan $\mathrm{C}$ can therefore be attributed to the negative charges induced on the coal surface. A mentioned above, ESA is the quantity actually measured by the instrument which is then converted to zeta potentlal based on solids volume percent and average particle size.

Flocculation Tests: Control of mixing conditions is crucial in obtaining flocs having the desired properties (Klimpel and Hogg, 1986; Keys, 1979). Hence, it is necessary to maintain uniform hydrodynamic conditions in flocculation tests. The mixing unit employed in this investigation is based on a standard tank design (Dirican, 1981). Dimensions of the mixing tank are as follows:

1. Mixing by a six blade stainless steel impeller

2. Impeiler diameter $=1 / 3$ tank diameter

3. Impeller height from tank bottom = impeller diameter

4. Irnpeller blade width $=1 / 5$ impeller diameter

5. $\quad$ Liquid height $=$ tank diameter

6. Baffle number $=4$

7. Baffle width $=1 / 10$ tank diameter

This tank design ensures constant turbulence, power consumption and flow pattern. The baffles suppress vortexing and maximize power consumption.

A $150 \mathrm{ml}$ beaker fitted with removable Plexiglas baffles of appropriate dimensions was used as the flocculation cell. A stainless steel turbine impeller with six blades, mounted on a variable speed motor was employed to agitate the sample. The dimensions of the flocculation cell used in this study 


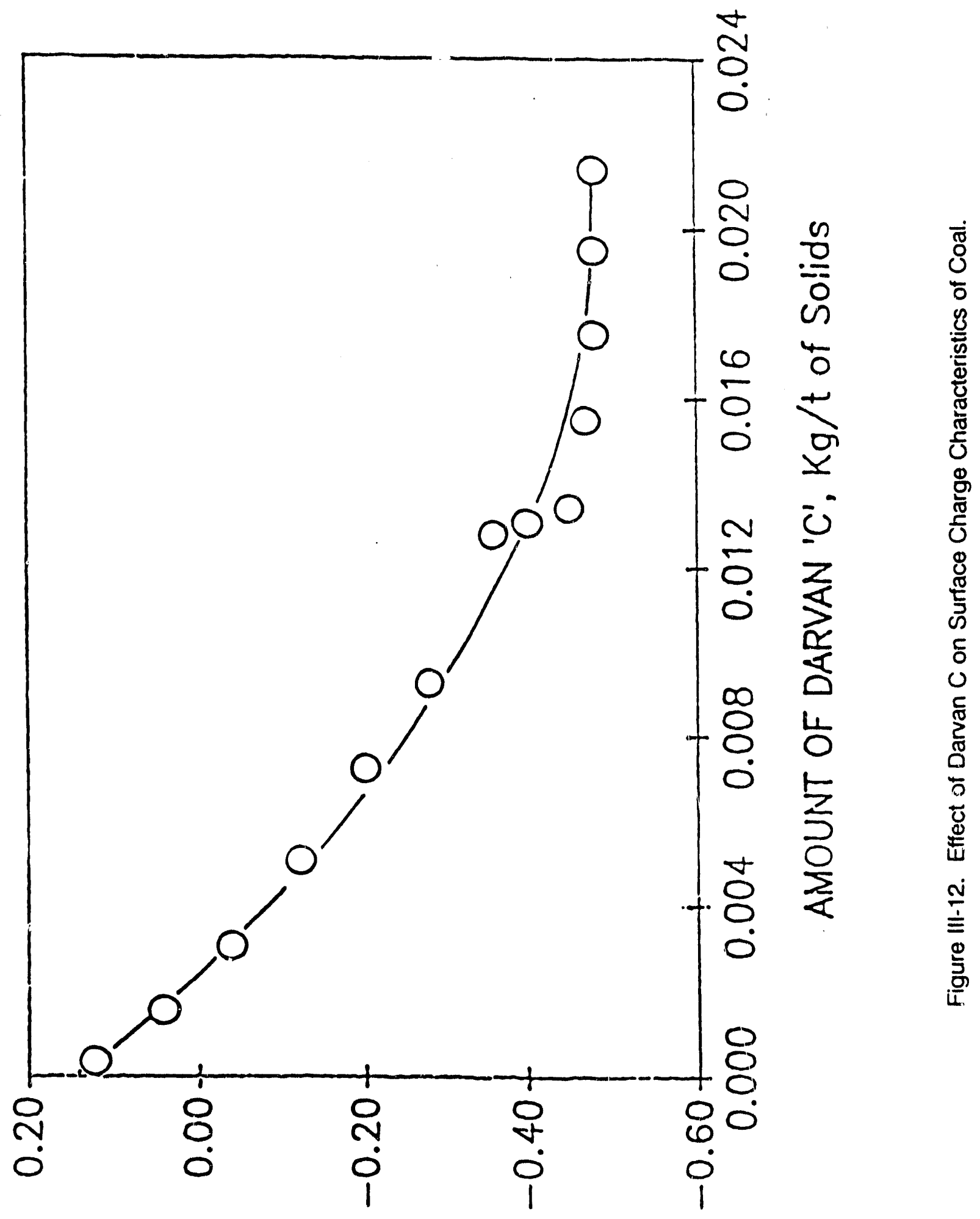

$\Lambda / W * D d W$ ' $\forall S \exists$ 
are as follows:

Tank diameter $=5.2 \mathrm{~cm}$

Impeller height from tank bottom $=1.73 \mathrm{~cm}$

Impeller blade width $=0.35 \mathrm{~cm}$

Liquid height $=5.2 \mathrm{~cm}$

Baffle width $=0.52 \mathrm{~cm}$

A schematic of the mixing assembly is shown in Figure III-13.

Flecculation procedure: The mineral suspension of the required solids wt\% was prepared in DI water. After aging, the sample was agitated for 4 minutes. All tests were conducted at 1100 rpm unless otherwise stated. After agitation the suspension was sonicated for 30 seconds to ensure complete dispersion. The suspension was further agitated for 30 seconds to keep the solids in suspension and a pre-determined amount of polymer was added. The agitation was continued for 2 more minutes during which time flocculation was observed to be complete. The flocs were separated from the suspension, dried at $50^{\circ} \mathrm{C}$, weighed and analyzed.

Separation of Flocs: The method of separation of flocs and fines is very important since it is the basis of evaluating the efficiency of a flocculant in terms of both recovery and grade of the minerals. The sedimentation method used in this study is described below.

A glass sedimentation column, shown in Figure $111-14$, with an 10 of $4.5 \mathrm{~cm}$ and a length of 73 $\mathrm{cm}$, and a stop-cock at the bottom, was used. The column was filled with deionized water and the flocculated mixture was fed into the column by pouring it on a sloping plate. The supernatant above a height of $4.5 \mathrm{~cm}$ from the bottom was siphoned out after a predetermined settling time. The settled material and the suspension were collected separately by opening the stop-cock at the bottom. 


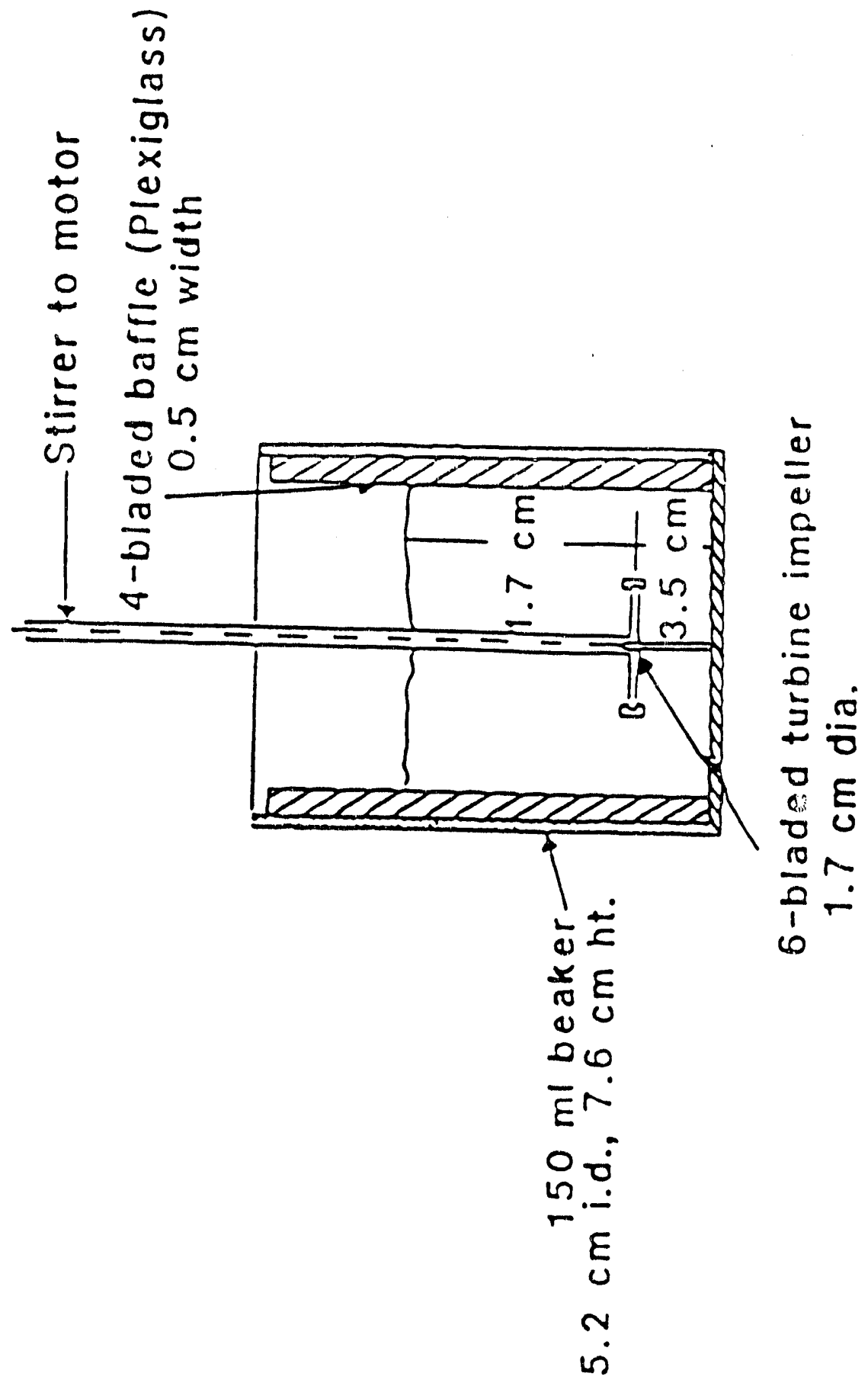

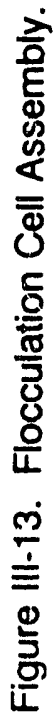




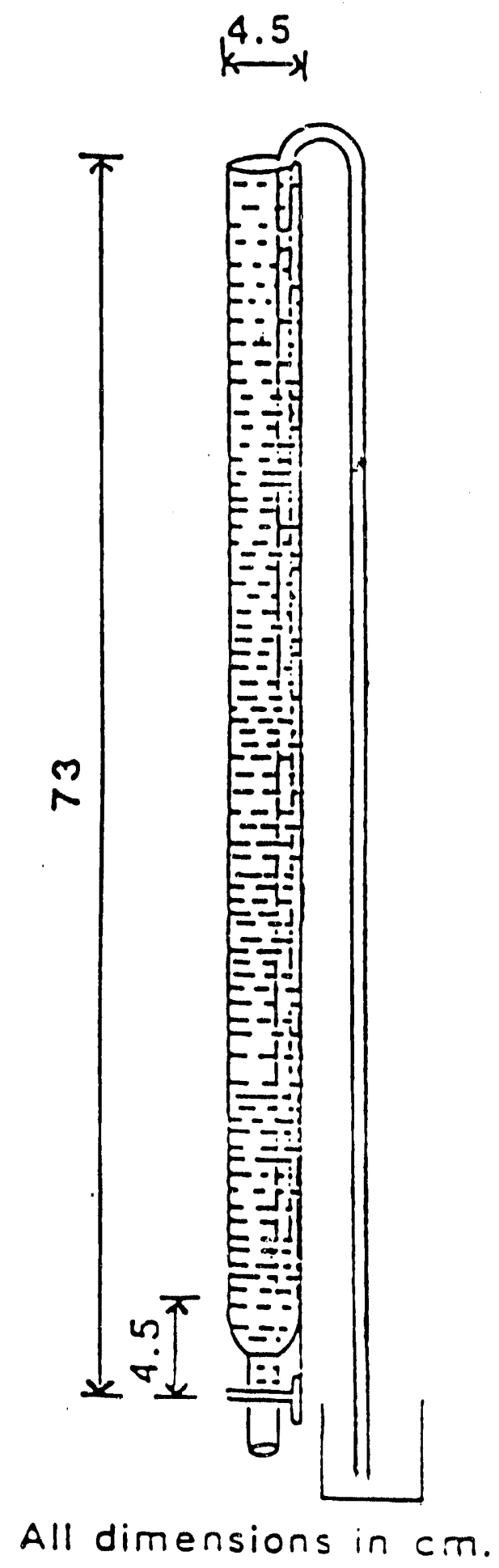

Figure III-14. Sedimentation Column for Floc Separation. 
Adsorption Studies: Adsorption tests were conducted using the depletion method. A given amount of solid was contacted with a polymer of known concentration. After agitation for a predetermined time the material was centrifuged out and the concentration of the residual polymer determined by viscosity measurement technique.

A UB40 viscometer was used to determine the efflux time for a constant volume of the liquid. The effective time of D.I. water was about 146.20 seconds. Polymer solutions of known concentration were prepared and the effective time measured to generate a calibration curve. A straight line fit using linear regression was obtained, and the slope of $\Delta T$ vs. concentration was determined to be 0.2438 . (see Figure III-15). 


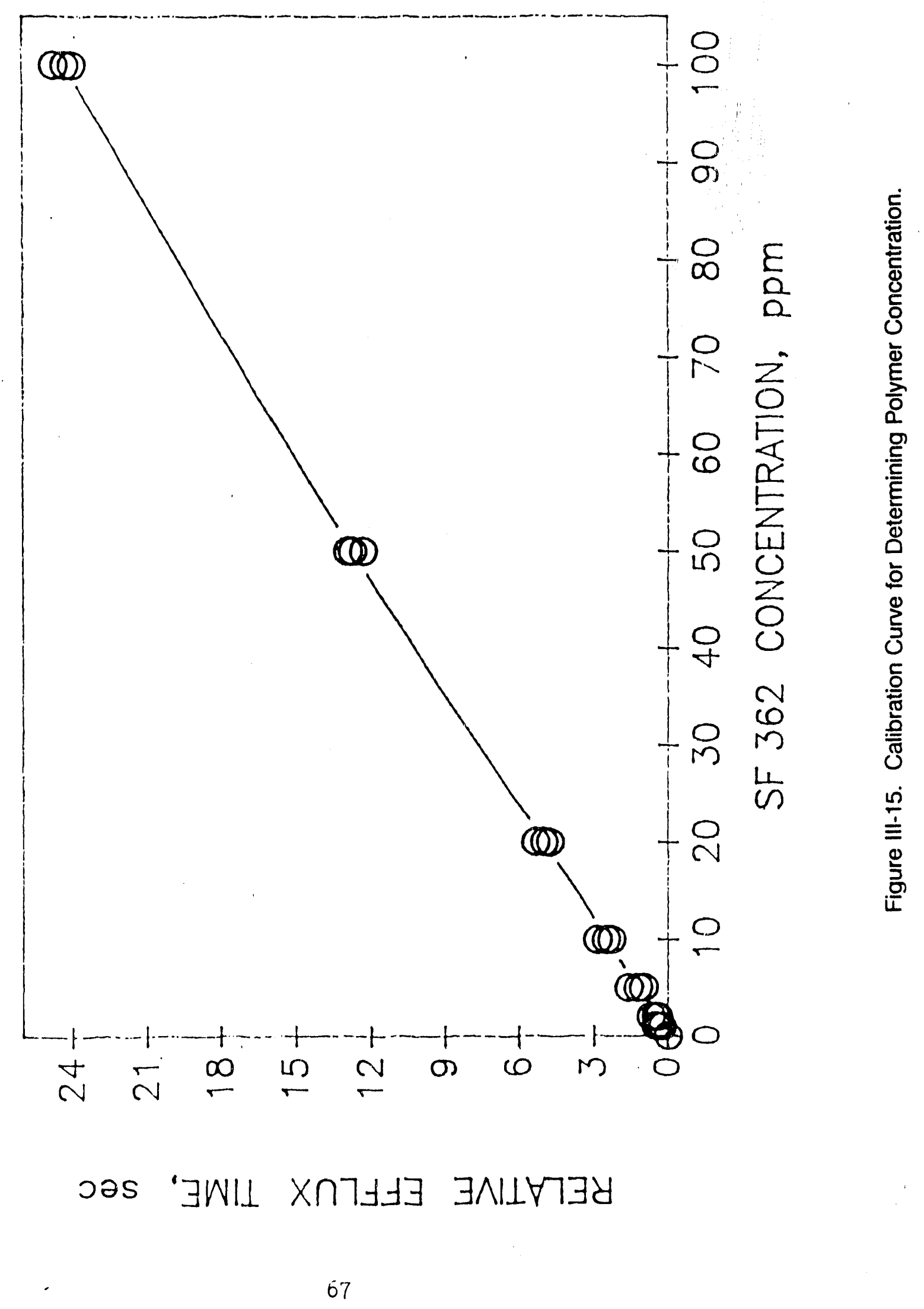




\section{Chapter IV}

\section{RESULTS AND DISCUSSION}

\section{Dispersion Studies:}

Settling rate data of 2 wt\% suspensions and microscopic examination revealed that montmorillonite was fully dispersed in $\mathrm{DI}$ water under natural pH conditions. In the case of coal, on the other hand, 30 seconds of sonication (Fisher Science Dismembrator, Model 300, setting 40) and 0.02 $\mathrm{Kg} / \mathrm{t}$ of dispersant DARVAN $\mathrm{C}$ were required to achieve the desired dispersion. Coal was observed to reaggregate upon 1 minute of sonication indicating the adverse effect of prolonged sonication. Quartz was found to be fully dispersed after 30 seconds of sonication and did not require any dispersant addition. Kaolinite, however, did not disperse even after repeated attempts of sonication at various lengths of time of up to 2 minutes, Use of dispersants DARVAN C, sodium silicate, and raising the pH of the suspension from the natural pH of 4.5 to 8 also did not disperse kaolinite. Kaolinite was determined to be dispersed with sodium metaphosphate which also resulted in dispersion of coal.

Pyrite dispersion studies indicated that 30 seconds sonication effectively lisperses pyrite suspension. Pyrite suspension was found to be unaffected by the presence of $0.02 \mathrm{Kg} / \mathrm{t}$ of DARVAN C - a coal dispersant.

It was decided to sonicate the samples for 30 seconds in the presence of $0.02 \mathrm{Kg} / \mathrm{t}$ DARVAN C as a standard dispersion procedure.

It was observed from individual settling rate results that no significant separation of coal from mineral matter and pyrite could be achieved by gravity settling alone.

Dispersion characteristics of various minerals are summarized in Table IV-1.

Single Mineral Flocculation Behavior: Preliminary flocculation tests indicated that Superfloc 362, a highly cationic polyacrylamide, did not flocculate coal but flocculated quartz and coal refuse. Coal, on the 
TABLE IV-1

DISPERSION CHARACTERISTICS OF COAL, COAL PYRTE, QUARTZ, AND CLAYS

\begin{tabular}{|c|c|c|c|}
\hline Material & $\begin{array}{c}\text { Mode of Existence in } \\
\text { Suspension }\end{array}$ & $\begin{array}{c}\text { Exent of Sonication* } \\
\text { Required }\end{array}$ & Dispersant Used \\
\hline \multirow[t]{2}{*}{ Coal } & Dispersed & $\begin{array}{l}30 \mathrm{sec} . \text { of Sonication } \\
(0.2 \mathrm{~kg} / \mathrm{t})\end{array}$ & Darvan C \\
\hline & Reaggregated & $1 \mathrm{~min}$. of Sonication & \\
\hline Pyrite & Dispersed & $\begin{array}{l}30 \text { sec. of Sonication } \\
\text { (Darvan } \mathrm{C} \text { addition }\end{array}$ & None \\
\hline Quartz & Dispersed & $30 \mathrm{sec}$. of Sonication & does not make any \\
\hline Montmorillonite & Dispersed & Without Sonication & Nonedifference) \\
\hline \multirow[t]{2}{*}{ Kaolinite } & $\begin{array}{l}\text { Not Dispersed } \\
\text { Sonication used }\end{array}$ & $\begin{array}{l}\text { Various times of } \\
\text { Sodium Silicate } \\
\text { (pH 8.6) also did not }\end{array}$ & $\begin{array}{l}\text { Darvan C, } \\
\text { disperse }\end{array}$ \\
\hline & Dispersed & $30 \mathrm{sec}$. of Sonication & Sodium Metaphosphate \\
\hline
\end{tabular}

* Sonication was carried out in Fisher Sonic Dismembrator model 300, setting 40 
other hand, was found to be flocculated with polyethylene oxide (PEO), Superfloc 206 (a highly anionic polyacrylamide) and a nonionic polyacrylamide type polymer (Superfloc 16). PEO flocculated clays but not quartz. A hydrophobic polymer, WCL 762 - a product of Calgon Corp. flocculated more coal than pyrite. Results with sorne of the polymers tested are summarized in Table IV-2.

Flocculation of coal, quartz and coal refuse with Superfloc 362 is compared in Figures IV-1 and IV-2, respectively. It appears from the results presented that flocculation of coal refuse and quartz improves as polymer dosage is increased. Flocculation of coal, on the other hand, progressively deteriorates at higher polymer dosages. This could be attributed to steric stabilization of coal at higher polymeric dosages indicating fewer available active sites on coal surface. It is observed that separation of coal from quartz and coal refuse may be possible at a polymer dosage of about $0.01 \mathrm{Kg} / \mathrm{t}$.

The effect of Superioc 206 on flocculation of coal and quartz is presented in Figure IV-3. This polymer, unlike Superfloc 362, flocculates coal instead of quartz (or coal refuse). A settling time of 4 minutes employed in these tests at optimum polymer dosage, however, did not seem to be sufficient enough to settle out all the coal flocs. This can be attributed to the floc properties especially the (smaller) size and (lower) density of the coal flocs. It is also indicated from the decline in amount of coal settled at higher polymer dosages that properties of the flocs formed are strongly influenced by the amount of the polymer added, probably due to onset of steric stabilization beyond the optimum dosage of about $0.02 \mathrm{Kg} / \mathrm{t}$.

The effect of polyethylene oxide (PEO) on coal flocculation is illustrated in Figure IV-4. Coal flocculation goes through a maximum at a PEO dosage of $.002 \mathrm{Kg} / \mathrm{t}$. Quartz is not flocculated with PEO.

Flocculation behavior of coal and quartz with a nonionic polyacrylamide is compared in Figure IV-5. It is observed that this polymer is a good flocculant of coal, irrespective of polymer dosage. Flocculation of quartz on the other hand, was found to be maximum at about $0.002 \mathrm{Kg} / \mathrm{t}$.

Coal pyrite was found to be flocculated with Superfloc 362. Effect of polymer dosage on coal 


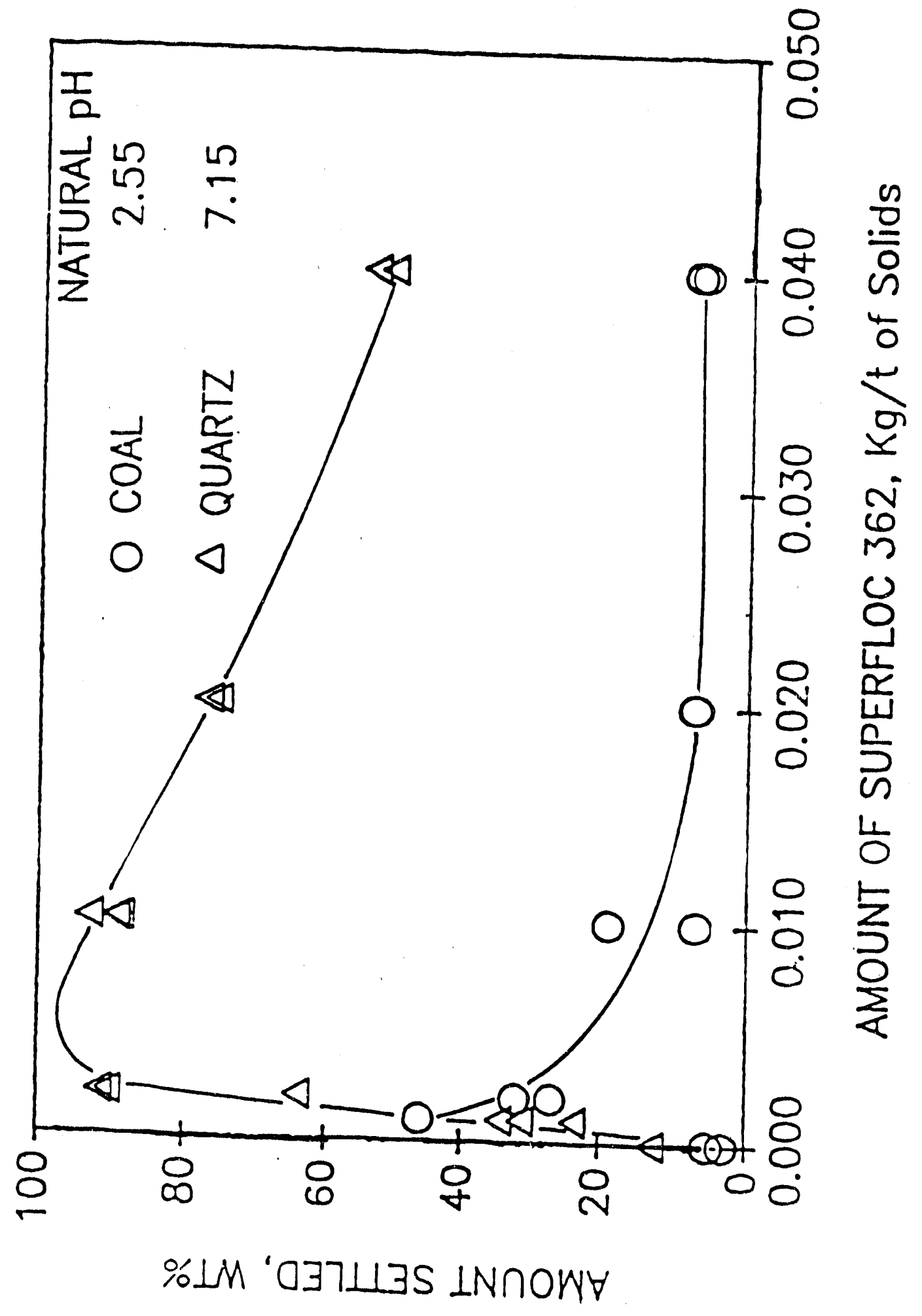

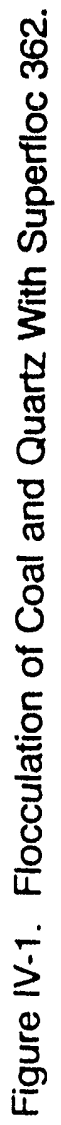




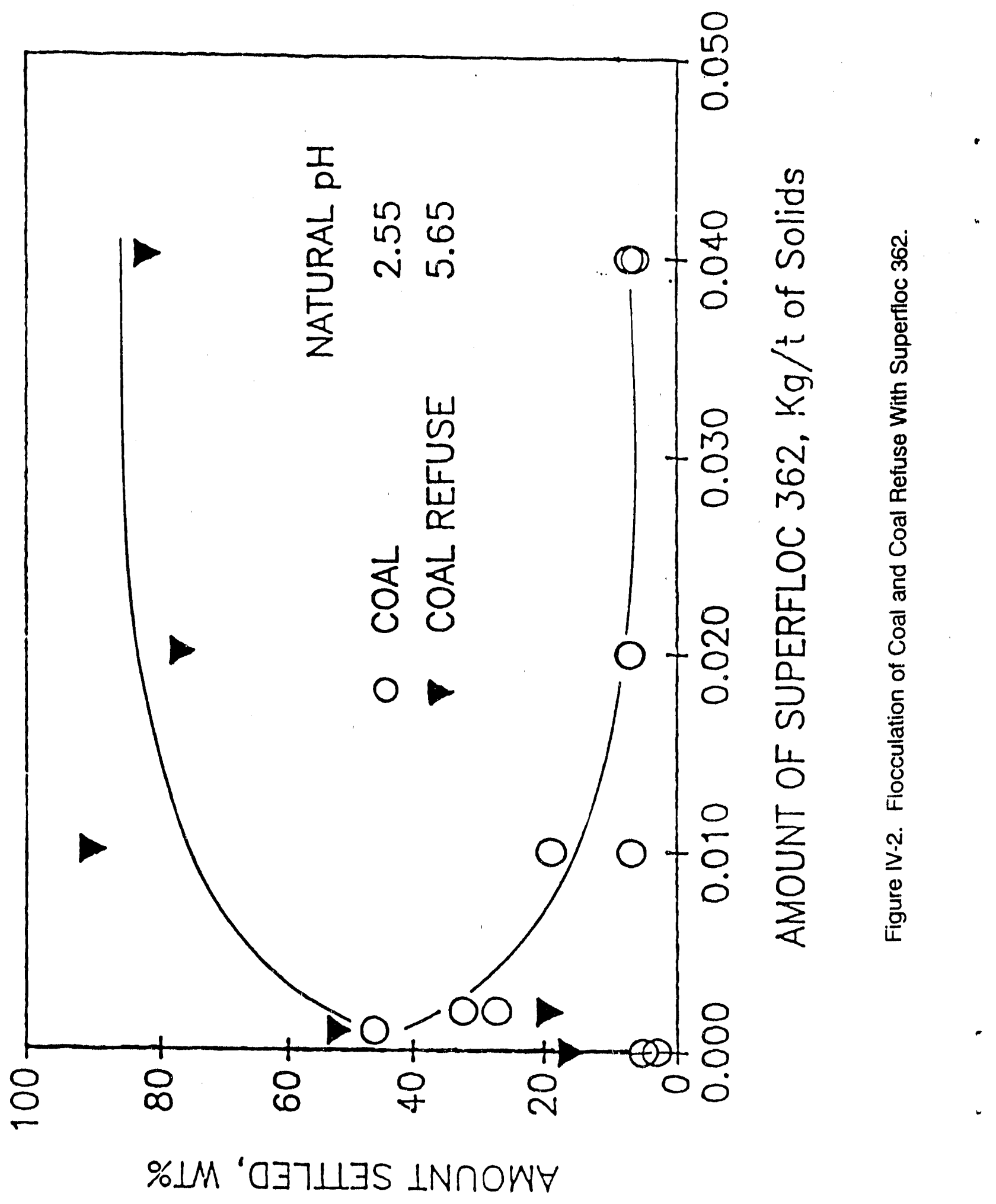




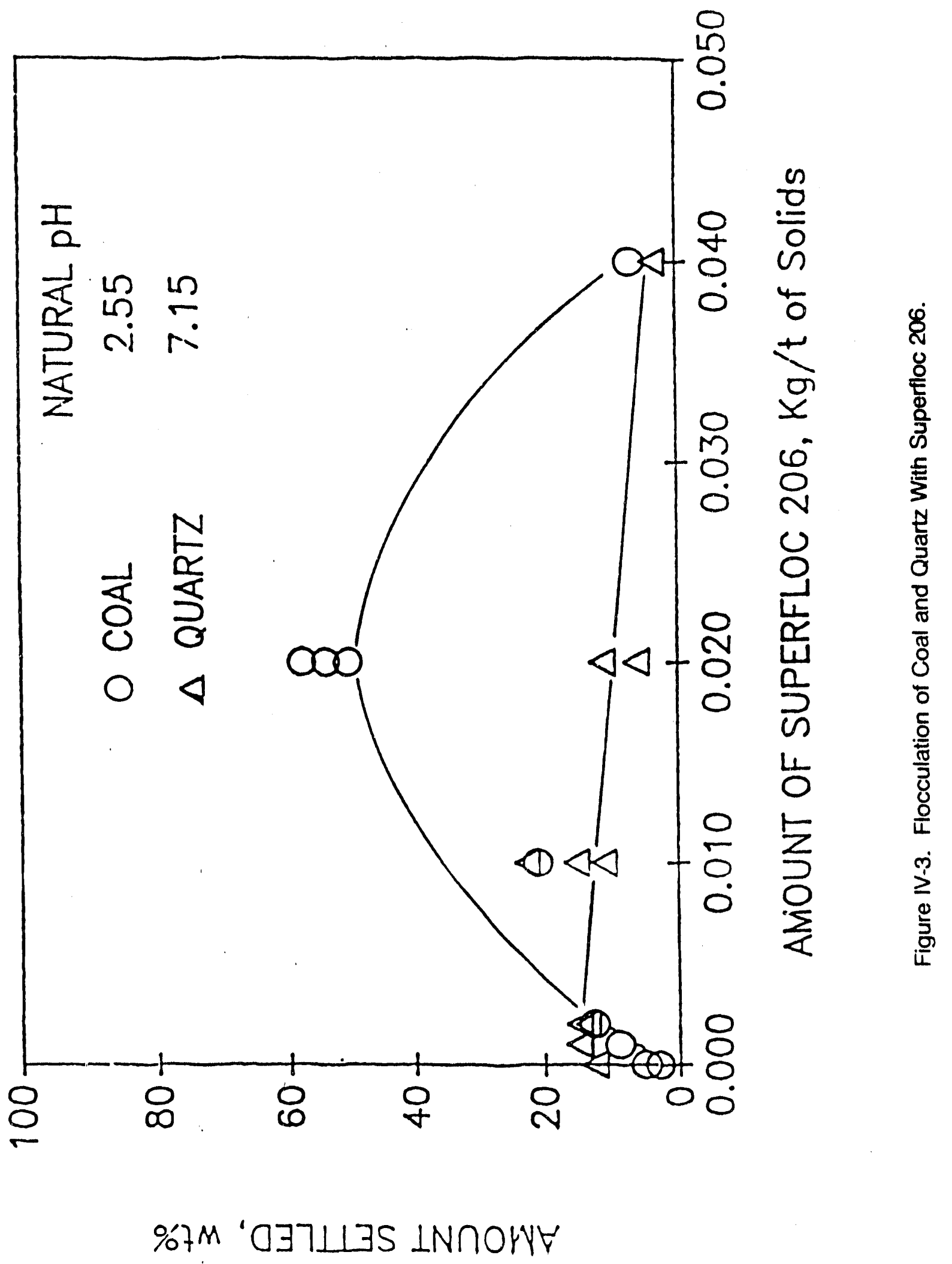




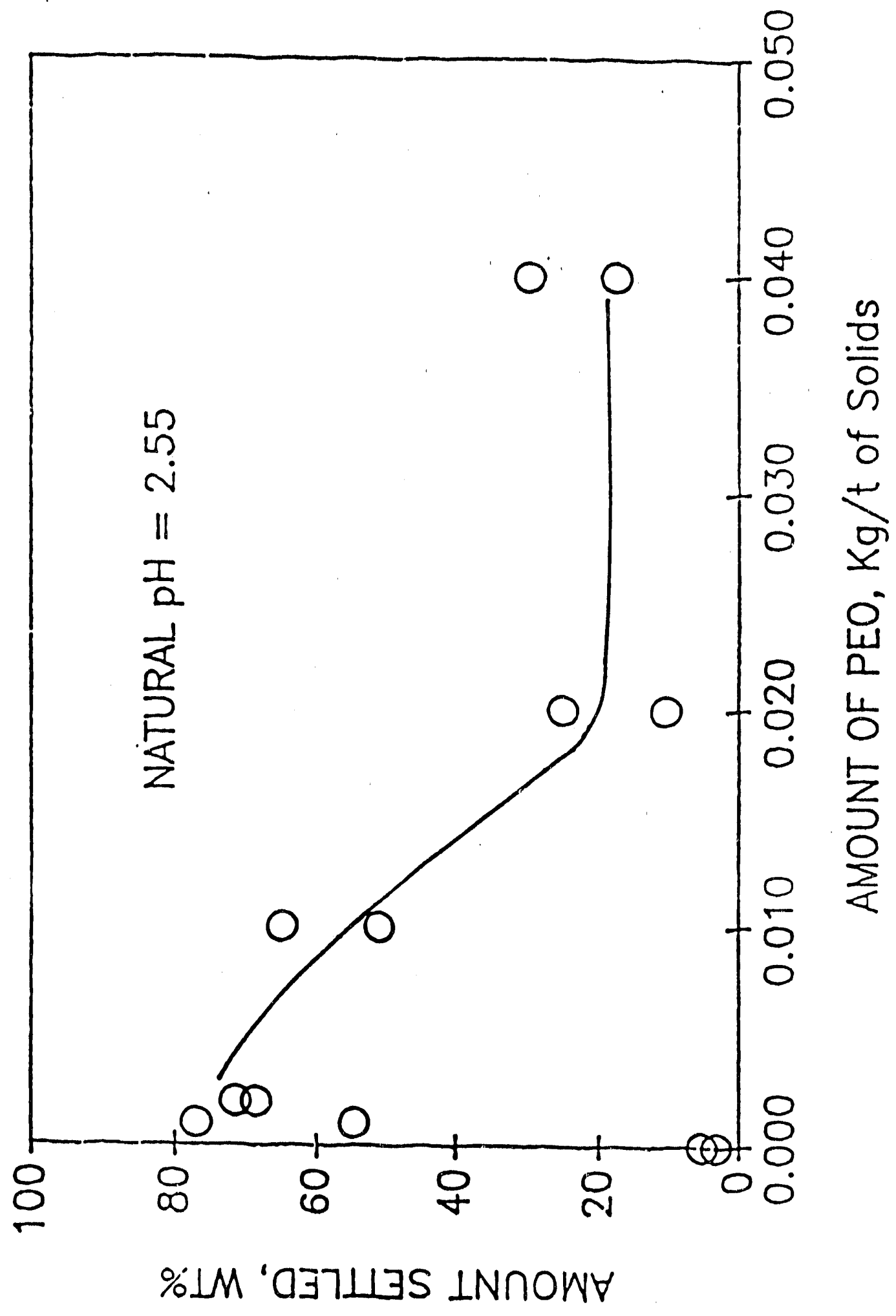

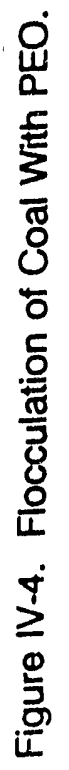




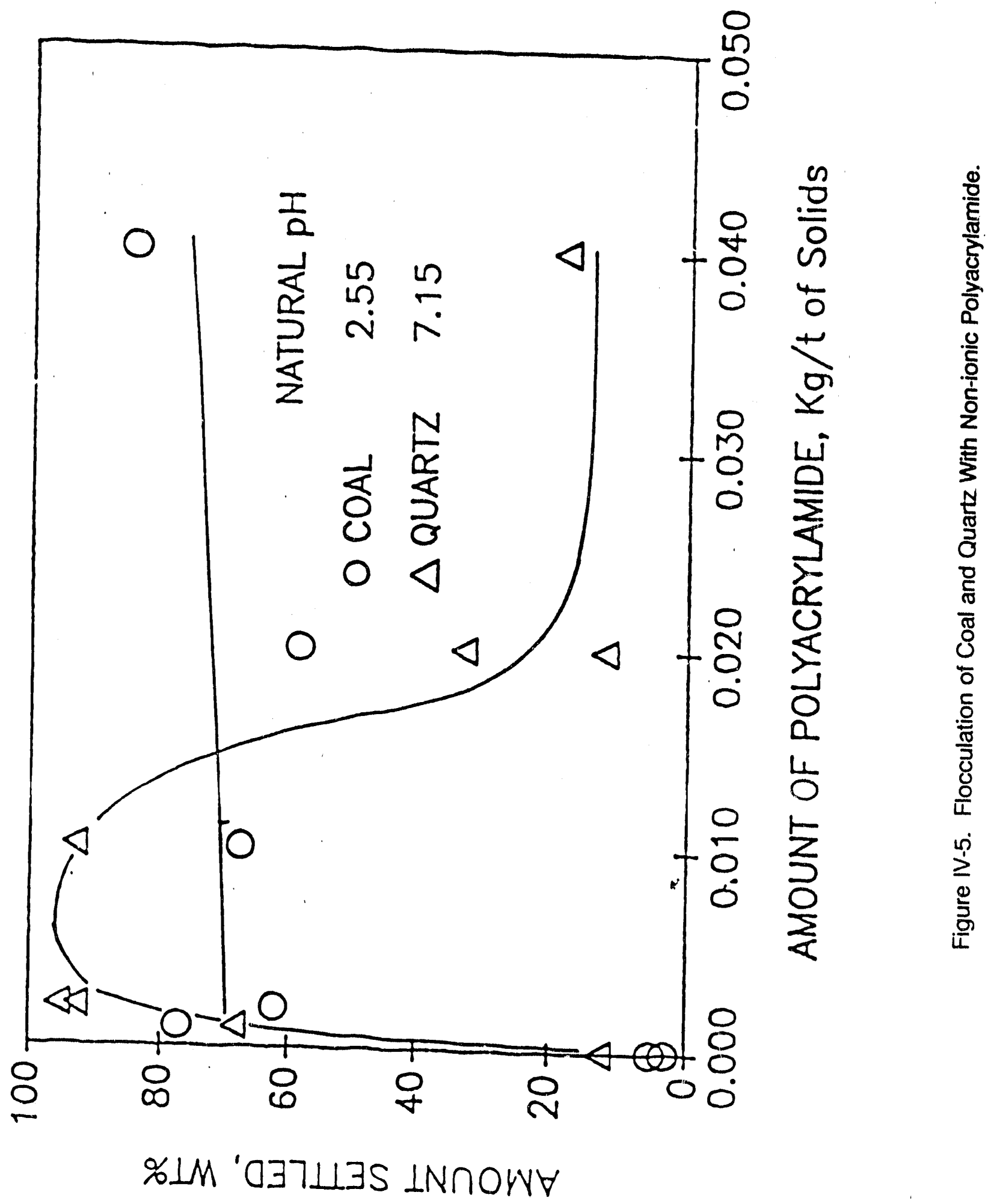


TABLE IV-2

PRELIMINARY FLOCCULATION TESTS

Dispersant Concentration $=2 \mathrm{mg} / \mathrm{gm}$ of Solids $\mathrm{pH}=4$

\begin{tabular}{|c|c|c|}
\hline Polymer & Coal & Pyrite \\
\hline \multicolumn{3}{|l|}{ SF $16^{*}$} \\
\hline $.01 \mathrm{~kg} / \mathrm{t}$ & No flow & No. flocs \\
\hline $.1 \mathrm{~kg} / \mathrm{t}$ & Small flocs & \\
\hline $1 \mathrm{~kg} / \mathrm{t}$ & Large flocs-rapid settling & Large flocs \\
\hline SE 107 & . & \\
\hline $0.1 \mathrm{~kg} / \mathrm{t}$ & No observable flocculation & No flocs \\
\hline $1 \mathrm{~kg} / \mathrm{t}$ & Small size flocs-slow settling & Medium flocs settled rapidly \\
\hline \multicolumn{3}{|l|}{ SE 127} \\
\hline $0.1 \mathrm{~kg} / \mathrm{t}$ & No flocs & No observable flocs \\
\hline $1 \mathrm{~kg} / \mathrm{t}$ & Large flocs-rapid settling & $\begin{array}{l}\text { Medium to large flocs. } \\
\text { Rapid settling }\end{array}$ \\
\hline \multicolumn{3}{|c|}{ WCL - 762 } \\
\hline $.01 \mathrm{~kg} / \mathrm{t}$ & No observable flocs & No observable flocs \\
\hline $1 \mathrm{~kg} / \mathrm{t}$ & Very small & No observable flocs \\
\hline $10 \mathrm{~kg} / \mathrm{t}$ & No flr ss at high $\mathrm{pH}(\mathrm{pH} 9)$ & Very big flocs \\
\hline
\end{tabular}

* Also tested with sodium meta-phosphate as a dispersant at the same concentratir: achieving the similar results. 
and coal pyrite flocculation is compared in Figure IV-6. It is observed that separation of coal from coal pyrite may be achieved at a Superfloc 362 dosage of $0.006 \mathrm{Kg} / \mathrm{t}$.

Superfloc 16, a nonionic polyacrylamide, was found to be a more efficient flocculant of pyrite than coal (see Figure IV-7). Although some flocculation of coal occurred, separation of coal from coal pyrite is indicated at a polymer dosage of $0.002 \mathrm{Kg} / \mathrm{t}$

Hydrophobic polymers have been used to flocculate coal instead of pyrito and mineral matter. Therefore, a hydrophobic polymer WCL 762 (product of Calgon Corp.) was used to flocculate coal pyrite and coal samples. It is seen from Figure IV-8, that although there is some difference in the flocculation behavior of coal and coal pyrite, both components are flocculated more or less to the same extent.

It is observed from the above results that more coal pyrite and mineral matter, as compared to coal, flocculates with Superfloc 362 (a cationic polyacrylamide) and Superfloc 16 (a nonionic polyacrylamide). More coal, however, may flocculate with Superfloc 206 (an anionic polyacrylamide), PEO and WCL 762 (a hydrophobic polymer). SF362 was selected for further investigation.

Virginia Tech. Samples: Single mineral flocculation tests using a number of polymers were conducted on the samples obtained from Virginia Tech. and the results are given in Table IV.3. It is indicated that the polyacrylamide type polymers, which earlier had shown selectivity are not selective in this case. WCL 762, a hydrophobic polymer form Calgon Corp., showed selectivity at high pH values with Darvan $\mathrm{C}$ as the dispersant. The tests were carried out at $\mathrm{pH} 4$ and $\mathrm{pH} 9$. In certain experiments both the dispersants Darvan $C$ and sodium meta-phosphate were used. After initial tests, further tests were conducted with WCL 762 to optimize the operating conditions. A number of parameters like,stirring time, settling time, $\mathrm{pH}$ and polymer dosage were studied (see Table IV-3).

It was found that for any appreciable flocculation of single mineral coal pyrite the stirring time had to be more than $4 \mathrm{~min}$. Higher $\mathrm{pH}(>9)$ was determined to be better for flocculation, as on increasing the $\mathrm{pH}$ more coal dispersed and large flocs of pyrite were formed. A polymer dosage of $50 \mathrm{mg} / \mathrm{g}$ 


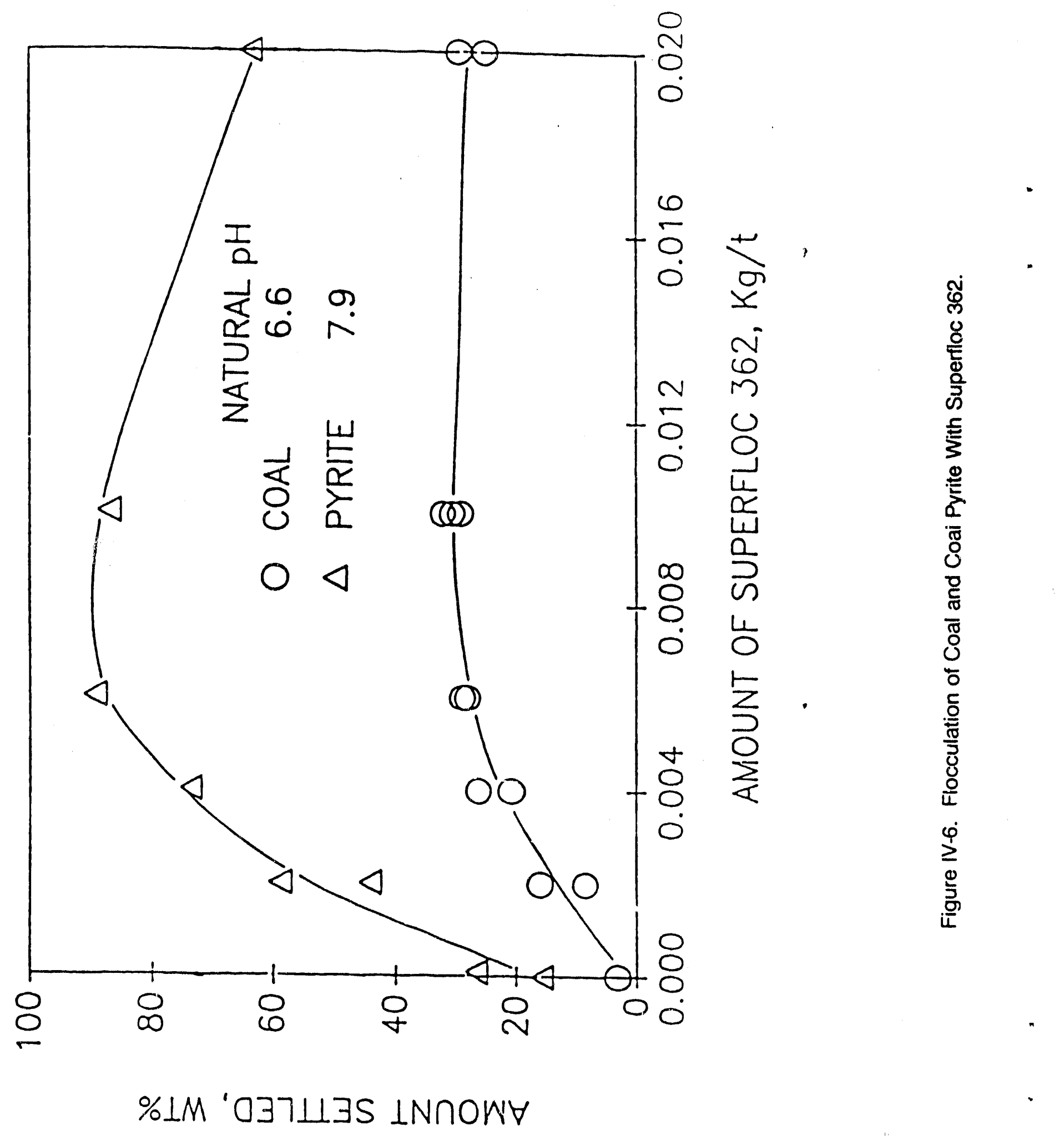




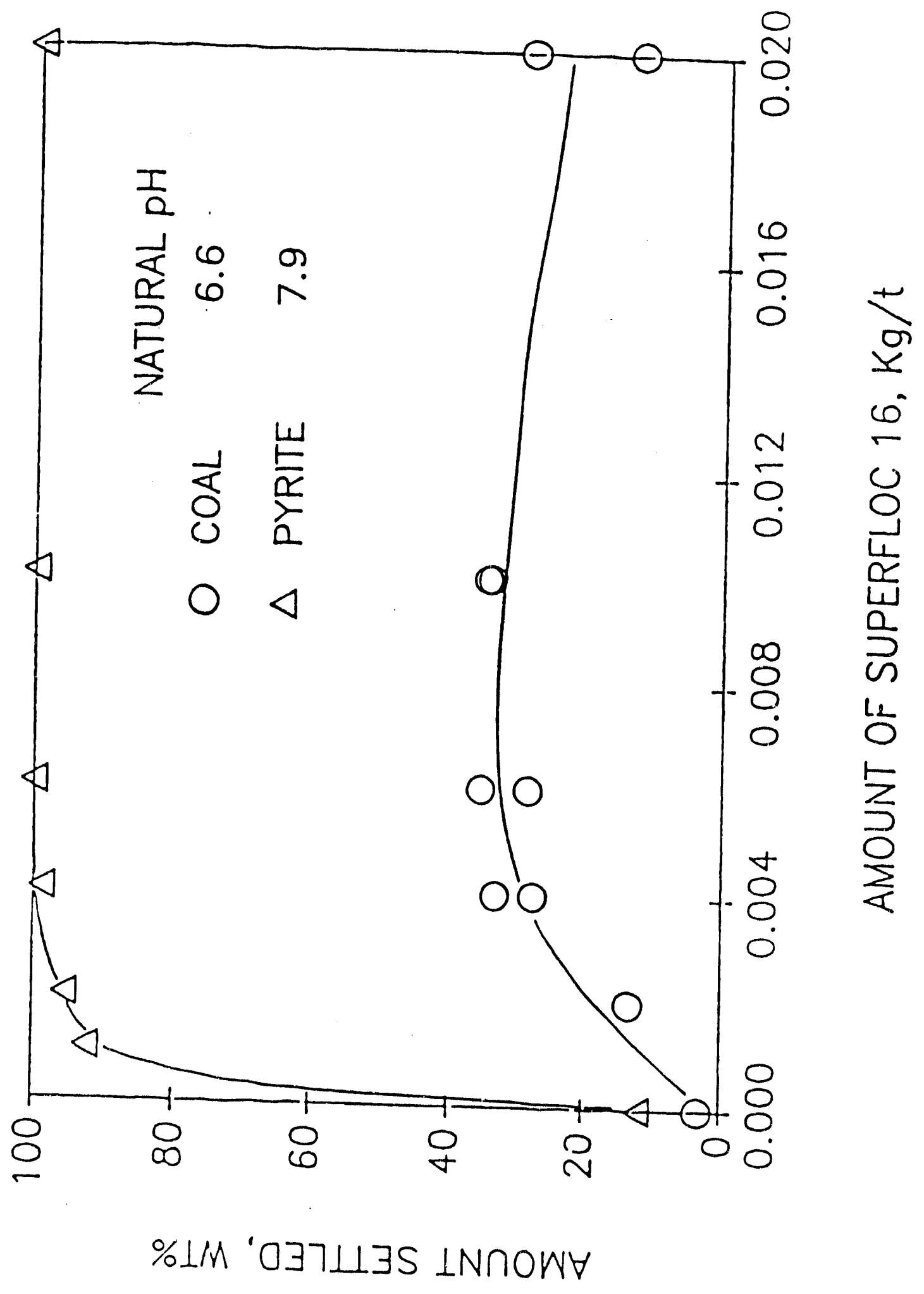

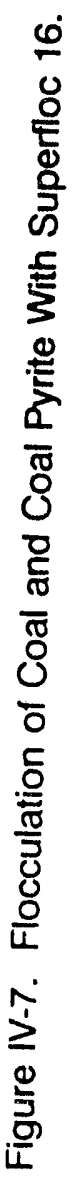




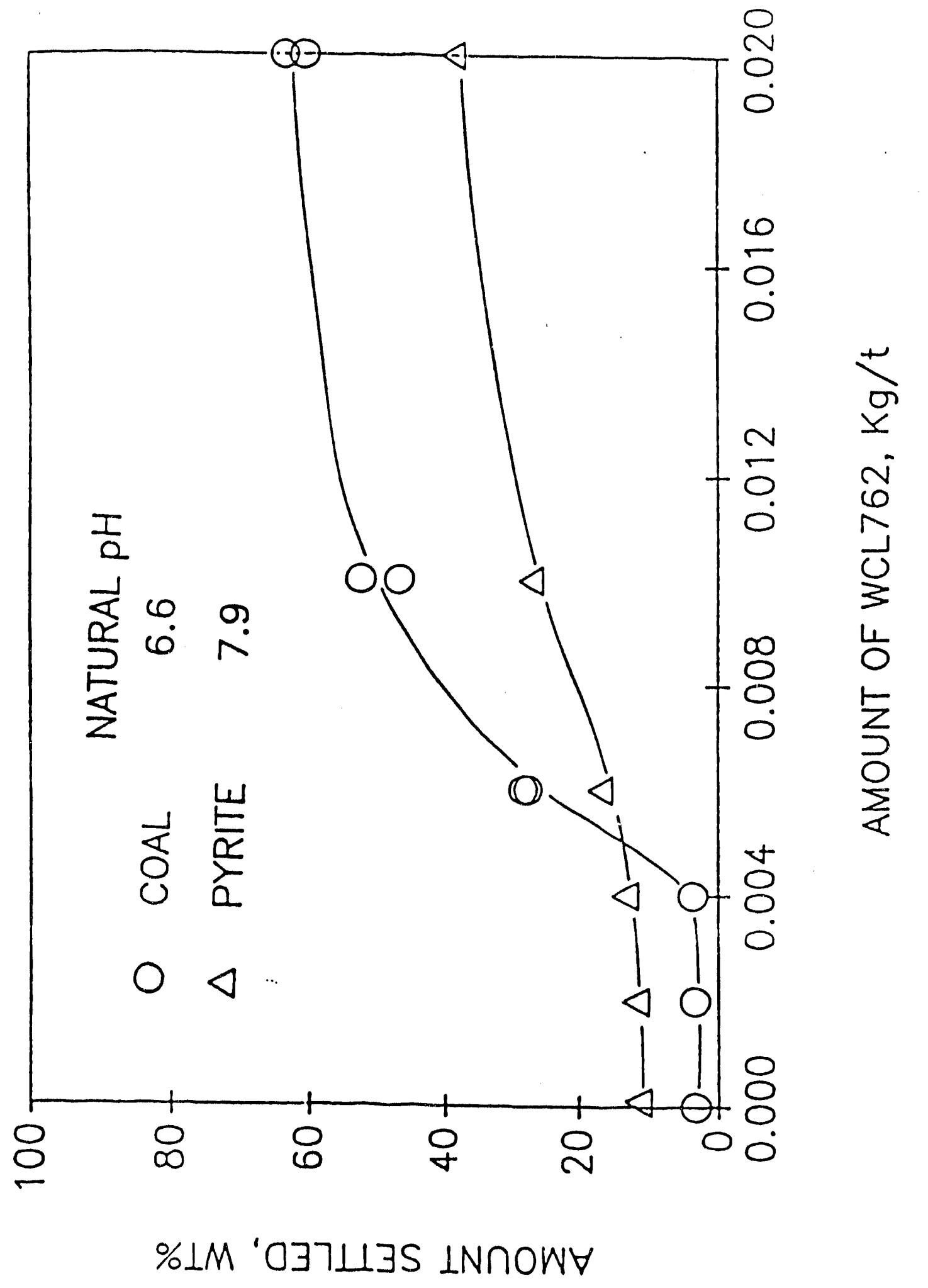

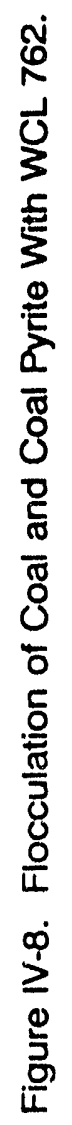


TABLE IV-3

SINGLE MINERAL FLOCCULATION BEHAVIOR

Feed: $0.5 \mathrm{gm}$ of Solids (Unless Otherwise Stated)

\begin{tabular}{|c|c|c|c|c|c|c|}
\hline Mineral & $\begin{array}{l}\text { Stirring } \\
\text { Time } \\
\text { (Min) }\end{array}$ & $\mathrm{pH}$ & $\begin{array}{l}\text { Settling } \\
\text { Time } \\
\text { (Min) }\end{array}$ & $\begin{array}{c}\text { Polymer } \\
\text { Dosage } \\
(\mathrm{mg} / \mathrm{g})\end{array}$ & Observations & $\begin{array}{c}\text { Amount } \\
\text { Settled } \\
\%\end{array}$ \\
\hline Coal & 5 & 9.05 & 4 & - & No Flocs & 3.07 \\
\hline Pyrite & 5 & 9.00 & 4 & - & No Flocs & 4.11 \\
\hline Pyrite & 4 & 4.25 & 4 & 50 & Medium Flocs & 35.80 \\
\hline Coal & 4 & 4.25 & 4 & 50 & Large Flocs & 59.76 \\
\hline Pyrite & 4 & 9.00 & 4 & 50 & Good Flocs & 25.26 \\
\hline Coal & 5 & 9.10 & 4 & 50 & No Flocs & - \\
\hline Coal & 4 & 9.1 & 4 & 50 & No Flocs & 2.60 \\
\hline Pyrite & 4 & 9.1 & 4 & 50 & Small Flocs & 9.06 \\
\hline Pyrite & 1 & 9.00 & 4 & 50 & No Flocs & 4.68 \\
\hline Pyrite & 2 & 9.00 & 4 & 50 & No Flocs & - \\
\hline Pyrite & 6 & 9.00 & 4 & 50 & Large Flocs & 34.58 \\
\hline Coal & 10 & 9.05 & 4 & 50 & No Flocs & 3.14 \\
\hline Pyrite & 10 & 9.05 & 4 & 50 & Moderate & 39.28 \\
\hline Coal & 4 & 9.2 & 4 & 500 & No Flocs & - \\
\hline Pyrite & 4 & 9.05 & 4 & 500 & Large Flocs & 49.7 \\
\hline Pyrite & 6 & 10.00 & 4 & 50 & Large Flocs & 40.32 \\
\hline $\begin{array}{l}\text { Pyrite }+ \\
\text { Coal Mix- } \\
\text { ture } \\
(1.0 \mathrm{gms})\end{array}$ & 7 & 10.00 & 4 & 500 & Large Flocs & 25.04 \\
\hline
\end{tabular}


seemed to be yielding flocs similar to that at higher dosages of $500 \mathrm{mg} / \mathrm{g}$, while $5 \mathrm{mg} / \mathrm{g}$ formed very small pyrite flocs (visual observation). In single mineral flocculation tests about 20 to $60 \%$ of pyrite could be settled while only about $4 \%$ of coal settled. Mixed mineral tests with WCL 762 resulted in about $25 \%$ of the mixture settling out in 7 minutes.

\section{Adsorption Studies:}

Adsorption tests were conducted for SF 362 (cationic polyacrylamide) on coal and coal pyrite samples obtained from DOE PETC. Adsorption as a function of time was carried out to determine the equilibration time. It is clear from Figure IV-9, that equilibrium is reached in about 16 hours at a polymer dosage of $2000 \mathrm{ppm}$.

Saturation Adsorption Tests: Saturation adsorption tests were conducted to estimate $\Phi_{\mathrm{R}}$, i.e. the relative nulunber of active sites on coal and coal pyrite. It is evident from the results presented in Figure IV-10 thint coal pyrite has a higher value of $\Phi$ as compared to coal. However, since adsorption is a function Of the available surface area, it seems that $\Phi_{\text {cos }}$ is higher. This implies that coal should flocculate more tim intin pyrite.

Nonequilibrium Adsorption (for $\theta$ ): To determine the fractional surface coverage ' $\theta$ ', adsorption malasurements for a polymer/solid contact time of 5 ninutes were conducted. It was determined that $\Theta$ Mas 0.23 for coal and 0.18 for coal pyrite. The polymer dosage was 100 ppm. Model Predictions:

The values of $\Phi$ and $\Theta$ generated were used in the model to predict the optimum selectivity. The valule of $\Phi_{R}$ ( $\Phi$ coal pyrite/ $\Phi$ coal) is 2 . It was shown for another system that the value of $\Theta$ does not afllist the S.I. (or recovery) except for extremely small or large values of $\theta$. For the purpose of simulation $\Theta$ was taken as 0.5 for both coal and coal pyrite. In a model simulation carried out for various $\Phi_{\text {A: }}$ values, the trend of $\Phi_{\mathrm{R}}$ equal to 2 is also presented (see Figure IV-11). The computational model 


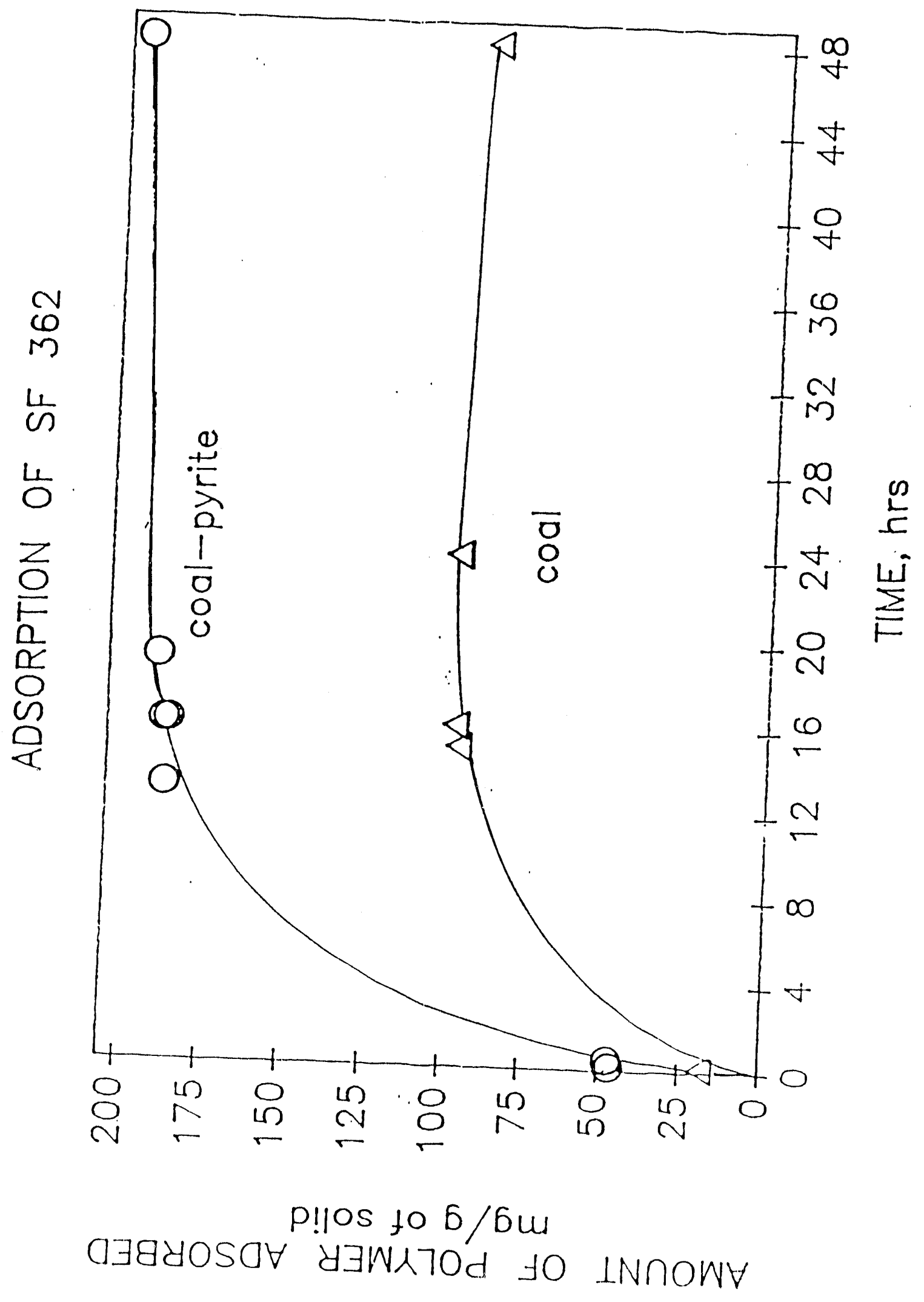

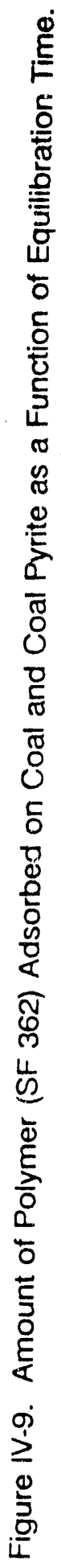




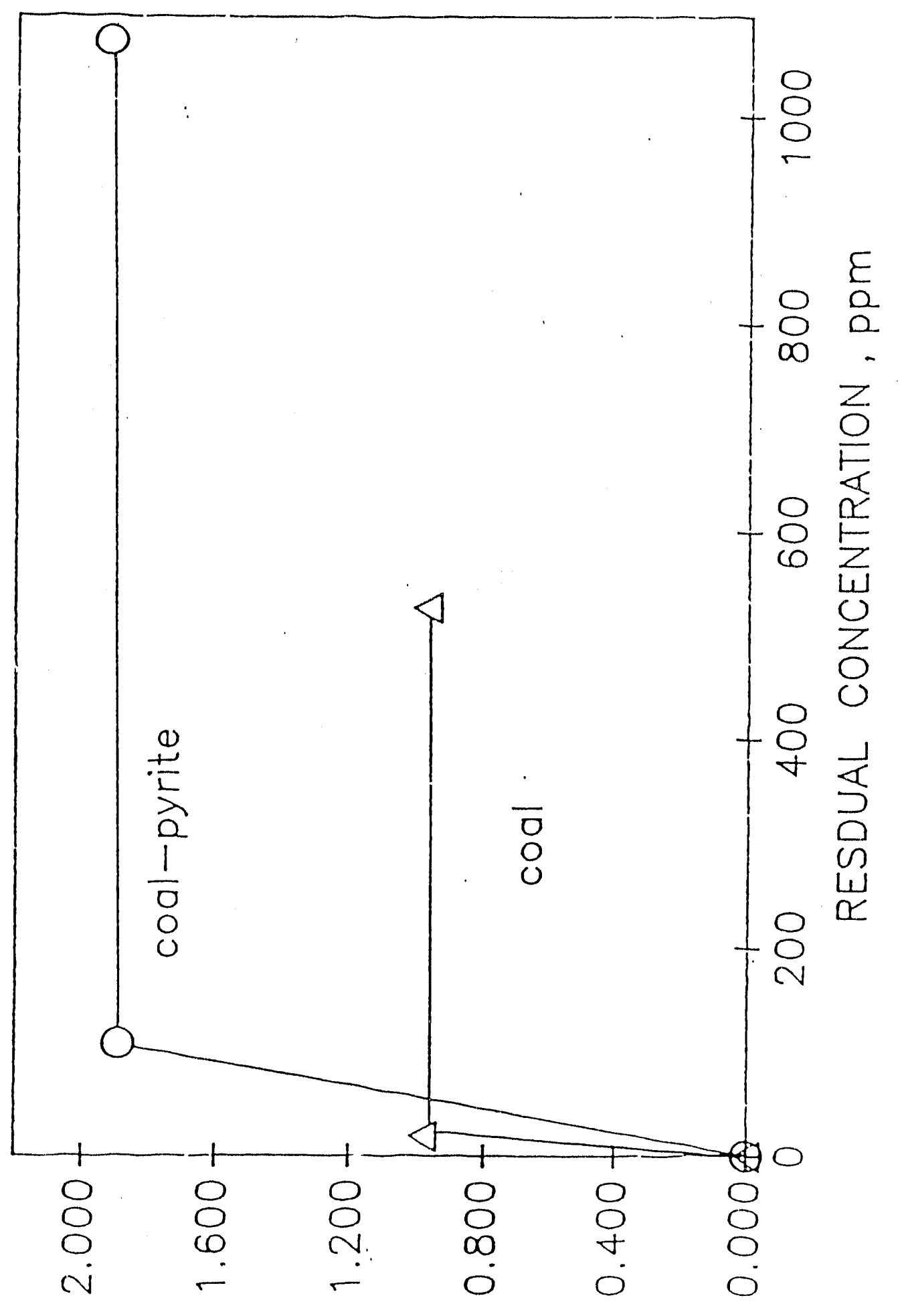

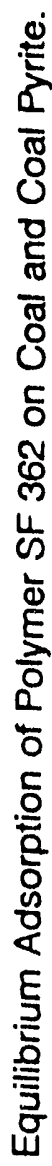

$\frac{0}{1}$
$\geq$
$\frac{1}{3}$
$\frac{9}{4}$

p!los mb / $6 m$ 'NOILdyOSOY y $\exists$ WhTOd 


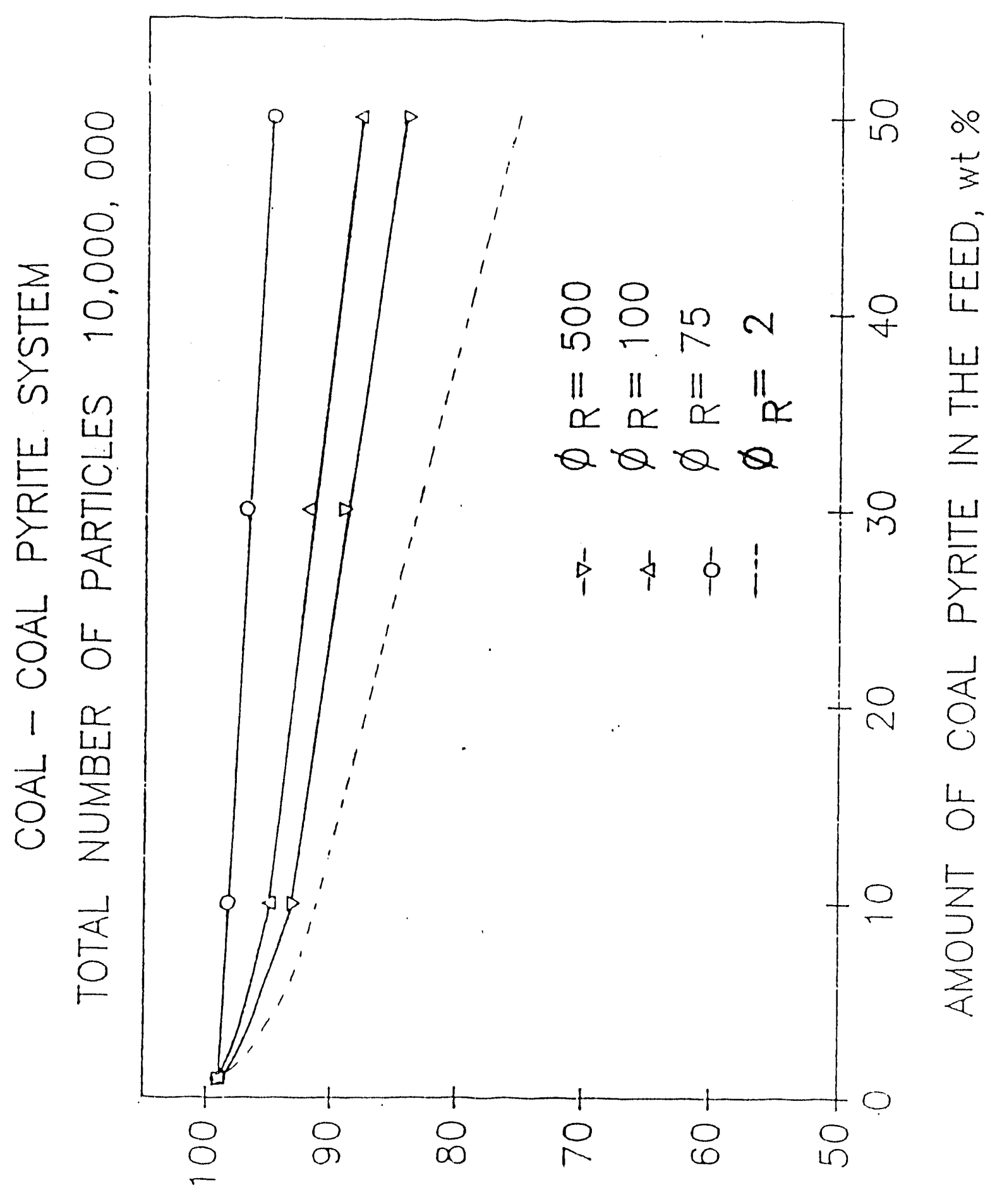

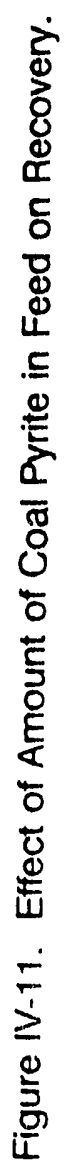


under present conditions yielded a selectivity index of less than 10 and a recovery of about $90 \%$ (see Figures IV-11 and IV-12). This is in agreement with experimental results described later in this chapter (see Table IV-6).

\section{ETIR Analysis:}

To characterize the specific adsorption site for SF 362 (cationic polyacrylamide) on coal and coal pyrite, a number of transmission spectras were also obtained in a liquid cell with a ZnSe crystal. Concentrated polymer solution was placed in the liquid cell and the dispersed solid slurry added to it. The spectras were taken at a high polymer concentration because lower concentrations cannot be detected due to a high affinity of water for the IR. Although these conditions are not favorable for flocculation (high polymer concentration), they would ascertain whether there is any specific interaction of the polymer with the solid surface. Spectras of water, polymer solution, slurry, slurry with; polymer solution were taken, and by carrying out suitable substractions desired information was obtained.

Figure IV-13 shows FTIR spectra of polymer, coal and coal with polymer (SF 362) while Figure IV-14 illustrates the spectra of SF 362 , coal pyrite and coal pyrite with SF 362 . In Figures IV-13 and IV-14 the kaolinite peak is very dominant unlike the coal spectra for diffuse reflectance, indicating coating of the ZnSe crystal by kaolinite. Another important observation in Figure IV-13 is the "blunting" of the peak around the kaolinite peak for the spectra of coal plus polymer SF 362 (wave number, 1035). This could imply either adsorption of the polymer on kaolinite or it could be an artifact introduced during data analysis (subtraction of spectra). However, a strong influence of kaolinite on SF 362 adsorption in both the coal and coal pyrite cannot be ruled out. Moreover, due to the inherent complexities of the coal and coal pyrite spectra it is difficult to say how much of the polymer adsorbed on coal or coal pyrite and how much on kaolinite. Therefore, it is possible that the presence of kaolinite and other mineral matter associated with coal and coal pyrite governs the overall adsorption behavior of SF 362 and is responsible for relatively low $\Phi_{R}$ values. 


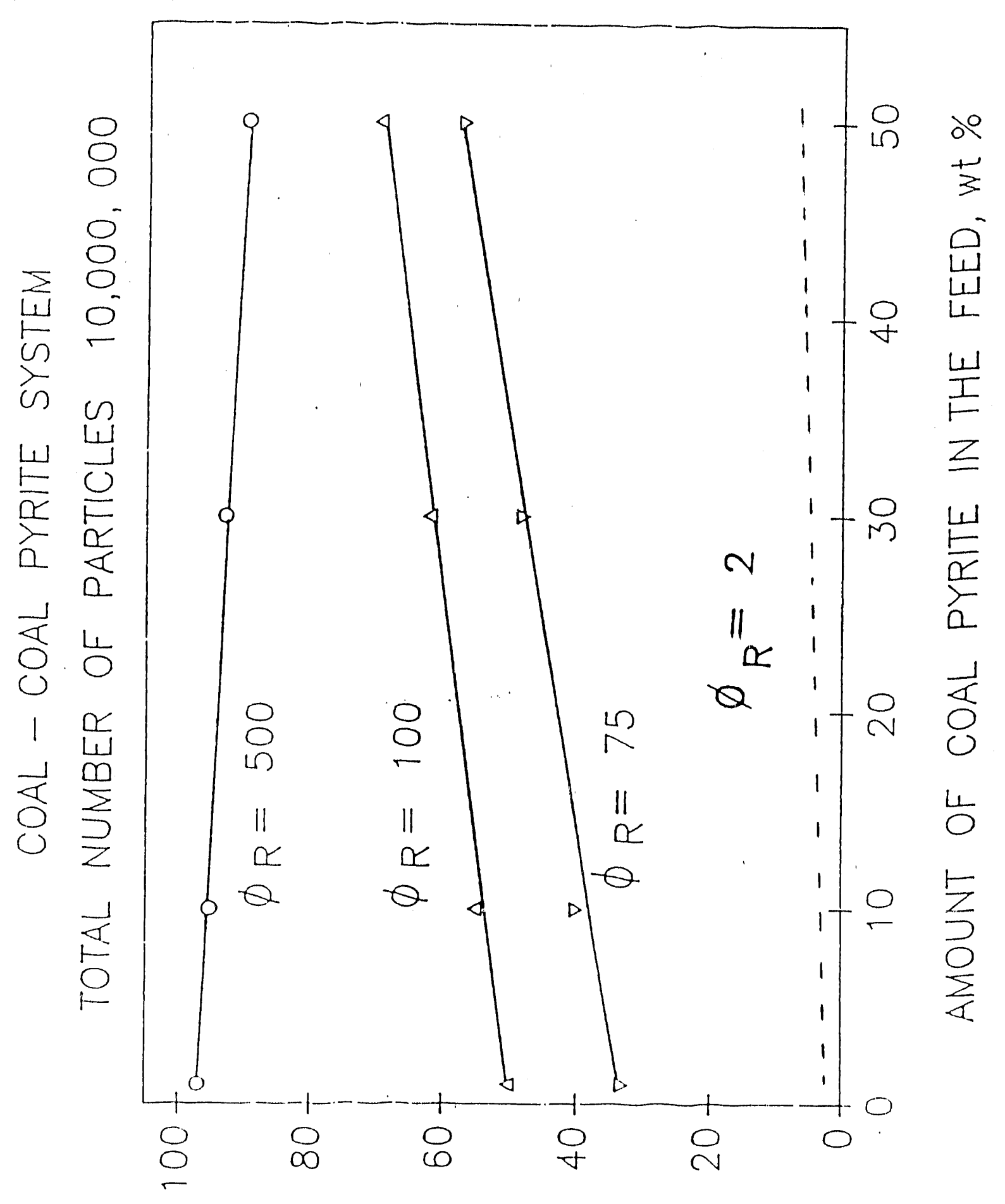

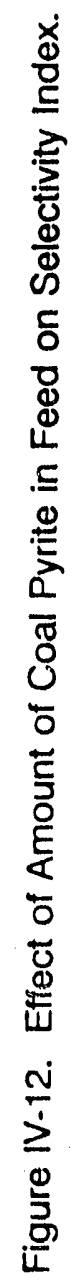

$X \exists O N I \quad U I N I \perp O \exists \operatorname{Bg} \exists S$ 

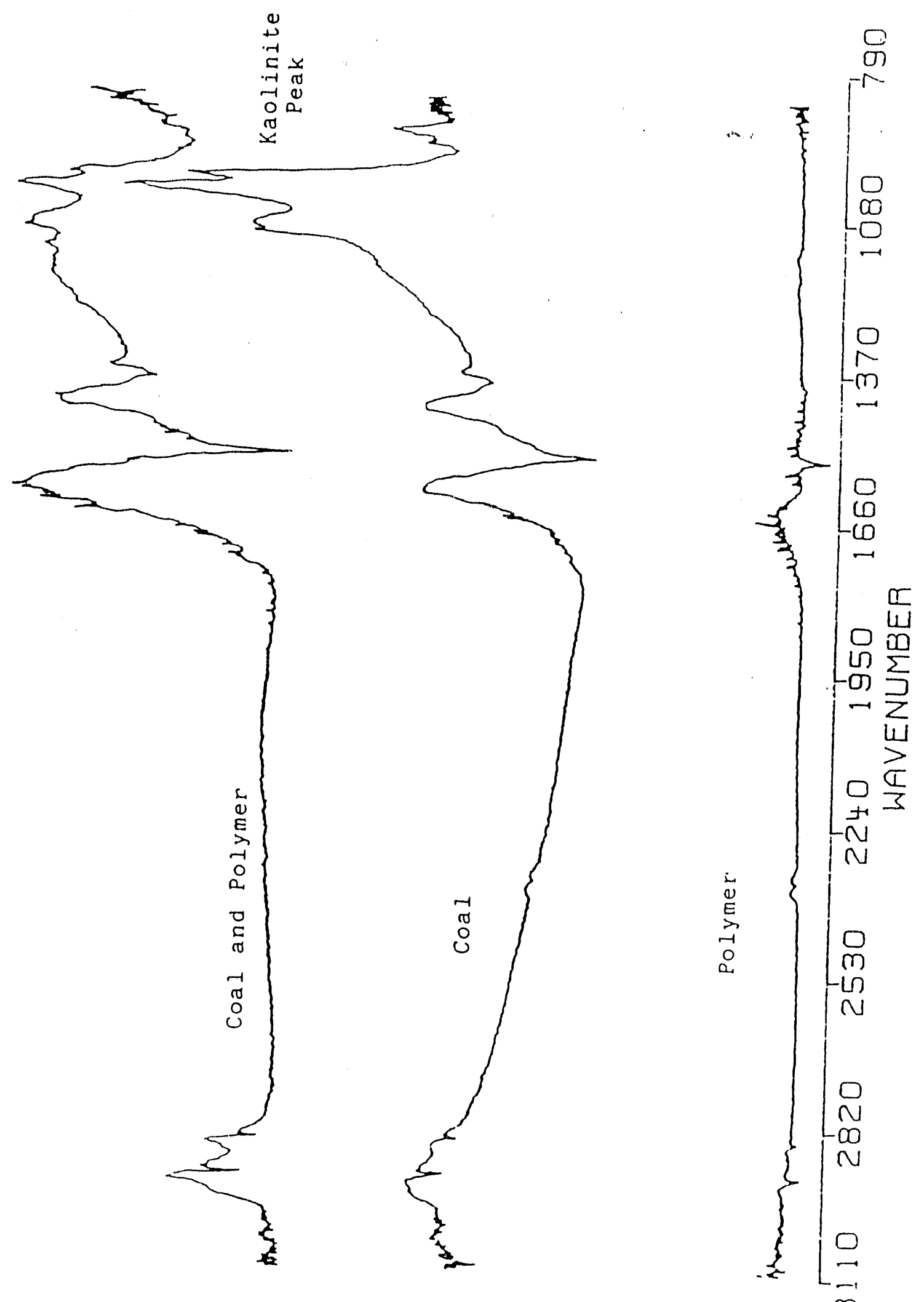

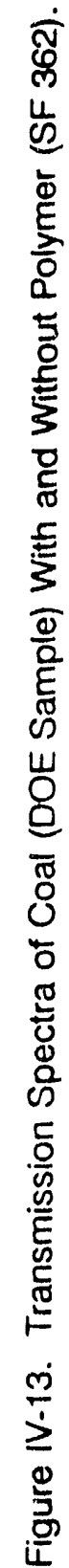




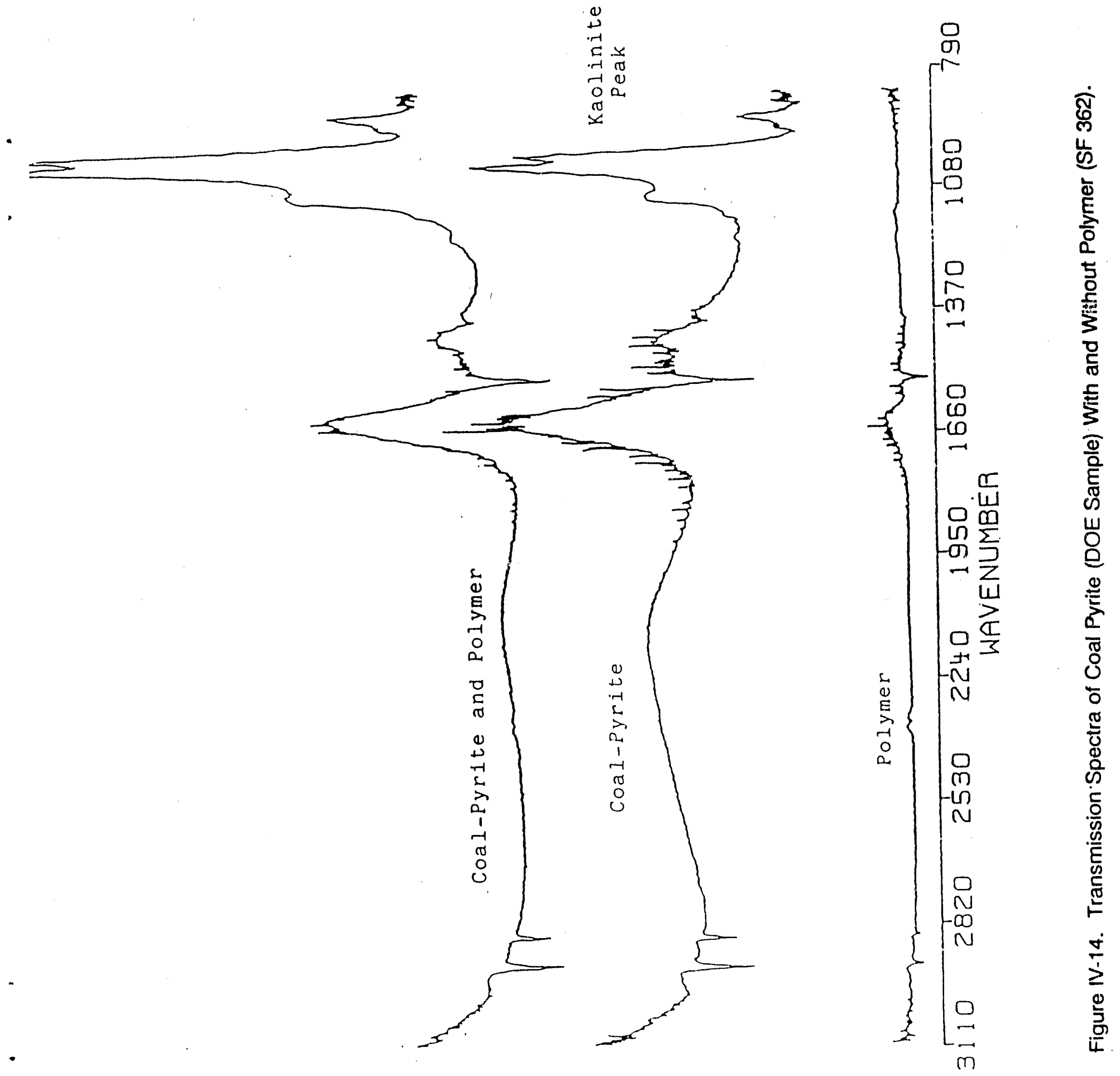


Mixed Mineral Flecculation:

Ceal-Quartz (Mineral Matter) System: Based on the single mineral flocculation tests, the polymer Superfloc 362 was selected as a possible selective flocculant for the mineral matter. Initially, the mixed mineral flocculation studies of coal/quartz systems were attempted.

Selective flocculation of $80: 20$ mixture of coal and quartz using Superfloc 362 indicated a $29 \%$ reduction in the ash content (from $26.9 \%$ to $18.6 \%$ ). The amount of material settled was $51.2 \%$. It is to be noted that in these tests emphasis was placed on achieving the optimum selectivity. Although a 29\% decrease in ash content was achieved in a single stage flocculation test, better selectivity was expected based on the single component tests. Subsequent tests indicated that reducing the settling tirne from 240 seconds to a lesser time can enhance the selectivity achieved. Also, optimization of polymer dosage is expected to improve the separation of coal from the mixture.

Ceal-Coal Pyrite System: The mixed mineral selective flocculation of coal and coal pyrite mixture was attempted. Synthetic mixtures of coal and coal pyrite in the ratio of 90:10 were prepared and the selective flocculation tests were carried out using the procedures outlined earlier. The flocculated material and the supernatant were collected separately and analyzed for ash and sulfur content.

Effect of polymer dosage: The effect of polymer dosage on the selective flocculation of pyrite from coal was studied at a settling time of 2 minutes. The settling time was selected on the basis of single mineral flocculation of pyrite.

The coal recovery and grade based on the solids amount and the ash analysis of the supernatant are compared in Table IV-4. It is observed that although the coal recovery is high, there is no significant change in the supernatant coal grade indicating heterofloccuiation under the present experimental conditions.

The floc bed and supernatant from these studies were analyzed also for pyritic sulfur. The pyritic sulfur content of the material flocculated with $0.0,0.001$ and $0.006 \mathrm{~kg} / \mathrm{t}$ of SF 362 was analyzed to be 
Table IV-4

EFFECT OF SF 362 DUSAGE ON SELECTIVE FLOCCULATION OF COAL PYRITE

Coal:Pyrite $=90: 10$

Average Feed Coal Grade $=87.0 \%$

\begin{tabular}{|lccc|}
\hline $\begin{array}{c}\text { SF 362 } \\
\text { Dosage } \\
\mathrm{kg} / \mathrm{t}\end{array}$ & $\begin{array}{c}\text { Coal Recovery in } \\
\text { Supernatant } \\
\text { *t\% }\end{array}$ & $\begin{array}{c}\text { Ash Analysis in } \\
\text { Supernatant } \\
\text { wt\% }\end{array}$ & $\begin{array}{c}\text { Coal Grade in } \\
\text { Supernatant } \\
\text { wt\% }\end{array}$ \\
\hline 0 & 96.4 & 11.4 & 88.6 \\
0.001 & 96.3 & 11.0 & 89.0 \\
0.002 & 95.8 & 11.1 & 88.9 \\
0.004 & 95.9 & 10.7 & 89.3 \\
0.006 & 96.8 & 10.6 & 89.4 \\
0.01 & 87.3 & 11.5 & 88.5 \\
\hline
\end{tabular}


$6.6 \%, 4.4 \%$ and $4.9 \%$, respectively. The supernatant for these experiments were observed to contain $1.8 \%, 1.5 \%$ and $1.9 \%$ sulfur, respectively, showing selectivity towards pyrite at these polymer dosages.

Some preliminary results of mixed mineral flocculation using hydrophobic polymer WCL-762 are shown in Table IV-5. As discussed earlier, this polymer flocculates coal rather than the mineral matter. At a polymer dosage of $0.01 \mathrm{~kg} / \mathrm{t}$, no significant flocculation of the suspension was observed. As seen from the results presented, maximum separation of the coal from pyrite/mineral matter was achieved at a polymer dosage of 0.02 to $0.03 \mathrm{~kg} / \mathrm{t}$. It is probable that multistage processing would yield higher selectivity.

Effect of $\mathrm{pH}$ of the slurry: The above experiments were performed at the natural $\mathrm{pH}$ of the coal/pyrite mixture (pH 8.3). In order to identify the optimum $\mathrm{pH}$, flocculation experiments were conducted as a function of $\mathrm{pH}$.

The slurry $\mathrm{pH}$ was observed to significantly affect the selective flocculation by SF 362 . As seen in Figure IV-15, maximum flocculation occurred at pH 7. The ash analysis of the supernatant fraction at $\mathrm{pH} 6$ and 7 , indicated coal grades of $88.1 \%$ and $88.5 \%$, respectively, which were slightly higher than the feed grade of $87 \%$ coal. At higher $\mathrm{pH}$ values of 8 and 10, the recovery in the supernatant fraction was high and the coal grade was measured to be $89.1 \%$ and $88.9 \%$, respectively, indicating marginally improved selectivity at higher $\mathrm{pH}$. This was confirmed by the ash analysis of the floc bed which showed higher ash content (19.6\% and $21.1 \%$ ash, respectively) than observed at lower $\mathrm{pH}$. These experiments were repeated with a lower dosage $(0.004 \mathrm{~kg} / \mathrm{t})$ of SF 362 to determine the effect of polymer dosage. Again, higher selectivity was obtained at higher $\mathrm{pH}$ values. These observations are in agreement with results repi irted by Attia et al. (1987).

Effect of settling time: Since higher recovery was observed in the supernatant at lower dosage levels of SF 362, it was decided to increase the settling time to determine its effect on the supernatant grade. The settling experiments conducted with $0.001 \mathrm{~kg} / \mathrm{t}$ dosage of SF 362 indicated a lower yield of coal at higher settling times (see Figure IV-16). The coal grade in the supernatant fraction, however, 


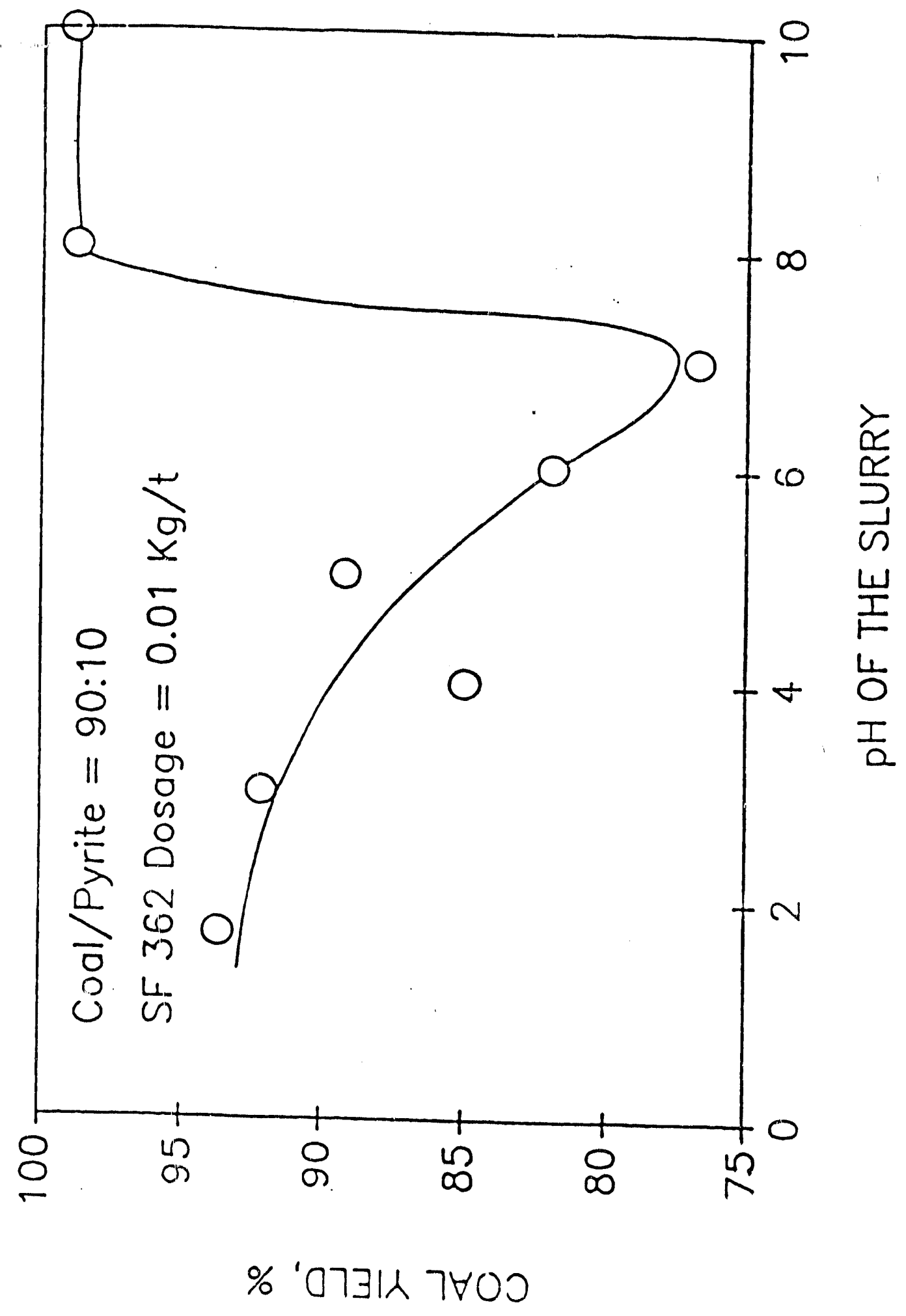

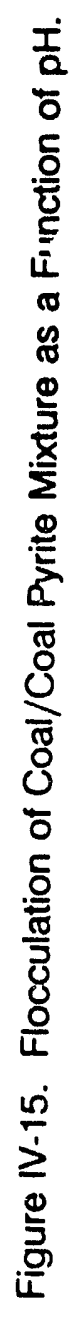




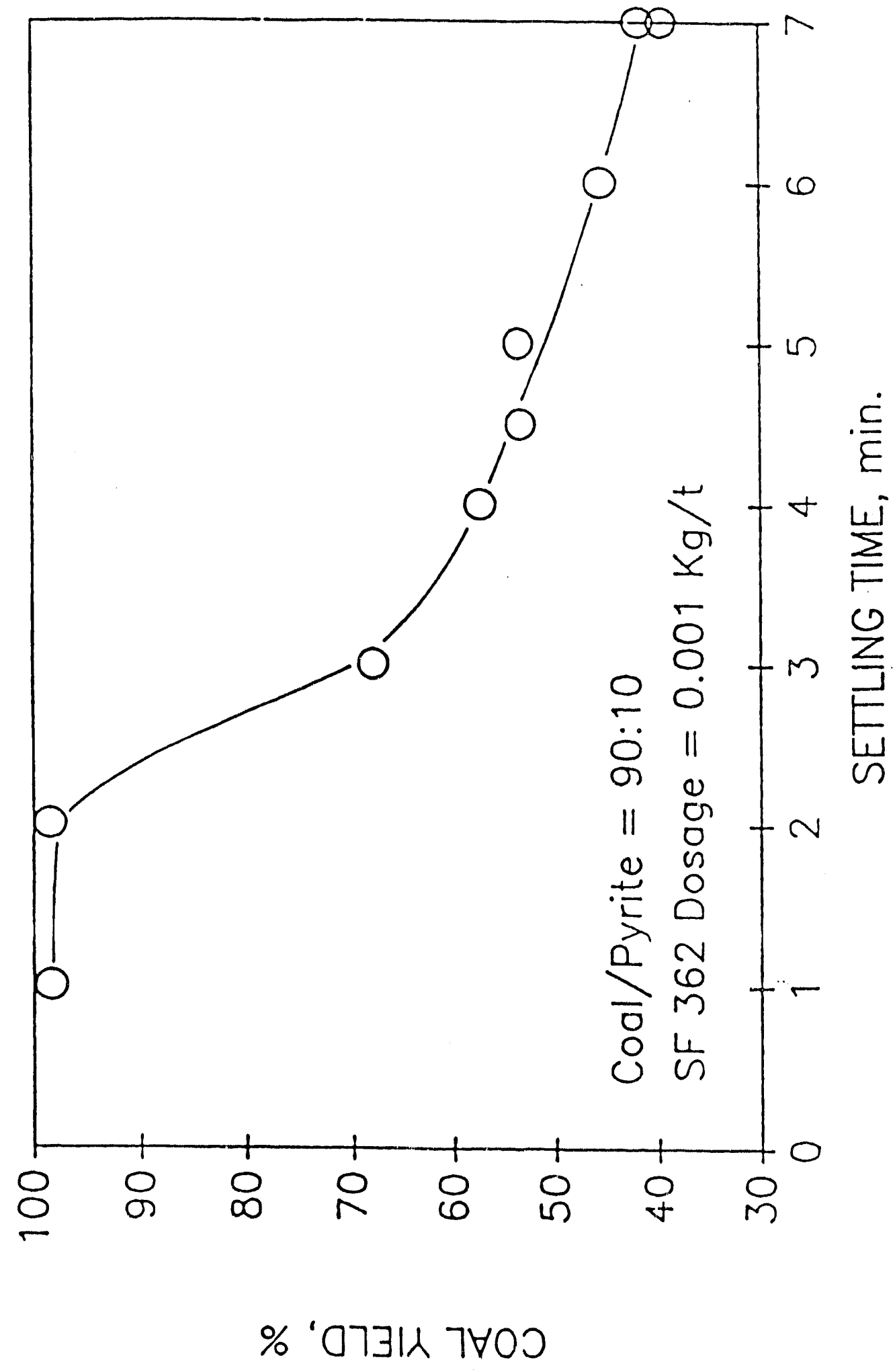

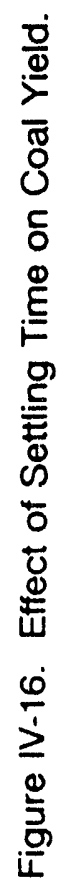


TABLE IV.5

MIXED MINERAL FLOCCULAITON OF COAL/COAL PYRITE

Coal:Coal Pyrite $=90: 10$

Polymer: WCL-762

Average Feed Ash $=13.0 \%$

\begin{tabular}{|ccc|}
\hline $\begin{array}{c}\text { WCL-762 Dosage } \\
\mathrm{kg} / \mathrm{t}\end{array}$ & \multicolumn{2}{c|}{ Ash Analysis, wt\% } \\
\hline 0.01 & 18.09 & Supernatant \\
\hline 0.02 & $12.02,11.4$ & 11.08 \\
0.03 & $11.64,10.58$ & $31.2,27.36$ \\
0.04 & 12.64 & $29.02,30.6$ \\
\hline
\end{tabular}


was not significantly affected (average value $=88.5 \%$ ). The results for the mixed mineral tests with SF 362 and SF 16 are given in Tables IV 6 and IV-7 respectively. These results showed that the polymers (SF16 and SF362) are not selective enough. As reported earlier, SF 362 had high adsorption densities on both coal and coal pyrite samples.

\section{Virginia Tech. Sample:}

Mixed mineral tests performed on these samples using WCL 762 polymer (which had exhibited selectivity in single mineral tests) did not yield the expected selectivity (see Tables IV-8, IV-9, IV-10). It can be seen that the selectivity is lost with respect to both the coal pyrite as well as ash forming mineral matter. A 50:50 mixture of coal-coal pyrite sample corresponds to about $15.7 \%$ pyrite and $45.8 \%$ ash forming mineral. The reasons for mixed mineral flocculation behavior need to be further investigated. 


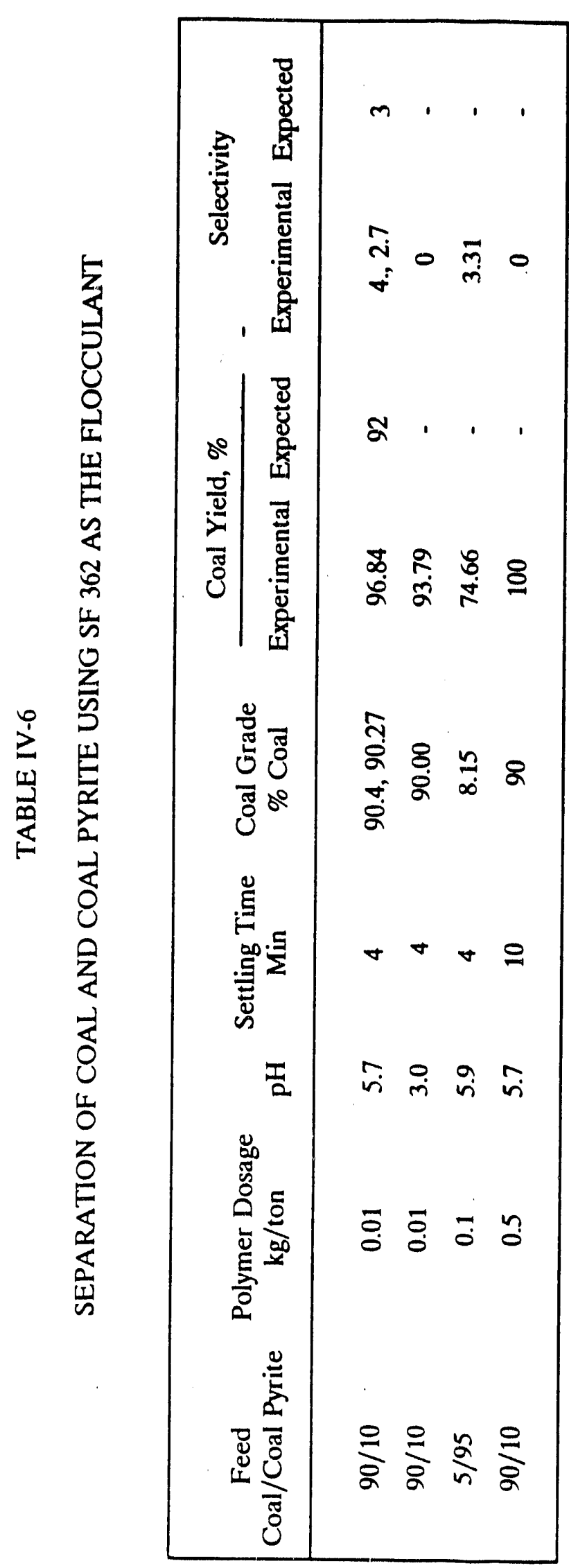




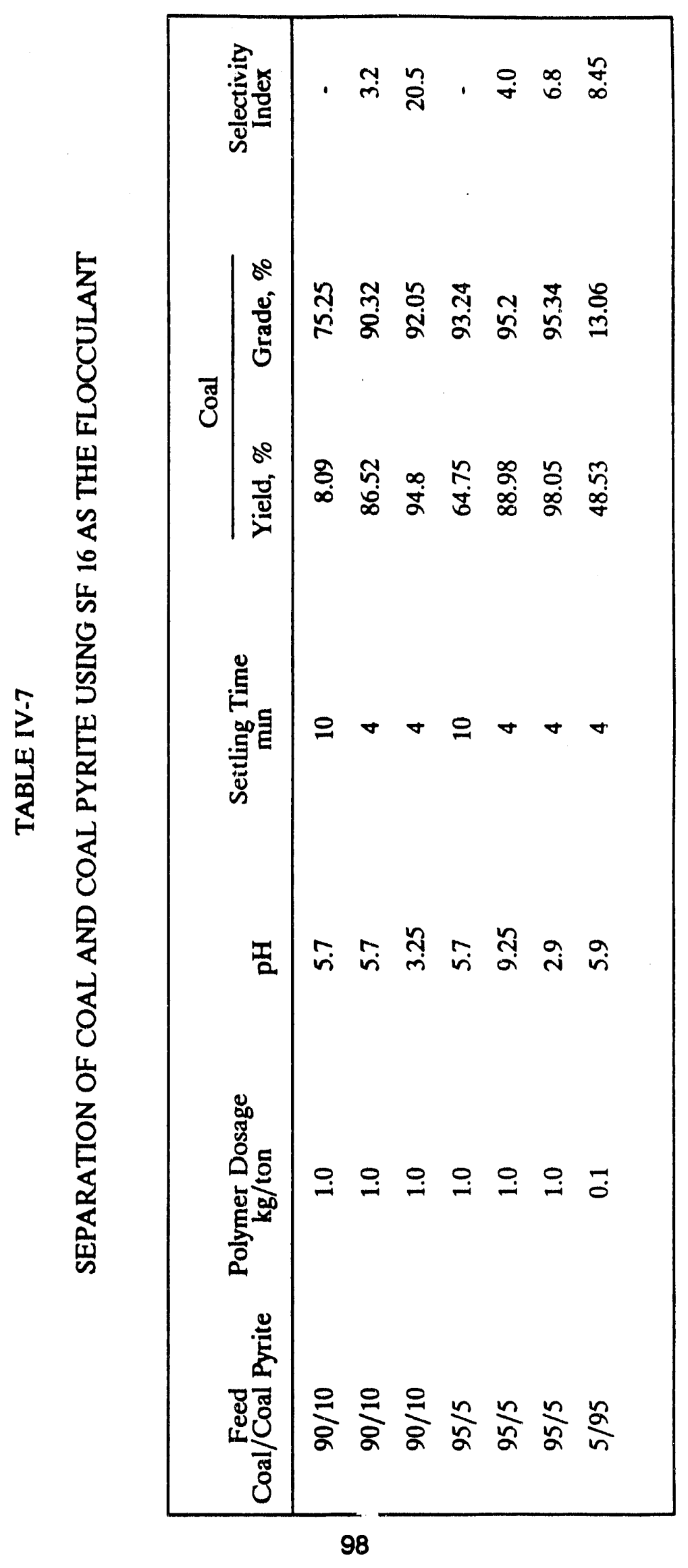


TABLE IV-8

MIXED MINERAL FLOCCULATION TESTS WITH WCL 762

Pyrite Analysis

Feed: $1 \mathrm{~g}$ of $50: 50 \mathrm{wt} \%$ Mixture

$\mathrm{Coal}=1.9 \%$

Coal Pyrite $=29.5 \%$

$\mathrm{pH}=10$

\begin{tabular}{|ccccc|}
\hline $\begin{array}{c}\text { Stirring } \\
\text { Time } \\
\text { (Min.) }\end{array}$ & $\begin{array}{c}\text { Settling } \\
\text { Time } \\
\text { (Min.) }\end{array}$ & $\begin{array}{c}\text { Polymer } \\
\text { Dosage } \\
\text { (mg/g) }\end{array}$ & $\begin{array}{c}\text { Settled } \\
\text { Mass } \\
\text { (wt \%) }\end{array}$ & $\begin{array}{c}\text { Pyrite in } \\
\text { Settled Mass } \\
\text { (wt \%) }\end{array}$ \\
\hline $6^{*}$ & 6 & 50 & 15.07 & 37.89 \\
$6^{*}$ & 4 & 500 & 17.75 & 35.98 \\
$6^{*}$ & 4 & 50 & 15.35 & 39.49 \\
7 & 4 & 500 & 25.04 & 34.39 \\
6 & 5 & 50 & 52.27 & 40.44 \\
6 & 3 & 50 & 42.63 & 37.83 \\
\hline
\end{tabular}

* Polymer Aged Overnight 
TABLE IV-9

MIXED MINERAL FLOCCULATION TESTS WTTH WCL 762

Ash Analysis

Feed: $1 \mathrm{~g}$ of 50:50 wt\% Mixture

Coal $=18.9 \%$

Coal Pyrite $=72.7^{\circ} \%$

$\mathrm{pH}=10.0$

\begin{tabular}{|ccccc|}
\hline $\begin{array}{c}\text { Stirring } \\
\text { Time } \\
\text { (Min.) }\end{array}$ & $\begin{array}{c}\text { Settling } \\
\text { Time } \\
\text { (Min.) }\end{array}$ & $\begin{array}{c}\text { Polymer } \\
\text { Dosage } \\
(\mathrm{mg} / \mathrm{g})\end{array}$ & $\begin{array}{c}\text { Settled } \\
\text { Mass } \\
(\mathrm{wt} \%)\end{array}$ & $\begin{array}{c}\text { Ash in } \\
\text { Settled Mass } \\
\text { (wt \%) }\end{array}$ \\
\hline 5 & 5 & 50 & 26.01 & 23.2 \\
6 & 5 & 50 & $47.20,45.52$ & $27.11,26.99$ \\
\hline
\end{tabular}


TABLE IV-10

\section{PYRITE FLOC BED ANALYSIS}

Flocculant: WCL 762

\begin{tabular}{|ccccc|}
\hline $\begin{array}{c}\text { Stirring } \\
\text { Time } \\
\text { (Min.) }\end{array}$ & $\begin{array}{c}\text { Settling } \\
\text { Time } \\
\text { (Min.) }\end{array}$ & $\begin{array}{c}\text { Polymer } \\
\text { Dosage } \\
\text { (mg/g) }\end{array}$ & $\begin{array}{c}\text { Sertled } \\
\text { Mass } \\
\text { (wt \%) }\end{array}$ & $\begin{array}{c}\text { Ash in } \\
\text { Settled Mass } \\
\text { (wt \%) }\end{array}$ \\
\hline 5 & 5 & 50 & 58.13 & 63.46 \\
6 & 5 & 50 & 62.35 & 66.86 \\
\hline
\end{tabular}




\section{REFERENCES}

Annual Book of ASTM Standards, D 3174-82, ASTM, (1982) and D 2492-84, ASTM, (1984), Philadelphia, PA.

Attia, Y. A., Shaning, Yu. and Vecci, S. in Flocculation in Biotechnology and Separation Systems. Ed. Y. A. Attia. Elsevier, 1987.

Attia, Y. A., Conkle, H. N., and Krishnan, S. V. in Gth Int. Symp. Coal slurry Combust. 1984, p. 582.

Blaschke, Z. Zersz. Nauk, Akad, Govn. Huln. Govn. 83, 109 (1977), C1:89,8662a.

Cammack, P., Coal Preparation and Use - A World Review. Ed. Ranga Raja Rao,S. 9th Int. Coal Prep. Congr. New Delhi, India, 1982, p. 61.

Campbell, J. A. L., and Sun, S. C. Trans. AIME. 247, 111; 120 (1970).

Chanchani, R., "The Effect of Deflocculants on the Rheological Behavior of Concentrated Phosphate Slime". M.S. Thesis. Univ. of Florici, 1976.

Dirican, C., "The Structure and Growth of Aggregates in Flocculation", M.S. Thesis. Pennsylvania State University, University Park, PA, 1981.

Goehin, R. J., Lekill, M., and Shergold, H. L. Ceal Prep., ?(1), 19 (1985).

Gregory, J. in Flocculation. Sedimentation, and Consolidation. Ed. B. M. Moudgil and P. Somasundaran, Engineering Foundation Publications, New York, 1985, p. 125.

Hogg, R. in Fine Particles Processing, P. Somasundaran, Ed., SME-AIME, New York, 2, 990, (1980).

Hogg, R. in J. Coll. Interface Sci., 102 (1), 232, (1984).

Killmeyer, R. F. Coal Minirig, 22, 45 (1985).

Klimpel, R. C. and Hogg, R., L. of Colloid and Interface Sci., 113, 121, (1986).

Klunder, H., and Koopmans, K., Delft Prog. Rep. 6(3), 190, (1981), C.. CA 96, 145 725g.

Kogan, R., K Discoll and Y.A. Attia, "Flocculation in Biotechnology and Separation Systems," Ed. Y.A. Attia, 321, Elsevier Science Publisher, B.V. Amsterdam, 1988.

Kulkarni, R. D., and Somasundaran, P., Int. J. Miner. Process., 4(2), 89 (1977).

Littlefair, M. J. and Lower, N. R. S., Int. J. Mineral Process. 17, 187 (1986).

Mann, R., Matec Corp., Personal Communication, 1989.

Mirville, R. J. and Hogg, R., "Polymer Adsorption and Flocculation in the Treatment of Coal Freparation Waste Water," presented at AIME Annual Meeting, New Orleans, La., Feb. 1979, SME Preprint 
No. $70-61$.

Moudgil, B. M., and Vasudevan, T. V., 1985, unpublished results.

Moudgil, B. M., Shah, B. D., and Soto, H. S., L. Colloid Interface Sci., 119, 466 (1987).

Moudgil, B. M., Vasudevan, T. V. and McCombs, A. (1988). University of Florida. To be published.

Moudgil, B. M., Vasudevan, T. V., and McCombs, A., in Ceramic Transactions: Ceramic Powder Science II, Vol. 1, G. L. Messing Ed., The American Ceramic Society, Westerville, Ohio, 1988, p. 372.

Painter, P.C. and M.M. Coleman, FTS/IR Notes No. 35, August (1980). Rowell, R. L.., Marganski, R. E., and Zhong, Z., in Proc. Int. Cont. Coal Sci., Pergamon, Sydney, Australia, 1:385, p. 565.

Shah, B. D., "Selectivity in Mixed Mineral Flocculation: Apatite-Dolomite System," M.S. Thesis, University of Florida, 1986.

Singer, J.M., F.C.A. Vekemans, J.W. Th. Lichtenbelt, F. Th. Hesselink, and P.H. Wersema: J. Col. Int. Scci. 45, 608 (1973).

Smellie, R. H., Jr. and LaMer V. K., J. Colloid Sci., No. 23, 589 (1958).

Smoluchowski, M. V., Versuch einer Mathematischen Theorie der Kogulationskirietic Kollider Losunge. Z. Physik Chem, 22, 129 (1917).

Somasundaran, P., in Fine Particle Processing, Ed., Somasundaran, P., Proc. Int. Symp. Fine Particles Processing, AIME, New York, NY, 1980, 347.

Tanaka, T., Yamagata, Y., Suzuki, S., and Yotsumata, H., Kogai Shigen Kenkyusho, 14(2), 27, 1984, Cf. CA Vol. 102, 98055u.

Vold, M. J., J. Colloid Interface Sci. 18, 684 (1963).

Wen, W. W., and Sun, S. C., Separation Science and Technology, 16(10), 1491 (1981). 

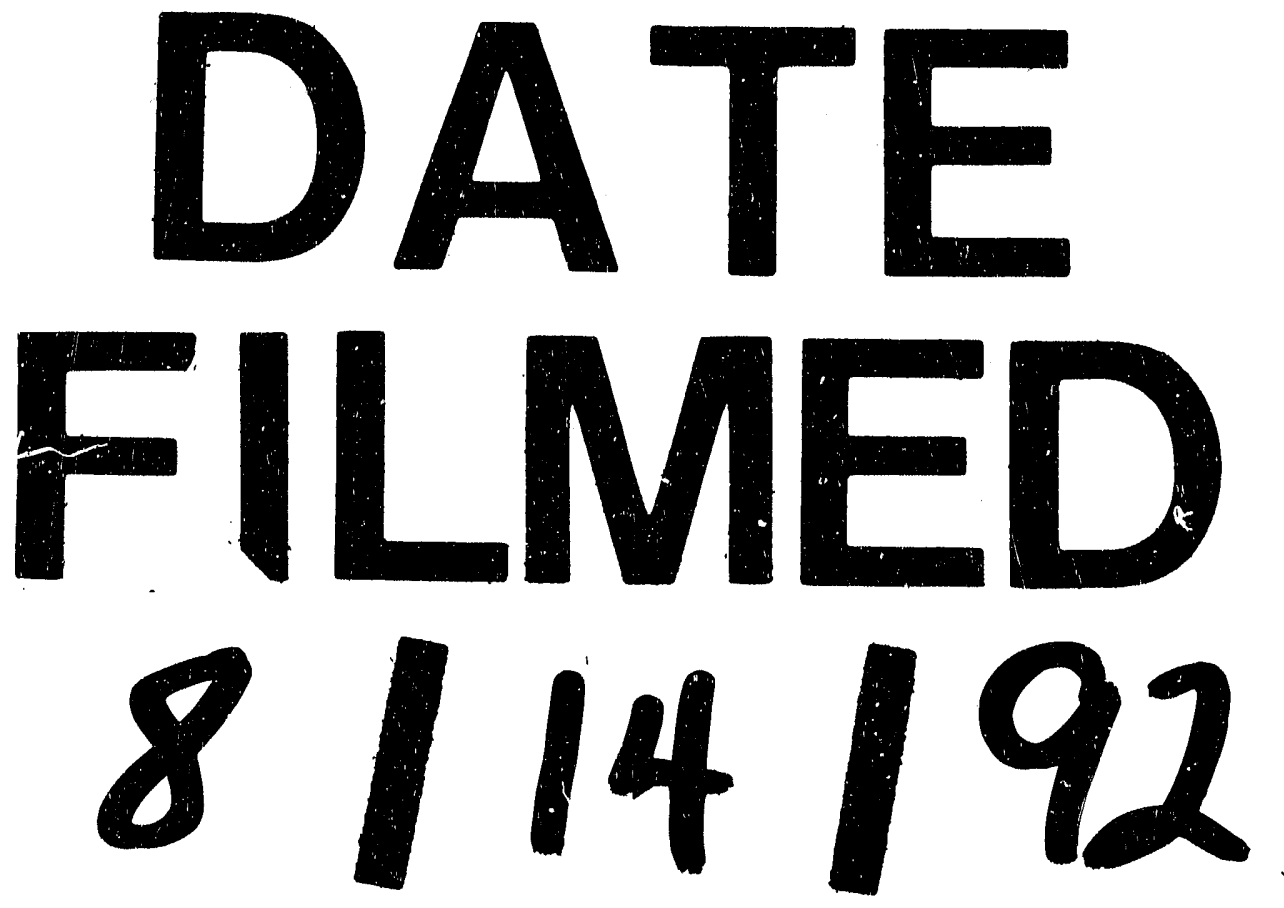

1 
